\title{
Neighborhood context and enduring differences in the density of charitable organizations: reinforcing dynamics of foundation and dissolution
}

\begin{abstract}
The organizational dimension has been relatively neglected within neighborhood studies, despite theory predicting a relative lack of organizations in more deprived neighborhoods. This paper provides a longitudinal empirical perspective, using a unique dataset which follows through time over 125,000 charitable organizations across the full distribution of neighborhood contexts in England from the mid-1990s onwards. It shows that there are enduring, sizeable and extensive differences in the density of charitable organizations according to neighborhood deprivation, which persist over time even as neighborhoods experience organizational turnover. It shows that these differences in density are maintained through reinforcing processes: first, compared to less deprived neighborhoods, in more deprived neighborhoods fewer charities are founded per head of population; second, even after foundation, charities in more deprived areas experience a higher hazard of dissolution.
\end{abstract}




\section{INTRODUCTION}

Spatial inequality between neighborhoods is considerable; it is evident across a variety of different outcomes; and it is enduring. Sampson's (2012) Great American City places enduring neighborhood spatial inequality as a central storyline to be explored in scientific enquiry:

'Neighborhood, in other words, is a near universal theme of human history, and the salience of neighborhood differences has persisted across long time scales and historical eras.. the consistency of [neighborhood] differentiation from ancient cities to contemporary Chicago suggests its.. theoretical centrality for the study of social stratification and social enquiry' (p.362).

Yet, as Sampson (2012) and Massey (2012) argue, much research begins and ends with individuals and their choices as the unit of analysis, and as the explanation, for local spatial inequality: differences across neighborhoods simply reflect differences in individuals' characteristics. The challenge for those advocating the importance of 'neighborhood effects', where spatial concentration itself is seen to shape and not merely reflect individual outcomes, has been to identify mechanisms through which neighborhood disadvantage is transmitted: why does concentrated poverty matter for people's lives?

Galster (2012) provides an overview of theoretical perspectives about the possible causal pathways underlying neighborhood effects. He groups these mechanisms under four headings. Social interactive mechanisms include social contagion, where individuals' behaviors and aspirations are influenced by neighborhood peers, and collective socialization 
processes. Thus Wilson (1987) argues that individuals in poor neighborhoods are socially isolated from mainstream Americans, depriving them of positive role models and limiting information about job opportunities. Environmental mechanisms, including exposure to pollutants or a decaying physical infrastructure, may directly affect the mental or physical health of residents. Geographical mechanisms relate to the position of the neighborhood within larger-scale social and economic structures. Thus neighborhoods may suffer a 'spatial mismatch' that sees employment opportunities restricted through a lack of jobs within easy access of residents. Finally institutional mechanisms include the possibility that neighborhoods may differ in terms of organizational resources.

However, providing empirical evidence to test hypotheses derived from these theories about the mechanisms underlying neighborhood effects has proved a challenge. This has limited our understanding of salient features of inequality in residential environments beyond the aggregated characteristics of individuals. Therefore the neighborhood has remained largely a 'black box' (Sampson 2008, 2012, p.46; Small and McDermott 2006, p.1698; see also Ellen and Turner 1997; Galster 2012; Sharkey and Faber 2014; Small and Newman 2001). The organizational dimension, in particular, has been identified as a priority for research within neighborhood studies (McQuarrie and Marwell 2009; Sampson 2011, 2012 ${ }^{1}$ ). Existing empirical research 'has focused largely on the compositional characteristics of neighborhoods as opposed to the institutions that are present within communities' (Sharkey and Faber 2014, p.27.7; Allard and Small 2013). Thus the extensive literature on neighborhood effects over the last 20 years has centered primarily on individuals, with less emphasis on how local organizations structure and mediate neighborhood context (Allard and Small 2013) ${ }^{2}$. Specifically, while institutional resources theories conceive of deprived neighborhoods as 
lacking in organizational resources, empirically testing this hypothesis remains an important priority for research.

Voluntary organizations have been identified as an 'especially' important but neglected component within neighborhood studies (Sampson 2011, p.233; Small and Stark 2005) ${ }^{3}$. We argue that this specific research need is significant. Conceptual work on the voluntary sector, embodied in the 'structural/operational approach' (Salamon and Anheier 1992), emphasizes that voluntary organizations ${ }^{4}$ involve some meaningful degree of voluntarism in the form of charitable donations and/or voluntary participation (Salamon and Anheier 1992; Kendall and Knapp 1993). Neighborhoods that differ in levels of deprivation may differ in terms of their ability to provide the 'enabling resources' for voluntary participation (Verba, Schlozman, and Brady 1995; Musick and Wilson 2008), and the financial resources for philanthropy (Salamon 1987), that support voluntary organizations. Therefore there is a theoretical basis for expecting a link between the 'compositional' characteristics of neighborhoods, in terms of the socioeconomic resources of individuals, and an important collective or 'emergent' characteristic, the density of voluntary organizations.

This paper's empirical focus is on charitable organizations, the primary legal framework for voluntary activity in the UK. The paper considers whether there are enduring differences in the density of charitable organizations between more and less deprived neighborhoods in England. The use of the word 'enduring' is important since it conveys an explicit longitudinal perspective. Neighborhoods are dynamic entities: as time progresses they will experience a turnover of organizations as some organizations are founded and others dissolve. To be a salient feature of inequality in individuals' residential environments, differences in the density of charitable organizations according to deprivation should persist over time even 
as neighborhoods experience organizational turnover. Therefore this paper uses longitudinal data in order to provide not only a snapshot of the relationship between neighborhood deprivation and the density of charitable organizations, but also to examine the extent to which this relationship is persistent over time, and to examine the underlying processes - in terms of rates of charitable founding and dissolution ${ }^{5}-$ through which any differences in charitable density according to neighborhood deprivation endure.

\section{Conceptual definition}

Salamon and Anheier (1992) argue that voluntary organizations are most helpfully defined not in terms of purpose - in terms of the functions that they carry out - but in terms of their basic structure and operation. This 'structural/operational' definition, which has proved influential, defines voluntary organizations as a collection of organizations that are:

- Formal: 'institutionalized to some extent' (Salamon and Anheier 1992, p.135) - for example, by having regular meetings and a constitution or set of rules.

- Private and self-governing: 'institutionally separate from government'; they 'have their own internal procedures for governance and are not controlled by outside entities' (Salamon and Anheier 1992, p.135).

- Non-profit distributing: any financial surplus is reinvested into the basic mission of the organization, rather than distributed to the owners or directors (Hansmann 1980). Therefore for-profit firms are excluded. Social enterprises - which are established for purposes which include making a profit - are also excluded (Morgan 2010). The nondistribution constraint also excludes workers and agricultural cooperatives, where earnings are distributed to members (Kendall and Knapp 1993). 
- Voluntary: benefit to a 'meaningful degree from philanthropy or voluntary citizen involvement' (Kendall and Knapp 1993, p.18). They may receive voluntary income from donations and fundraising. As Kendall and Knapp (1993) argue, even if an organization's income is dominated by fees or by income from government rather than by donations, voluntarism is provided through voluntary work in the actual conduct of the agency's activities or in the management of its affairs. Indeed voluntarism, and in particular the unremunerated voluntary work of those involved in their governance, is regarded as perhaps the most important defining feature of voluntary organizations ${ }^{6}$ (Kendall and Knapp 1993; Harris 2001).

This paper specifically focuses on charitable organizations in England. Since charitable organizations are a subset of the voluntary sector, the above structural/operational criteria apply. Charitable status, which is the primary legal framework for voluntary activity in the UK (Morgan 2010), is also underpinned by the specific criterion of 'public benefit' - that an organization should 'benefit the public in general or a significant section of the public' ${ }^{7}$. As Kendall and Knapp (1993) point out, though 'public benefit' is a feature of charitable law, many commentators would consider it a defining characteristic of the wider concept of the voluntary sector, implicitly linked to the 'nonmaterialistic' motivations of unpaid trustees. Indeed organizations where the owners/directors derive financial benefits from organizational earnings are excluded from the voluntary sector under the nondistribution constraint of the 'structural/operational' definition. Therefore, as Morgan (2010) explains, in practice the vast majority of voluntary organizations meet the requirements of charitable status in the $\mathrm{UK}^{8}$. Indeed the National Council of Voluntary Organizations (NCVO) uses charitable status as a basis for identifying 'voluntary organizations' in England and Wales in its annual publication providing statistics on the voluntary sector ${ }^{9}$ (Kane, Heywood, and Bass 2014). While there 
is a close link between the terms 'voluntary organization' and 'charitable organization' in the UK, for definitional precision in the remainder of the paper we will refer specifically to 'charitable organizations'. NCVO emphasize, in keeping with the structural/operational definition of the voluntary sector, that 'a defining characteristic' of charitable organizations 'is their voluntary nature, whether in governance through trustee board, in finance through donations, or in resources through the help of volunteers' (Kane et al. 2014, p.13).

Income from individuals is the most important aggregate source of funding for the charitable sector in England. The majority of income from individuals is received through charitable donations and legacies. However an important component - around a third (34\%) of aggregate income from individuals - is received through the payment of fees in connection with the provision of benefits and services (Kane et al. 2014). This is relevant to the salience of local socioeconomic context: according to the level of deprivation, neighborhoods may differ not only in the opportunity for charities to benefit from charitable donations - but also in the opportunity for charities to receive income from fees. Note that, as with nonprofits in the US (Allard 2009; Smith and Lipsky 1993), the charitable sector in England has seen increases in government funding associated with charities' increased role in public service delivery. According to the most recent data 13 percent of organisations indicate that government funding in the form of grants and/or contracts is their most important income source $^{10}$ (Clifford, Geyne, and Mohan 2013). Therefore, as well as considering the socioeconomic characteristics of neighborhoods, it is important to consider how local institutional resources may be affected by the role of extra-local actors (see Small 2009; Small and Stark 2005). 
Aim: to link compositional and emergent characteristics of neighborhoods

This paper's empirical focus on organizations, rather than on individuals, makes theoretical sense: if neighborhood effects exist, 'presumably they stem from social-interactional and institutional processes that involve collective aspects of community' - properties of neighborhoods that cannot be understood with reference to individuals' characteristics alone (Sampson 2012, p.47; emphasis added; Raudenbush and Sampson 1999). Sampson (2012) draws on Lazarsfeld and Menzel's (1961) conceptual framework to describe different measures of neighborhood characteristics. Compositional properties of neighborhoods, like average income, are derived from the aggregation of individual characteristics. In contrast emergent measures, like organizational density, aim to describe explicitly collective aspects of community life. There is a growing awareness of the need to broaden the scope of our measurement of neighborhood context beyond compositional measures through measuring emergent properties directly (Harding et al. 2011; Sampson 2012; Sharkey and Faber 2014). Indeed, as Harding et al. (2011, p.11) argue, 'since our theories [about the importance of neighborhood context] are often about emergent properties of neighborhoods rather than neighborhood composition, we need to measure emergent properties'. Therefore measuring the organizational characteristics of neighborhoods, central to institutional resources theories, is a priority for empirical work.

Institutional resources theories conceptualize organizational resources as a mediating mechanism between concentrated poverty and individuals lives. This mediating process rests on two main hypotheses: first, that organizational resources vary systematically according to concentrated poverty - in other words, that there is a systematic relationship between a compositional measure of neighborhood context (concentrated poverty) and an emergent 
measure of neighborhood context (organizational resources); second, that this systematic variation in organizational resources is salient to individuals' lives.

It is important to emphasize the specific remit of this paper. It presents empirical evidence relevant to the first hypothesis (relationship A in Figure 1), which is one part of the broader hypothesized causal process which sees enduring differences in the density of charitable organizations as one possible mediator in the relationship between neighborhood poverty and individuals' lives. However a full mediation analysis would also examine the relationship between the presence of charitable organizations and individuals' wellbeing (relationship B in Figure 1), and seek to quantify how much of the relationship between neighborhood poverty and individual outcomes $(\mathrm{C}$ in Figure 1) is accounted for by these differences in organizational resources. This full mediation analysis is not attempted in this paper.

Instead this paper focuses on the specific task of assessing whether there are enduring differences between neighborhoods, according to the level of poverty, in the density of charitable organizations. While this is not sufficient to establish that charitable organizations represent a mechanism which mediates the relationship between neighborhood context and people's lives, it is an important part of the hypothesized process ${ }^{11}$. Therefore examining organizational density in different neighborhoods is in itself an important empirical question relevant to institutional theories of neighborhood effects (Small and Stark 2005).

Theoretical basis: variation in the resources for charitable activity

In assessing the nature of the neighborhood context, the specific challenge is to identify emergent characteristics of neighborhoods which vary systematically according to 
neighborhood disadvantage. Therefore there should be a theoretical basis for expecting a systematic link between neighborhood disadvantage and that emergent characteristic. This provides a rationale for this paper's empirical focus on charitable organizations: not only do charitable organizations represent important collective aspects of neighborhood life, but there is a theoretical basis for expecting variation in the density of charitable organizations according to the extent of neighborhood disadvantage.

This theoretical basis for expecting a link with concentrated poverty stems from a conceptual understanding of charitable organizations in terms of their structure and operation (Salamon and Anheier 1992) - particularly in terms of the voluntarism that is regarded as an essential defining characteristic of charitable organizations (Harris 2001; Kendall and Knapp 1993; Kane et al. 2014; Salamon and Anheier 1992). Charitable organizations benefit to a meaningful degree from philanthropic financial resources and/or from voluntary participation. Both philanthropic financial resources, and the enabling resources for voluntary participation, are likely to vary significantly according to the compositional characteristics of neighborhoods.

Salamon's (1987) theory of voluntary sector failure provides the basis for expecting neighborhood differences in philanthropic resources. Salamon argues that, given the effort required to mobilize government response to social need, the voluntary sector has certain advantages over government provision. But the voluntary sector has its own weaknesses, including 'the inability to generate resources on a scale that is both adequate and reliable enough to cope with the human services problems of an advanced industrial society' (p.39). Importantly, this 'philanthropic insufficiency' is particularly evident in certain geographical areas 'since the resources are frequently not available where the problems are most severe' 
(p.40). Opportunities for charitable organizations to benefit from private income, including fees and voluntary donations from individuals, may be very different in different kinds of areas. 'Serious gaps' in coverage may emerge because 'private charitable resources may or may not be available where the need for them is greatest' (p.45). Therefore, when considering the distribution of local charitable sector activity, this focuses attention not just on the demand for public goods and services (Weisbrod 1975) but also on the supply of resources and how this varies geographically. In deprived neighborhoods, where people may have little money left over after meeting basic needs, combining internal resources 'can represent little more than multiplying zero times zero; the result is still zero' (Logan and Molotch 1987, p. 136-137).

Importantly, issues of uneven supply are likely to relate to the availability of social 'entrepreneurs' (James 1987), as well as to finances ${ }^{12}$. This becomes clear when we understand voluntary participation in charitable organizations as unpaid work, in the sense that it involves the provision of a service to others or the production of goods for the consumption of others' (Taylor 2004, p.38). By considering the productive aspect of volunteer work in this way, we recognize that - like other work - voluntary work consumes resources and requires certain skills (Musick and Wilson 2008). In particular, educational level is a consistent and strong predictor of voluntary participation (Mohan and Bulloch 2012), considered important in the way it promotes cognitive ability, awareness of the roots of social problems, and self-confidence. Occupational status, in terms of the relationship between paid and unpaid work, is also important. Higher status occupations may promote the development of 'civic skills' that are important for voluntary work, including organizing meetings, making presentations, writing letters, and making strategic decisions (Verba et al. 1995; Musick and Wilson 2008). Thus high status occupations may 'provide more [voluntary] 
participation-enhancing activities than do lower-level jobs (Schlozman, Burns, and Verba 1999, p.37). In terms of financial resources, individuals on low incomes may be dissuaded by any incidental costs associated with voluntary work (Reitsma-Street, Maczewski, and Neysmith 2000). Overall it is clear that voluntary participation is enabled and constrained by resources, in terms of money, education, time and civic skills (Verba et al. 1995). As Musick and Wilson (2008) argue, these 'enabling resources' for voluntary work are not evenly distributed among the population. Empirical evidence suggests that it is in the deprived neighborhoods, where need is greatest, where the 'civic core' with the enabling resources for voluntary participation is most scarce (Mohan and Bulloch 2012).

Importantly, if theory about philanthropic insufficiency (Salamon 1987) and about the necessary 'enabling resources' for unpaid work (Verba et al. 1995; Musick and Wilson 2008) provide a strong basis for expecting unevenness in charitable activity according to compositional differences in socioeconomic resources, we should expect particular unevenness at the neighborhood level - the same level in which we see particular unevenness in levels of deprivation. Indeed, while the causes of deprivation may be related to economic restructuring at a higher scale, the housing market, residential sorting and institutional factors serve to concentrate deprivation in particular places within towns, cities, and rural areas, such that differences in economic activity are particularly evident at the neighborhood level (McCulloch, Mohan, and Smith 2012; North and Syrett 2008). Note that in this context neighborhood residential sorting of individuals with particular characteristics is not a statistical nuisance to be controlled away - instead, it is a fundamental process which helps us understand neighborhood differentiation, and therefore of key substantive interest in its own right (Sampson 2012). Indeed, for Wilson (1987; 1996), residential sorting has important implications for the viability of neighborhood organizations, since middle and upper income 
families are an important base of support for neighborhood institutions. Therefore, for example, the outmovement of middle income black families from inner cities in the United States in the latter decades of the twentieth century was seen to remove an important 'social buffer' which may have otherwise provided some resilience to macrostructural economic changes (Sampson and Wilson 1995). Note that the process of residential sorting cannot be understood independently from the wider political economy. Therefore institutional factors, as well as individual preferences, are important (Logan and Molotch 1987). In the UK context, the institutional structure of education in the UK, where residence is important to the system of school assignment, serves to reinforce class-based neighborhood stratification: more affluent families have the resources to 'vote with their feet' by moving to residential areas with desirable schools (Reay and Lucey 2004; see also Butler and Robson 2003). Institutional decisions relating to the location of public housing have also been important, serving to concentrate individuals at the bottom of the income distribution into particular neighborhoods (McCulloch et al. 2012; see also Logan and Molotch 1987; Massey and Denton 1993). This tendency towards concentration was reinforced by UK housing policy in the 1980s: the introduction of the 'right to buy' by the Thatcher administration for tenants of public housing both reduced the stock of public housing and meant that it became increasingly confined to particular localities (Taylor 2003).

It is helpful to make two further points about the hypothesized relationship between the compositional characteristics of neighborhoods and the density of charitable organizations. First, this may be a reinforcing circular relationship. This is because the presence of charitable organizations within a community may itself promote the development of individuals' civic skills and social networks, in turn promoting the civic engagement that is important to the subsequent development of future organizations. Indeed Greve and Rao 
(2012, p.636) explain how organizations may leave an 'institutional legacy' of collective civic action, which provides an environment favorable to the founding of subsequent organizations. Second, while this paper focuses on compositional differences in the socioeconomic resources of individuals between neighborhoods, there may also be compositional differences in subjective dispositions that are relevant for charitable activity. Generalized trust, a relatively stable disposition regarded as a product of socialization which expresses faith in people who you do not know and who may be different from yourself (Uslaner 2006), is associated with both charitable giving and with voluntary participation (Uslaner 2002). There is some evidence for selective migration, according to individuals' trusting disposition, into certain kinds of neighborhoods (Uslaner 2012), which may help to explain an association between high levels of neighborhood deprivation and low levels of generalized trust (Sturgis et al. 2011). We would expect neighborhoods with high levels of generalized trust to have a higher density of charitable organizations. In addition, since we would expect generalized trust to be associated with institutionalized trust (Uslaner 2002), through promoting trust in those involved in running charitable organizations, high levels of generalized trust in a neighborhood may promote support and engagement with existing neighborhood organizations. However this is not something that we are able to examine in this paper: our measure of neighborhood deprivation summarizes compositional differences in socioeconomic resources, but not compositional differences in generalized trust.

\section{Measurement: a longitudinal approach}

This paper takes a longitudinal perspective to the measurement of charitable institutional resources within neighborhoods. There is a growing awareness of the need to incorporate longitudinal approaches within neighborhood studies, and of the importance of time in 
understanding the salience of neighborhood context (Sampson, Morenoff, and GannonRowley 2002; Sampson 2012; Van Ham et al. 2013; Sharkey and Faber 2014). Empirical evidence shows that, because families experience limited 'contextual mobility' between different levels of the hierarchy of neighborhood status, the effects of neighborhood disadvantage on individuals accumulate over time - both across individuals' lives and across generations (Sharkey 2008; Sharkey 2013). Just as it is important to take a longitudinal approach to the study of individuals' exposure to neighborhood context, so it is important to take a longitudinal approach when describing emergent features of the neighborhood context: to what extent are these features 'consistent' over time? Indeed the population of charitable organizations in different neighborhoods will evolve over time as some organizations are founded and others dissolve. To be a salient feature of inequality in individuals' residential environments, differences in the density of charitable organizations according to deprivation should endure over time even as neighborhoods experience organizational turnover. Therefore this paper assesses not only whether 'rich' and 'poor' neighborhoods differ in the density of charitable organizations, but also considers whether these gradients in organizational density are maintained over time. In assessing the consistency of the neighborhood context, we focus on the underlying processes as well as the patterns. We do this by examining the organizational dynamics - in terms of the rate of charitable foundations and the rate of charitable dissolutions - through which any differences in charitable density according to neighborhood deprivation may persist. This longitudinal approach is considered a more complete empirical perspective relevant to institutional resources theory than that provided by a cross-sectional description of organizational density alone. 


\section{DATA AND METHOD}

\section{Definition of charity data}

In this paper we make use of a unique dataset which allows us to follow the population of registered charities in England and Wales through time. The dataset is built from information in the Register of Charities, maintained by the Charity Commission, which regulates charities in England and Wales.

The Register of Charities is fundamental to the Charity Commission's regulatory role and contains key information on the activity of all registered charities in England and Wales. Unlike in many countries where registration is not compulsory and which do not have a comprehensive listing of organisations (United Nations 2011; Hénon 2014), the Charity Commission's system of registration is well established. Indeed while there are significant benefits to charitable status - including tax and reputational benefits - there are also strict requirements (Morgan 2010; Morgan 2012) ${ }^{13}$. For those organizations that meet the charitable definition, charitable registration is not an option: registration and annual reporting is compulsory.

The Register of Charities was introduced in the early 1960s. Importantly, ever since the computerization of the Register of Charities was completed in the mid-1990s, the records of those charities that dissolve have been retained on the Register even after the date of dissolution. Thus, since the mid-1990s, records of organizations have accumulated over time as new charities have been formed while others dissolve. Therefore we are able to use the information in the Register of Charities to build a dataset that contains covariate information 
on the population of registered charities to have existed in England and Wales over our analysis period from 1996 to 2011 inclusive.

Table 1 summarizes the main covariate data that are available for each charity. This includes the year of charitable registration and, for dissolved charities, the year of charitable dissolution; longitudinal data on charities' headline annual income and expenditure in each year of our analysis period; a statement of the charity's purpose; and a series of binary classification variables describing the role that the charity performs and the beneficiaries that it serves. There are two independently reported variables that serve to locate an organization geographically: the address of the charity, with postal code; and structured information in which charities are asked to indicate their charitable 'area of operation' - the local authority (or the overseas country) "where the charity does its work or provides its benefit' ${ }^{14}$. This suite of covariate information, originally provided through the annual returns ${ }^{15}$ that charities are required to file as part of the Charity Commission's regulatory process, is structured in a variety of different files (extracts) in the Register. We link these files using the unique charity registration number identifier.

We prepared the data carefully before analysis. Our panel of charities contains both preexisting organizations, which were founded before 1996, and organizations which were founded over the analysis period ${ }^{16}$. We follow organizations from 1996, or from the year of foundation ${ }^{17}$ if after 1996, until the year of dissolution ${ }^{18}$ or until 2011 if they survive to the end of the analysis period ${ }^{19}$. Table 2 illustrates the nature of our data by providing a list of exemplary organizations ${ }^{20}$. The horizontal line, showing the longitudinal span of annual financial data between 1996 and 2011, illustrates the years in which charities are active over our analysis period. 
We have data on the population of registered charities in England and Wales. Since the following organisations are not encompassed by the Charity Commission Register, the analysis in this paper does not consider:

- A small number of groups of organisations that are charitable in status but which are 'exempted' from charitable registration: they fall outside the Charity Commission's jurisdiction since they are regulated by a different organisation. This includes most universities and other further and higher education institutions, voluntary sector providers of housing, and national museums and galleries ${ }^{21}$. In addition, Christian churches linked to certain denominations - including, for example, the Church of England and the Church of Wales - have traditionally been 'excepted' from registration with the Charity Commission and are therefore not included in our data ${ }^{22}$.

- Charities registered in Scotland or Northern Ireland, and not with the Charity Commission in England and Wales.

- Non-charitable civil society organisations, including mutuals, cooperatives and social enterprises. Organisations where owners/directors derive financial benefits from organisational earnings are not eligible for charitable status, since charities must be run by trustees who do not personally benefit from the charity. These organisations are excluded from the voluntary sector under the non-distribution constraint of Salamon and Anheier’s (1992) 'structural/operational’ definition.

Table 3 shows how we arrive at the final subpopulation of charities considered in our analysis. We start by identifying the total population of registered charities in existence over our analysis period. Since we are interested in examining patterns in the density, foundation and dissolution of charitable organizations according to neighborhood context, we next identify the most appropriate subpopulation for analysis: the c. $60 \%$ of charities that indicate that they operate within one specific local authority ${ }^{23}$. In addition, since the measure of neighborhood 
deprivation that is available for Wales is not directly comparable to the English measure, we restrict analysis to charities with an address in England. There are 127,392 charities in our final dataset, contributing 1,374,553 charity years over the analysis period, with 38,504 charitable foundations and 36,992 charitable dissolutions. Therefore, on average, there are 2.7 dissolutions per 100 charity years. Table 4 presents the number of observations by different covariates used in the analysis.

The subpopulation of charities that we consider is diverse. In terms of their beneficiaries, $57 \%$ indicate that their work benefits children/ young people; $29 \%$ the elderly/ older people; $23 \%$ 'people with disabilities'; $17 \%$ other charities/ voluntary bodies; $15 \%$ 'other [unspecified] defined groups'; 6\% 'people of a particular ethnic/racial origin'; $42 \%$ the 'general public/mankind, ${ }^{24}$. In terms of their general field of activity ${ }^{25}, 25 \%$ of charities fall within the 'social services' group of the International Classification of Nonprofit Organisations (ICNPO 4) ${ }^{26} ; 22 \%$ within 'education and research' (ICNPO 2) ${ }^{27} ; 14 \%$ within 'development and housing' (ICNPO 6) ${ }^{28} ; 11 \%$ within 'culture and recreation' (ICNPO 1); 28\% within other ICNPO groups. This diversity is consistent with Kendall's (2003) characterisation of the charitable sector, and the array of organisations within it, as a 'loose and baggy monster'. Indeed the charities in our data are united not by the field in which they operate but, in keeping with our conceptual definition, by their basic structure and operation (Salamon and Anheier 1992): they are formal, private and self-governing, non-profit distributing organisations which benefit to a meaningful degree from voluntarism.

\section{Linking charity data and contextual data}

We measure neighborhood context using the 2007 Index of Multiple Deprivation (IMD). The IMD is a summary measure, based on the aggregation of individual characteristics, of seven 
domains of deprivation relating to: income; employment; health and disability; education, skills and training; barriers to housing and services; crime; and characteristics of the local environment (see Noble et al. 2006). It is measured at the level of the Lower Super Output Area (LSOA), which have an average population of c.1500 people, designed for the reporting of information about small areas ${ }^{29}$. There are c.32,000 LSOAs in England. Note that, since the IMD measure is not designed to enable the monitoring of changes in neighborhood-level deprivation, we assume neighborhood context does not change with time. Indeed empirical evidence suggests that patterns of local deprivation tend to persist for considerable periods of time, as neighborhoods maintain their relative positions in the urban hierarchy (Dorling et al. 2000; Sampson 2012; McCulloch et al. 2012) ${ }^{30}$. Nevertheless we do perform robustness checks: our results are robust to whether the 2004 IMD, 2007 IMD, or the 2010 IMD, are used; our results are also robust to an alternative modelling specification which considers neighborhood deprivation as a time-varying, rather than fixed, covariate ${ }^{31}$.

We link charities to LSOAs, and therefore to covariate data on the nature of local deprivation, using the postcode of the charity address (Figure 2). The address provided on the Charity Commission Register is the charity contact address. While charities are not asked to indicate whether this listed address represents the location where charitable activities are carried out, they do provide valuable complementary information about their area of operation at the local authority level (Table 1). Therefore we have the advantage of being able to use the area of operation data to exclude those charities with an extensive spatial reach whose listed address does not provide a guide to the locality of charitable activity ${ }^{32}$. Thus we consider address information specifically for those charities whose operation is nested within one particular local authority. Indeed, as Bryson et al. (2002) and Milligan and Fyfe (2004) point out, if we leave aside the agglomeration of administrative offices associated with the presence of regionally and nationally focused organizations, the majority of charitable organizations 
operate within limited geographical boundaries and are oriented to the local area in which they are located. Moreover, since the Charity Commission stipulate that the address listed on the Register should relate to a physical address ${ }^{33}$, we do not face a problem relating to the prevalence of post office box addresses often faced by researchers examining the geography of nonprofits in the US (Peck 2008). Note that the charity address in our analysis is fixed rather than time-varying. This stems from the structure of information in the Charity Commission Register (Table 1). The financial data on the Register are organized by charity year: there are multiple records for each charity, providing annual headline income and expenditure over our analysis period. However the address information on the Register is organized by charity: there is one record for each organization, providing the current address or, for dissolved charities, the address at the time of charitable dissolution ${ }^{34}$. We use this address record as an indicator of the charity's address since the beginning of our analysis period / since the time of foundation if the charity was founded after 1996. Therefore, in our analysis, we consider the location of charities to be stable over time ${ }^{35}$.

We are able to test the robustness of our results to an alternative method of locating an organization geographically. We repeat our analysis using the charity's reported area of operation, rather than the charity address, as a means of attaching covariate data on population and deprivation (Figure 2). The area of operation is at a different spatial scale: it provides the local authority, rather than the LSOA, in which the charity provides its benefit. Therefore, as a measure of deprivation at the local authority level, we use the population weighted average of the LSOA deprivation scores. We then compare across local authorities, examining differences in the density and dynamics of charitable organizations according to deprivation, and assess the consistency of our results with those from the LSOA analysis which uses the charity address as a measure of location. 


\section{Method}

We begin by examining the relationship between neighborhood context and the density of charitable organizations, expressed as the number of charities per 1000 people, using a series of log-linear models of the form

$$
\log E\left(Y_{i}\right)=\log \left(n_{i} \mu_{i}\right)=\log \left(n_{i}\right)+\boldsymbol{x}_{i}^{\prime} \boldsymbol{\beta}
$$

where $Y_{i}$ is the number of charities, and $n_{i}$ the population size, in neighborhoods in percentile $i$ of the IMD distribution. The relationship between neighborhood deprivation $\boldsymbol{x}_{i}^{\prime}$ and organizational density $\mu_{i}$ is described by the vector of parameters $\boldsymbol{\beta}$. The offset term $\log \left(n_{i}\right)$ controls for differences in population size according to neighborhood context ${ }^{36}$. We use negative binomial models, since the variance exceeds the mean, which include an additional parameter to account for overdispersion.

After examining patterns in charitable density, we examine organizational dynamics - in terms of the rate of charitable foundation and dissolution - according to neighborhood context. To describe patterns in the rate of charitable foundation, expressed as the number of charities founded per 1000 people over our analysis period, we use a series of negative binomial loglinear models using the same framework as in equation (1): here, $Y_{i}$ is the number of charities founded between 1997 and 2011 in neighborhoods in percentile $i$ of the IMD distribution and the vector of parameters $\boldsymbol{\beta}$ describes the relationship between neighborhood deprivation $\boldsymbol{x}_{i}^{\prime}$ and the rate of charitable foundation $\mu_{i}$ over the period, adjusting for population size using the offset $\log \left(n_{i}\right)$. 
To describe patterns in the hazard of a charity dissolving ${ }^{37}$ according to neighborhood context, we use a series of piecewise exponential proportional hazard survival models of the form

$$
\lambda_{i j}=\lambda_{j} \exp \left\{\boldsymbol{x}_{i}^{\prime} \boldsymbol{\beta}\right\}
$$

where $\lambda_{i j}$ is the hazard of dissolution for charity $i$ in time interval $j, \lambda_{j}$ is the baseline hazard for interval $j$, and $\exp \left\{\boldsymbol{x}_{i}^{\prime} \boldsymbol{\beta}\right\}$ is the rate ratio, a proportionate increase or decrease in the hazard associated with the covariate characteristics $\boldsymbol{x}_{i}$ (see, for example, Yamaguchi 1991; Rodriguez 2007). Process time $j$ is the age of the organization, measured by the number of years since foundation. We divide $j$ into intervals (0-4 years since foundation, 5-9, 10-19, 20+), assuming that the hazard is constant within each interval. This provides a good approximation to the baseline hazard. Importantly, we find that differences in survival according to neighborhood context are robust to alternative specifications of the hazard, and indeed to a non-parametric approach which leaves the baseline unspecified (Cox 1972). (Figure A2 in the Appendix presents a comparison of rate ratios from the proportional hazards model with rate ratios from a Cox model). We organize our data into pseudoobservations, one for each combination of charity $i$ and time interval $j$, for the period 1997$2011^{38}$. We create measures of exposure $t_{i j}$, denoting time lived by charity $i$ in interval $j$, and of dissolution $d_{i j}$, taking the value 1 if charity $i$ dissolves in interval $j$ and zero otherwise. Noting the equivalence with the piecewise exponential proportional hazards model (Holford 1980; Laird and Oliver 1981), we fit a Poisson log-linear model to these pseudo-observations, where the dissolution indicator is the response and the log of exposure time is an offset (see Rodriguez 2007) ${ }^{39}$. 
When examining charitable density, and rates of charitable foundation and dissolution, we adopt a number of stages in the analysis. First, we examine overall patterns according to neighborhood context, comparing between neighborhoods according to the level of local area deprivation. Here and subsequently we parameterize deprivation rank, expressed as a percentile of the LSOA deprivation distribution ${ }^{40}$, as a continuous variable, and test for the most appropriate functional form for deprivation by assessing the significance of the change in likelihood for nested regression models. Next, we examine whether these patterns in density/foundation/survival by neighborhood context extend to a variety of different kinds of organizations: for models describing patterns in density and in rates of foundation (equation 1), we fit a series of separate models with $Y_{i}$ relating to different subpopulations of charities; for models describing patterns in survival (equation 2), we include an interaction between neighborhood context and the kind of organization ${ }^{41}$. We are able to identify a number of specific types of charities, including parent teacher associations, preschools and youth clubs ${ }^{42}$, and charities performing a variety of particular roles $^{43}$ (for example, providing services; grantmaking). We also assess whether the patterns in density/foundation/survival by neighborhood context extend to a variety of different areas across the country by disaggregating according to wider area context - with area context defined by the Area Classification for Great Britain, which used socioeconomic and demographic data from the 2001 census to identify areas of the country with similar characteristics.

As Firebaugh (2008) and others have argued, empirical research should demonstrate the substantive significance, and not just the statistical significance, of observed differences. In order to do this, we present our regression results graphically, presenting results from fitted models - in terms of the number of charities per 1000 people/ the number of charitable foundations per 1000 people over the analysis period/ the number of charitable dissolutions 
per 100 organization years over the analysis period - across different neighborhood contexts. We do this by calculating fitted marginal dissolution rates from the relevant model, averaged over organizations in the data, according to neighborhood context - at 10 equally spaced points in the deprivation distribution, from the $5^{\text {th }}$ to the $95^{\text {th }}$ percentiles. These graphs are helpful in illustrating the substantive significance of the differences in charitable density, and in organizational dynamics, across different kinds of neighborhoods.

\section{RESULTS}

Neighborhood context and organizational density

The results show that neighborhood context is significantly related to the density of charitable organizations: less deprived neighborhoods have a much higher density of charitable organizations than more deprived neighborhoods (Model A1, Table 5). The size of these differences is best illustrated graphically (Figure 3$)^{44}$. In the least deprived LSOAs, at the $95^{\text {th }}$ percentile of the IMD distribution, there are 2.32 charities per 1000 people. In the most deprived LSOAs, at the $5^{\text {th }}$ percentile of the IMD distribution, there are 1.18 charities per 1000 people. Therefore the density of organizations in the least deprived neighborhoods is twice that in the most deprived: the density ratio $D R_{5}^{95}$, expressing relative differences in density between the $95^{\text {th }}$ and $5^{\text {th }}$ percentiles of the IMD distribution, is 1.97 (95\% confidence interval (CI) 1.85-2.09). While overall there is a strong negative relationship with neighborhood deprivation, note that the density of organizations at the $5^{\text {th }}$ percentile of the deprivation distribution $(1.17 ; 95 \%$ CI 1.13-1.23) - reflecting the most deprived neighborhoods of all - is slightly higher than that at the $15^{\text {th }}$ percentile $(1.03$; 95\% CI 1.09 1.07). 
Does the relationship between neighborhood context and the rate of dissolution extend to a variety of different kinds of charities? Models A2-A4 (Table 5), which disaggregate the overall pattern according to the size of the charity, provide strong evidence that the relationship is different for different sizes of charities (see Figure 4). There are sizeable gradients according to neighborhood context for smaller charities, with a much higher density in less deprived areas than in more deprived areas. Indeed, for charities with a median annual income of less than $£ 10,000$, the $D R_{5}^{95}$ is 2.71 (95\% CI 2.49-2.94); for charities with a median income between $£ 10,000$ and $£ 100,000$, the $D R_{5}^{95}$ is 2.40 (95\% CI 2.25-2.55). In contrast there is no clear relationship between neighborhood context and the density of larger charities that a median income of more than $£ 100,000$. However, while generally these larger organizations are few in number irrespective of neighborhood context, there is a slightly higher density at the $5^{\text {th }}$ percentile of the IMD distribution. This distinctive pattern, which also accounts for the non-linear relationship observed at the tail of the deprivation distribution when considering the density of the charitable population as a whole (Figure 3), is likely to reflect the targeting of government funding to support charitable organizations in the most deprived neighborhoods.

Importantly, the relationship between neighborhood context and the density of charitable organizations extends to a number of different types of charities. While the charitable population is very diverse, made up of a variety of different organizations in different fields of activity, we are able to identify a number of coherent groups of charities with a common focus across different neighborhood contexts - parent teacher associations, preschools and youth clubs. Parent teacher associations are organizations linked to schools to facilitate parental participation, and which often assist with raising funds. Preschools provide care for children under compulsory school age. They include playgroups, which provide part-time 
care where children learn through play, and more formally structured settings that intend to provide an introduction to primary education. Youth clubs include independent groups, as well as affiliated groups of uniformed organizations like the scouts, guides, and sea cadets. In Models A5-A8 (Table 5), we disaggregate the overall results to examine patterns in the density of organizations for these specific types of charity. There are sizeable gradients according to neighborhood context for each of these types of organizations (see Figure 5): less deprived neighborhoods have a higher density of parent teacher associations, a higher density of preschools, and a higher density of youth clubs than do more deprived neighborhoods. Indeed, the pattern by neighborhood context is pervasive. We identified different groups of charities performing particular roles (for example, grantmaking organizations; those providing buildings/facilities/open space; those providing services; and umbrella bodies) and examined the relationship between density of organizations and neighborhood context for each of these groups (Models A9-A17, Table 5-6). Compared to more deprived neighborhoods, less deprived neighborhoods have a higher density of organizations in each of these categories (see Figure 6). There is only one exception to this general pattern: there is a higher density of organizations providing advocacy, advice and information in the most deprived neighborhoods. For those organizations providing services, and for those providing building/facilities/open space, while overall there is a negative relationship between neighborhood deprivation and organizational density, the very most deprived neighborhoods have a higher density of charities than those slightly less deprived.

Importantly, just as the relationship between neighborhood context and organizational density extends to a number of different types of charities, so it extends to a variety of different wider area contexts across the country. We used information from the Area Classification for Great Britain, which used socioeconomic and demographic data from the 2001 census to identify 
areas of the country with similar characteristics. It classified 325 local authorities in England $^{45}$, the areas which local government has responsibility for, into 12 groups: Centers with Industry, Coastal and Countryside, Industrial hinterlands, London (split into London Centre, London Cosmopolitan, London Suburbs, and Thriving London Periphery), Manufacturing towns, New and growing towns, Prospering Smaller Towns, Prospering Southern England, and Regional Centers. The local authority of Manchester, for example, was classified within the 'Centers with Industry' group. (Table A1 in the Appendix lists the local authorities within each particular Area Classification). We examined charitable density by neighborhood context within each of these different kind of areas (Models A18-A26, Table 6). Importantly, there are significant gradients according to neighborhood context within each type of area (see Figure 7). For example, within those parts of the country classified as 'Manufacturing Towns', concentrated for example in Southern Yorkshire, the density of charitable organizations is 1.77 per 1000 people in the least deprived neighborhoods, and 1.23 in the most deprived ( $D R_{5}^{95} 1.44,95 \%$ CI $\left.1.13-1.76\right)$. Within those parts of the country classified as 'Regional centers', consisting of built-up urban areas, the density of charitable organizations is 2.29 per 1000 people in the least deprived neighborhoods, and 1.30 in the most deprived ( $D R_{5}^{95} 1.76,95 \%$ CI $\left.1.39-2.14\right)$. Within those parts of the country classified as 'Prospering Smaller Towns', concentrated for example in the middle of England, the density of charitable organizations is 2.23 per 1000 people in the least deprived neighborhoods, and 1.01 in the most deprived ( $D R_{5}^{95} 2.21,95 \%$ CI $1.81-2.61$ ). Similar differentials by neighborhood are evident within each of the other remaining contexts $^{46}$. Therefore, it is clear that the relationship between neighborhood context and charitable density is not restricted to a particular type of city, or a particular part of the country. On the contrary - across the full variety of metropolitan and rural contexts, neighborhood context is important. 
Is there evidence that the relationship between neighborhood context and charitable density is enduring? Models A27-A30 (Table 6) answer this question by exploiting the temporal range encompassed by our data, which include not only currently active charitable organizations but also those that have dissolved since the mid-1990s, to describe the density of charitable organizations known to be active at particular points during the analysis period: 1996, 2001 and 2006. Figure 8 collates the results, including those from the end of our panel (2011, already presented in Figure 3). Importantly the density of charitable organizations is stable over time - and this stability is evident across the distribution of neighborhood context (Table 6; Figure 8). Therefore there is an enduring gradient in density according to neighborhood deprivation. Indeed throughout the analysis period the density of charitable organizations in the least deprived neighborhoods is twice that in the most deprived neighborhoods: in 1996, the $D R_{5}^{95}$ is 2.1 (95\% CI 1.9-2.3); in 2001, the $D R_{5}^{95}$ is 2.1 (95\% CI 1.9-2.3); in 2006, the $D R_{5}^{95}$ is 2.1 (95\% CI 1.9-2.2); in 2011, the $D R_{5}^{95}$ is 2.0 (95\% CI 1.9-2.1). Notably this gradient persists during a period in which there is a significant turnover in the population of organizations. Indeed, of the c.88,900 charities in our panel at the beginning of our panel of our analysis period in 1996, c.30,400 (34\%) are no longer active at the end in 2011. Meanwhile there are c.31,900 organizations in 2011 that have been founded in the period since 1996. This significant rate of organizational turnover underscores the importance of assessing the relationship between neighborhood context and rates of charitable foundation and charitable dissolution.

Figure 9, based on Model B1 (Table 7), presents rates of charitable foundation by neighborhood context. More deprived neighborhoods have a lower rate of charitable 
foundation than do less deprived neighborhoods. In the most deprived LSOAs, at the $5^{\text {th }}$ percentile of the IMD distribution, 0.73 charities (95\% CI 0.70-0.77) are founded per 1,000 people across the fifteen years of our analysis period (1997-2011); in the least deprived LSOAs, at the $95^{\text {th }}$ percentile of the IMD distribution, 0.90 charities (95\% CI 0.86-0.94 ) are founded per 1,000 people over the analysis period. Therefore the rate ratio $R R_{95}^{5}$, expressing relative differences in the rate of foundation between the 5 th and $95^{\text {th }}$ percentiles of the IMD distribution, is 0.82 (95\% CI 0.76-0.87). Note that the rate of charitable foundation is higher at the $5^{\text {th }}$ percentile of the IMD distribution than at the $15^{\text {th }}$ percentile, such that the most sizeable difference in rates of foundation is between the $15^{\text {th }}$ and $95^{\text {th }}$ percentiles $\left(R R_{95}^{15}=0.68\right.$, $95 \%$ CI 0.64-0.72).

Figure 10 presents rates of charitable dissolution by neighborhood context ${ }^{47}$. Charities in more deprived neighborhoods have a higher rate of dissolution than those in less deprived neighborhoods. Results from Model C1 (Table 9), which includes only neighborhood context and process time (age) as covariates ${ }^{48}$, show that there are 3.69 charity dissolutions per 100 charity years in the most deprived neighborhoods and 2.15 charity dissolutions per 100 charity years in the least deprived neighborhoods. Thus the rate of dissolution in the most deprived neighborhoods is 1.7 times higher than in the least deprived $\left(R R_{95}^{5}=1.72 ; 95 \%(\mathrm{CI})\right.$ 1.63-1.75). This gradient in the rate of dissolution according to neighborhood context persists when controlling for organization size and form in Model C2 (Figure 10; $R R_{95}^{5}=1.87$, 95\% CI 1.81-1.94). Therefore, compared to less deprived neighborhoods, more deprived neighborhoods not only have lower rates of charitable foundation - they also have higher rates of charitable dissolution. 
The differences in the vital rates of charitable organizations according to neighborhood context extend to a variety of different types of charities. Thus, compared to less deprived neighborhoods, more deprived neighborhoods have lower rates of foundation of parent teacher associations $\left(R R_{95}^{5}=0.20 ; 95 \%\right.$ (CI) $0.17-0.23$ ); lower rates of foundation of preschools $\left(R R_{95}^{5}=0.43\right.$; $\left.95 \%(\mathrm{CI}) 0.34-0.53\right)$; and lower rates of foundation of youth clubs $\left(R R_{95}^{5}=0.34 ; 95 \%\right.$ (CI) 0.24-0.44) (Models B2-B5; Table 7 and Figure 11). Importantly there are corresponding and sizeable gradients in the survival rates of each of these types of organization: compared to less deprived neighborhoods, more deprived neighborhoods have higher rates of dissolution of parent teacher associations $\left(R R_{95}^{5}=4.01 ; 95 \%\right.$ (CI) $\left.3.47-4.56\right)$; higher rates of dissolution of preschools $\left(R R_{95}^{5}=2.39 ; 95 \%(\mathrm{CI}) 2.08-2.71\right)$; and higher rates of dissolution of youth clubs $\left(R R_{95}^{5}=2.52 ; 95 \%\right.$ (CI) 2.07-2.98) (Model C3; Table 9 and Figure 12).

In general these insights also apply when examining particular groups of charity according to their role ${ }^{49}$. For most of the different categories considered, there is a negative relationship between neighborhood deprivation and rates of charitable foundation (Models B6-B14; Table 7 and Figure 13). Organizations providing advocacy, advice and information are an exception to this general pattern, with a higher rate of foundation in the most deprived neighborhoods. For certain groups of charities, while overall there is a negative relationship between neighborhood deprivation and rates of foundation, the very most deprived neighborhoods have higher rates than those slightly less deprived. This pattern is particularly marked for service providing charities, where rates of foundation are similar in the most deprived and least deprived neighborhoods $\left(R R_{95}^{5}=1.08\right.$; 95\% (CI) 0.97-1.19). Meanwhile the results from survival models illustrate a positive relationship between neighborhood context 
and rates of charitable dissolution: irrespective of role, charities in more deprived areas experience higher rates of dissolution (Models C4-C12; Table 10 and Figure 14).

The differences in the vital rates of organizations also extend to different kinds of area contexts across the country: overall, more deprived neighborhoods have lower rates of charitable foundation than do less deprived neighborhoods (Models B15-B23; Table 8 and Figure 15). Note that, as with the charitable population as a whole, in a number of area types - including 'Centers with Industry' and 'Industrial Hinterlands' - the very most deprived neighborhoods have a higher rate of foundation than those slightly less deprived. Importantly the differences in rates of foundation are reinforced by differences in rates of survival: in every type of area across the country, charities in more deprived neighborhoods have higher rates of dissolution (Model C13; Table 11 and Figure 16). For example, within those parts of the country classified as 'Manufacturing Towns', the rate of dissolution is 4.01 per 100 charity years in the most deprived neighborhoods and 2.23 in the least deprived $\left(R R_{95}^{5} 1.80\right.$, 95\% CI 1.54-2.06); within those parts of the country classified as 'Regional centers', the rate of dissolution is 4.16 per 100 charity years in the most deprived neighborhoods and 2.35 in the least deprived ( $R R_{95}^{5} 1.77,95 \%$ CI $1.53-2.01$ ); within those parts of the country classified as 'Prospering Smaller Towns', the rate of dissolution is 4.34 per 100 charity years in the most deprived neighborhoods and 2.16 in the least deprived ( $R R_{95}^{5} 2.01,95 \%$ CI $\left.1.82-2.20\right)$. 
A distinctive strength of our dataset is that we have two independently reported pieces of information which serve to locate each charity geographically. Unlike previous studies on nonprofit location, we have access to data directly reported by charities indicating the area in which they operate. Therefore we are able to assess the consistency of our results when we use the area of operation, rather than the charity address, as a measure of charities' location (Figure 2). We link the area of operation information, which indicates the local authority in which the charity provides its benefit (Table 1), to a measure of deprivation at the local authority level: the population weighted average of the LSOA IMD scores. We find that comparing between local authorities, based on charities' reported area of operation, reveals similar patterns to comparing across LSOAs, based on charities' address (see Figures A3 A11 in the Appendix). Thus, compared to less deprived local authorities, more deprived local authorities have a lower density of charitable organizations $\left(D R_{5}^{95} 0.41,95 \%\right.$ CI 0.28 0.54; Figure A3), lower charitable foundation rates $\left(R R_{95}^{5} 0.61,95 \%\right.$ CI $0.44-0.78$; Figure A6) and higher charitable dissolution rates $\left(R R_{95}^{5} 1.64,95 \%\right.$ CI 1.56-1.72; Figure A7) - and these differences across local authorities in the density and vital rates of charitable organizations extend to a variety of different types of charities (Figures A4, A8-A9) and to charities performing a variety of different roles (Figures A5, A10-A11). Therefore the results from our analysis are robust to the choice of geographical scale (comparing across LSOAs, or comparing across local authorities) and to the use of different measures of charity location (using the address, or using directly reported information about the charity area of operation $)^{50}$. 
Enduring, sizeable and extensive differences between neighborhoods

In summarizing the results we highlight important aspects of the empirical evidence presented here. First, the differences across neighborhoods in the density of charitable organizations are not only enduring; they are also sizeable, and maintained through reinforcing differences in rates of foundation and rates of dissolution that are themselves sizeable. Indeed it is important that empirical research demonstrates the substantive significance, and not just the statistical significance, of observed differences. Our results reveal the substantive significance of neighborhood context: the density of charitable organizations is less deprived areas is twice that in the most deprived areas. There are sizeable differences in the underlying organizational dynamics: across the organizations as a whole, the rate of foundation is 0.82 times lower in the most deprived neighborhoods compared to the least deprived (Figure 9) and the rate of dissolution in the most deprived neighborhoods is almost twice that in the least deprived (Figure $10 ; R R_{95}^{5} 1.87$ ). To further illustrate the implications of these differences in the rates of survival, consider the associated survival function (Figure 17). This compares the cumulative percentage of surviving organizations in the least and most deprived neighborhoods, from year 0 after charitable foundation, based on hypothetical cohorts of organizations experiencing the neighborhood and age specific dissolution rates in our analysis period (based on Model C2 - see Table 9). After 10 years, $68 \%$ of organizations remain in the most deprived neighborhoods, compared to $82 \%$ in the least deprived; after 25 years, $34 \%$ of organizations remain in the most deprived neighborhoods, compared to $56 \%$ in the least deprived. Indeed, the survival functions (not shown) for particular subpopulations of charities - like parent teacher associations, preschools and youth clubs, with particularly sharp differences in the risk of dissolution according to deprivation (Figure 12) - would show even larger neighborhood 
differences than evident in Figure 17. Together the substantively significant differences in organizational dynamics maintain the enduring differences in the density of organizations between more and less deprived areas: by 2011 the charitable population is quite different to 1996 - with a 34\% turnover of organizations overall - and yet the gradient in charitable density according to neighborhood deprivation remains unchanged.

Second, the differences across neighborhoods in the density of charitable organizations are extensive, maintained through reinforcing differences in rates of foundation and rates of dissolution that are themselves extensive. Causal inference is strengthened if the linkage occurs in a variety of settings (Lieberson and Horwich 2008; Ni Bhrolchain and Dyson 2007). This strengthens the evidence for the importance of neighborhood context, because we show that neighborhood differences in charitable density, charitable foundation and charitable dissolution extend across a variety of different kinds of organizations - including parent teacher associations, preschools and youth clubs - and, with the exception of those providing advocacy/advice/information, those performing a variety of different roles. They also extend across the full variety of different metropolitan and rural area contexts in England. Therefore the importance of neighborhood context is not restricted to one particular kind of organization, or to one particular city or type of neighborhood context.

\section{DISCUSSION}

Important theory argues that, if neighborhood effects exist, presumably they stem from 'processes that involve collective aspects of community' - 'emergent' properties of neighborhoods that cannot be understood with reference to individuals' characteristics alone (Sampson 2012, p.47). Therefore there is a growing awareness that our understanding of the 
mechanisms underlying neighborhood effects would be enhanced by empirical work which is able to measure these emergent properties directly, by illustrating salient features of inequality in residential environments beyond the aggregated characteristics of individuals (Harding et al. 2011; Sampson 2012; Sharkey and Faber 2014).

One important theoretical perspective suggests that neighborhoods may differ in terms of their institutional resources. Here a relevant 'emergent measure' is organizational density (Sampson 2012). In poor neighborhoods, without the presence of a critical threshold of economically stable households, community organizations may be less viable and therefore more scarce (Wilson 1987; 1996; Logan and Molotch 1987). Indeed recent reviews have identified the organizational dimension as a priority for research within neighborhood studies (Allard and Small 2013; McQuarrie and Marwell 2009; Sampson 2011, 2012; Sharkey and Faber 2014; Small 2014). Thus Allard and Small (2013) call for a renewed focus on the ways in which local organizations mediate and structure neighborhood context. An important priority for empirical work is to examine whether - as predicted by institutional resources perspectives - the presence of organizations does indeed vary systematically according to the extent of neighborhood disadvantage.

Since voluntary organizations are regarded as an 'especially' important and neglected component of neighborhood studies (Sampson, 2012, p.233; Small and Stark 2005), this paper focuses on charitable organizations in England. It provides empirical evidence for a systematic relationship between the compositional measure of neighborhood context - in terms of the Index of Multiple Deprivation, a summary measure reflecting the aggregation of individuals' socioeconomic characteristics - and an emergent neighborhood characteristic, the density of charitable organizations. 
Importantly this paper presents empirical evidence that differences between neighborhoods in the density of charitable organizations are enduring. The paper's approach is based on the principle that the salience of neighborhood context is best understood from a longitudinal perspective. From the perspective of individuals, the importance of neighborhood will vary between people according to the extent of their exposure over their lifespan (Harding et al. 2011; Sharkey and Faber 2014), and the consequences of disadvantage will be compounded for families that experience limited contextual mobility between different generations (Sharkey 2008; 2013). However a longitudinal approach is also fundamental to an understanding of the nature of the neighborhood context itself. Here the interest centers on the 'consistency' of the relevant emergent neighborhood properties. This paper shows that the gradient in charitable density according to neighborhood context - twice as high in the least deprived neighborhoods as in the most deprived neighborhoods - remains stable over time. Therefore, and despite significant turnover in the organizational population, charitable density represents a persistent feature of inequality in the residential environment. Less deprived neighborhoods have a persistent organizational advantage.

This underscores the importance of interrogating mechanisms of continuity amidst continual change (Sampson 2013): even as neighborhoods and their organizational populations continually evolve, there is a stable pattern of neighborhood stratification. This shifts the empirical interest away from cross-sectional patterns to underlying organizational dynamics. Importantly this paper shows that the persistent patterns in charitable density are the result of two mutually reinforcing processes. First, compared to less deprived neighborhoods, in more deprived neighborhoods fewer charities are founded per head of population. Second, 
compared to less deprived neighborhoods, charities in more deprived areas experience a higher hazard of dissolution in a given organizational year ${ }^{51}$. These twin processes are themselves enduring over time: in each of the five year periods in our data, more deprived neighborhoods experienced lower rates of foundation (1997-2001: $R R_{95}^{5} 0.73$, 95\% CI 0.640.81; 2002-2006: $R R_{95}^{5} 0.87,95 \%$ CI $0.81-0.94 ; 2007-2011: R R_{95}^{5} 0.87,95 \%$ CI $\left.0.80-0.94\right)$; in each of the five year periods in our data, more deprived neighborhoods experienced higher rates of dissolution (1997-2001: $R R_{95}^{5} 1.97,95 \%$ CI 1.85-2.09; 2002-2006: $R R_{95}^{5} 2.11,95 \% \mathrm{CI}$ 1.98-2.23; 2007-2011: $R R_{95}^{5} 1.63,95 \%$ CI $\left.1.54-1.72\right)^{52}$. These interlocking processes mean that the lower density of organizations in more deprived areas persists even as neighborhoods experience organizational turnover. Therefore the organizational characteristics of residential environments are durable over time. These findings are consistent with Sampson's (2012; 2013) thesis that neighborhoods are 'sticky' in character: the characteristics of neighborhoods, and the level of inequality across neighborhoods, are seen to be durable over time since neighborhoods 'reproduce themselves in highly structured ways' (Sampson 2013, p.10; see also Denton 2013).

The finding that enduring differences in charitable density reflect both low foundation rates and high dissolution rates in more deprived areas points to the importance of neighborhoodlevel differences in the supply of resources for voluntary action across the organizational life cycle. The process of founding a charitable organization is likely to be resource intensive in terms of both human resources - as strategic decisions and practical arrangements are made about the charities purpose, structure and governance - and financial resources as any initial capital costs are raised. However, even after foundation, we show that charitable organizations in deprived areas are less resilient. One important factor here may be related to 
succession: in more deprived areas, when volunteers important to the governance or the operation of the organization choose to step down or are unable to continue, there may be difficulty in finding other individuals with the 'enabling resources' to replace them. More generally, different kinds of neighborhoods are likely to provide an 'unevenly contoured terrain' which presents differences in the distribution of 'opportunities and constraints' to existing organizations (Hay 2002, p.129). Organizations in more deprived areas may be less able to adopt a diverse funding portfolio that benefits from individuals' donations and fees to complement any income from government (Clifford et al. 2013; Salamon 1987), and less able to draw on the 'civic core' with the skills and experience for public activities (Mohan and Bulloch 2012; Musick and Wilson 2008; Verba et al. 1995), than those in less deprived areas. In turn, given that organizations with multiple sources of funding, and with skilled governance, on average have better life chances (Bielefeld 1994; Hager 2001; Tuckman and Chang 1991; Wollebaek 2009), we would expect these differences in strategy to translate into higher rates of dissolution in deprived neighborhoods ${ }^{53}$.

The role of extra-local actors: public funding of charitable organizations

The results from this paper also shed light on an underexplored theme: the way in which institutional resources within neighborhoods are influenced by the intersecting roles of government and the charitable sector through the public funding of charitable organizations. Charitable organizations are self-governing and institutionally separate from government (Salamon and Anheier 1992). However there is a growing trend towards partnership between government and the charitable sector in the United Kingdom (Deakin 2001; Harris 2010; Lewis 1993), as in the United States (Allard 2009; Smith 2002; Smith and Lipsky 1993), which has seen increases in government funding of charitable organizations (Boris and 
Steuerle 2006; Kane et al. 2014). In the UK, while the majority of charities receive no money from government (Clifford et al. 2013), as part of neighborhood regeneration initiatives spatially targeted government funding has been available to charitable organizations in the most deprived areas. This has reflected a broader policy direction to tackle neighborhood deprivation, stemming from concern about the geographical dimensions of social exclusion (Durose and Rees 2012). Indeed national and local government programmes use the same IMD measure used in this paper to target funding to the most deprived neighborhoods.

This paper is able to observe the implications of this spatial targeting for the distribution of charitable organizations because it examines the whole range of more and less deprived neighborhood contexts across England. It reveals a distribution of charitable density which is highly distinctive in shape: while in general more deprived neighborhoods have a much lower density of charitable organizations, the very most deprived neighborhoods have a slightly higher density than those slightly less deprived. This distinctive shape relates to the charitable population as a whole (Figure 3) and specifically to larger organizations (Figure 4); to those providing buildings/facilities/open space (Figure 6); and to those providing services (Figure 6). It is slightly more evident at the end of the analysis period than at the beginning (Figure 8), reflecting a similarly distinctive pattern in the rate of foundations. Indeed while more deprived neighborhoods have a lower foundation rate across the distribution as a whole, the very most deprived neighborhoods have a higher rate than those slightly less deprived - a pattern relating to the charitable population as a whole (Figure 9) and particularly to those providing buildings/facilities/open space and to those providing services (Figure 13).

These distinctive patterns in density and in rates of foundation are consistent with the availability of spatially targeted government funding to support organizations in the very 
most deprived neighborhoods ${ }^{54}$. Therefore, while this paper argues that charitable organizations are an important priority for research within neighborhood studies, it is important that future research is sensitive to the way in which the neighborhood distribution of these institutional resources may be affected by the role of extra-local actors (Small and Stark 2005; Small, Jacobs, and Massengill 2008; Small 2009; see also Logan and Molotch 1987). Indeed this may prove an interesting theme for cross-country comparative research. Theory about the importance of resources to voluntary action provides a basis for expecting that the basic patterns presented here for England - enduring differences in the density of charitable organizations according to the level of neighborhood deprivation - may also be found in other country contexts (Musick and Wilson 2008; Salamon 1987; Verba et al. 1995). However the nature of any policy response, for example in terms of the extent of government financial support targeted to support organizations in deprived areas, may vary between countries with different traditions of welfare. Therefore, while this paper shows that in England the very most deprived neighborhoods have a slightly higher density than those slightly less deprived, this distinctive pattern may not be evident in countries with a less strong redistributive tradition.

A twin challenge: sustaining as well as creating organizations in deprived areas

Above and beyond wider neighborhood regeneration policy, in recent years in the UK specific initiatives have been launched to tackle the perceived lack of charitable organizations in more deprived areas. In 2008 the Conservative party, while they were still in opposition, launched a Green Paper in which they outlined plans to target 'charity deserts' in areas of deprivation by supporting development 'to establish new voluntary organizations where none previously existed' (Conservative Party 2008). After the Conservatives came to power as part of a Coalition government, the Department for Communities and Local Government 
announced a new $£ 10$ million scheme to fund the setting up of uniformed youth clubs, like the scouts, guides and police cadets, in 400 deprived communities across the country, with a vision to provide 10,000 more places for youths. Andrew Stunnell, the Communities Minister, announced the scheme in Tottenham, North London, the scene of riots in 2011, commenting: 'if you go to [more affluent] areas you find.. scout groups and other uniformed youth clubs, but if you go to Tottenham they are much thinner on the ground' (Sherman 2012).

However, a simple and important message from the empirical material in this paper is that such initiatives, though welcome, may not on their own be sufficient. While funding for this initiative has been provided to 'kick start' the new organizations, the idea is that once established, these new organizations 'are expected to be permanently self-sustaining, raising their own running costs through local fundraising activity and/or subscriptions, giving the programme a substantial and long term legacy' (Department for Communities and Local Government 2012). This is in keeping with the emphasis in wider policy: while the government does recognize the need for 'targeted action' to support voluntary action in the poorest areas, the emphasis seems to be on stimulating 'the creation and development' of neighborhood organizations (Conservative Party 2010; emphasis added). The implicit assumption underlying this emphasis in policy, representing an answer to Greve and Rao's (2012, p.670) important question 'why [do] some communities have a persistent organizational advantage'?, is that no organizations 'previously existed' in deprived areas (Conservative Party 2008). Therefore, the potential for differences in the rates of survival of charitable organizations between neighborhoods is not acknowledged.

However, this paper shows that enduring differences in charitable density reflect reinforcing processes of not only low foundation rates but also high dissolution rates in more deprived 
neighborhoods. Indeed, the rate of dissolution of youth clubs in the most deprived neighborhoods is 2.5 times higher than in the least deprived (Figure 12). Therefore the results suggest that, while encouraging the development of new organizations in deprived areas is important, there is also a real need to think in the longer term and to consider strategies to support the sustainability and survival of organizations in these areas.

\section{Limitations and agenda for future research}

The analysis in this paper has its limitations. In terms of data, while we have information on the population of registered charities, we are not able to consider a small number of groups of organizations which are 'exempted' or 'excepted' from charitable registration. Examining patterns for these organizations - and in particular, those relating to Christian churches would be a fruitful avenue for future research ${ }^{55}$. The Charity Commission Register contains one address record for each charity. Therefore, while for the subpopulation of local organizations that we consider there is a substantive basis for expecting consistency in location over time, we are unable to examine this empirically. We focus on describing differences according to neighborhood-level compositional differences in the socioeconomic resources of individuals, but our neighborhood measure does not consider compositional differences relating to generalized trust. In addition, we do not have data on the different income sources of charitable organizations. Therefore, while the highly distinctive shape of the patterns in charitable density that we observe are consistent with the increased reliance on spatially targeted public funding in the most deprived neighborhoods, we are not able to directly examine neighborhood-level patterns in organizations' revenue profiles. In terms of methods, our models do not consider spatial autocorrelation ${ }^{56}$. We consider the density, and rates of foundation and dissolution, of charitable organizations, but we are not able to 
examine whether there are systematic differences between neighborhoods in organizational 'quality ${ }^{, 57}$ - in terms of the level of service of organizations, or the resources commanded by organizations.

This paper provides empirical evidence relevant to one part of the hypothesized institutional resources mechanism: it shows an enduring relationship between neighborhood deprivation (a compositional measure of neighborhood context) and the density of charitable organizations (a collective aspect of neighborhood life). It does not assess the empirical evidence for the second part of the hypothesized mechanism: the salience of these neighborhood-level differences for individuals' lives. However we point to influential research which would provide a helpful framework for future empirical work on this second theme. Small (2009) emphasizes the 'organizational embeddedness' of individuals' social capital, illustrating how everyday organizations provide the setting for routine collective activities that can promote positive outcomes for individuals. From this perspective, local organizations affect the size, quality and usefulness of people's networks, providing access to resources, information and support through ties to other people and other organizations. Therefore the 'organizational isolate', 'unplugged from the most reliable way to form ties' (p.196), is considered particularly disadvantaged. This paper's results point to the importance of considering the spatial dimensions of 'organizational isolation' in future research. Indeed, as Wilson (2012) argues, bringing together Small's (2009) organizational perspectives on social capital with institutional perspectives on urban inequality may extend our understanding of the 'social isolation' experienced by individuals in deprived neighborhoods. 


\section{CONCLUSION}

Sharkey and Faber's (2014) recent review of the neighborhood effects literature identifies the need for progress in identifying and measuring salient features of residential context, beyond compositional characteristics, that vary between neighborhoods. What aspects of the residential environment differ systematically between neighborhoods according to the level of deprivation? What characteristics of the neighborhood might individuals be 'exposed' to, on the basis that a high proportion of the residents in a neighborhood are disadvantaged? This paper provides empirical evidence relevant to this priority by illustrating sizeable, enduring and extensive differences in density of charitable organizations according to neighborhood disadvantage in England - differences which persist over time through reinforcing dynamics: compared to less deprived areas, more deprived neighborhoods have both a lower rate of charitable foundation and a higher rate of charitable dissolution.

In the European welfare state context core public services are provided on a universal basis, funded through centralized funding mechanisms, with policies targeted to counter disadvantage (Powell and Boyne 2001). This makes the basis for a negative link between neighborhood disadvantage and the institutional context of public service provision less intuitive $^{58}$ (Hastings 2009; Galster 2012). Therefore the evidence presented in this paper points to the particular value of a focus on charitable organizations when considering the relationship between neighborhood context and institutional resources. Indeed there are likely to be fruitful avenues for future interdisciplinary research at the intersection of neighborhood studies and voluntary action which would enrich both sets of literatures. 


\section{REFERENCES}

Allard, Scott W. 2009. Out of Reach: Place, Poverty, and the New American Welfare State. New Haven: Yale University Press.

Allard, Scott W, and Mario L Small. 2013. "Reconsidering the Urban Disadvantaged the Role of Systems, Institutions, and Organizations." The ANNALS of the American Academy of Political and Social Science 647(1):6-20.

Allison, Paul David. 2009. Fixed Effects Regression Models. Los Angeles: Sage.

Baum, Joel A. C., and Christine Oliver. 1991. "Institutional Linkages and Organizational Mortality." Administrative Science Quarterly 36(2):187-218.

Bielefeld, Wolfgang. 1994. "What Affects Nonprofit Survival?" Nonprofit Management and Leadership 5(1):19-36.

Boris, Elizabeth T, and C Eugene Steuerle. 2006. "Scope and Dimensions of the Nonprofit Sector." Pp. 66-88 in The Non-Profit Sector: A Research Handbook, edited by Walter W. Powell and Richard Steinberg. New Haven: Yale University Press.

Bryson, John R., Mark McGuiness, and Robert G. Ford. 2002. "Chasing a 'Loose and Baggy Monster': Almshouses and the Geography of Charity." Area 34(1):48-58.

Butler, Tim, and Garry Robson. 2003. "Plotting the Middle Classes: Gentrification and Circuits of Education in London." Housing Studies 18(1):5-28.

Carroll, Glenn R. 1983. "A Stochastic Model of Organizational Mortality: Review and Reanalysis." Social Science Research 12(4):303-29.

—. 1984. "Organizational Ecology." Annual Review of Sociology:71-93.

Carroll, Glenn R, and Michael T Hannan. 2000. The Demography of Corporations and Industries. Princeton: Princeton University Press. 
Clifford, David, Frida Geyne-Rahme, and John Mohan. 2013. "Variations between Organisations and Localities in Government Funding of Third-Sector Activity: Evidence from the National Survey of Third-Sector Organisations in England." Urban Studies 50(5):959-76.

Conservative Party. 2008. A Stronger Society: Voluntary Action in the 21st Century. Policy Green Paper 5. London: Conservative Party.

—. 2010. Big Society Not Big Government: Building a Big Society. London: Conservative Party.

Cox, David R. 1972. "Regression Models and Life-Tables." Journal of the Royal Statistical Society. Series B (Methodological) 34(2):187-220.

Deakin, Nicholas. 2001. "Public Policy, Social Policy and Voluntary Organisations." Pp. 2136 in Voluntary Organisations and Social Policy in Britain, edited by Margaret Harris and Colin Rochester. Basingstoke: Palgrave.

Denton, Nancy. 2013. "Great American Sociology." City \& Community 12(1):1-6.

Department for Communities and Local Government. 2012. Announcement: Volunteer Push Will Create 10,000 Youth Group Places for Young People. London: Department for Communities and Local Government.

Dorling, Danny, Richard Mitchell, Mary Shaw, Scott Orford, and George Davey Smith. 2000. "The Ghost of Christmas Past: Health Effects of Poverty in London in 1896 and 1991." BMJ: British Medical Journal 321(7276):1547-51.

Ellen, Ingrid Gould, and Margery Austin Turner. 1997. "Does Neighborhood Matter? Assessing Recent Evidence." Housing Policy Debate 8(4):833-66.

Elwert, Felix, and Christopher Winship. 2014. "Endogenous Selection Bias: The Problem of Conditioning on a Collider Variable." Annual Review of Sociology 40:31-53. 
Fernandez, Juan J. 2008. "Causes of Dissolution among Spanish Nonprofit Associations." Nonprofit and Voluntary Sector Quarterly 37(1):113-37.

Firebaugh, Glenn. 2008. Seven Rules for Social Research. Princeton: Princeton University Press.

Fischer, Claude S. 2013. "Showing That Neighborhoods Matter." City \& Community 12(1):712.

Freeman, John, Glenn R Carroll, and Michael T Hannan. 1983. "The Liability of Newness: Age Dependence in Organizational Death Rates." American Sociological Review:692-710.

Galster, George C. 2012. "The Mechanism (s) of Neighbourhood Effects: Theory, Evidence, and Policy Implications." Pp. 23-56 in Neighbourhood Effects Research: New Perspectives, edited by Maarten van Ham, David Manley, and Nick Bailey: Springer.

Greve, Henrich R, and Hayagreeva Rao. 2012. "Echoes of the Past: Organizational Foundings as Sources of an Institutional Legacy of Mutualism." American Journal of Sociology 118(3):635-75.

Grønbjerg, KA, and L Paarlberg. 2001. "Community Variations in the Size and Scope of the Nonprofit Sector: Theory and Preliminary Findings." Nonprofit and Voluntary Sector Quarterly 30(4):684-706.

Hager, Mark A, Joseph Galaskiewicz, and Jeff A Larson. 2004. "Structural Embeddedness and the Liability of Newness among Nonprofit Organizations." Public Management Review 6(2):159-88.

Hager, Mark A. 2001. "Financial Vulnerability among Arts Organizations: A Test of the Tuckman-Chang Measures." Nonprofit and Voluntary Sector Quarterly 30(2):376-92.

Hannan, Michael T, and John Freeman. 1977. "The Population Ecology of Organizations." American Journal of Sociology 82(5):929-64. 
—. 1987. "The Ecology of Organizational Founding: American Labor Unions, 1836-1985." American Journal of Sociology:910-43.

—. 1988. "The Ecology of Organizational Mortality: American Labor Unions, 1836-1985." American Journal of Sociology:25-52.

—. 1989. "Organization Ecology." Cambridge: Harvard University Press.

Hannan, Michael T, László Pólos, and Glenn R Carroll. 2007. Logics of Organization Theory: Audiences, Codes, and Ecologies. Princeton: Princeton University Press.

Hansmann, Henry B. 1980. "The Role of Nonprofit Enterprise." The Yale Law Journal 89(5):835-901.

Harding, David J, Lisa Gennetian, Christopher Winship, Lisa Sanbonmatsu, and Jeffrey R Kling. 2011. "Unpacking Neighborhood Influences on Education Outcomes: Setting the Stage for Future Research." Pp. 277-96 in Whither Opportunity? Rising Inequality, Schools, and Children's Life Chances, edited by Greg J Duncan and Richard Murnane. New York: Russell Sage Foundation Press.

Harris, Bernard. 2010. "Voluntary Action and the State in Historical Perspective." Voluntary Sector Review 1(1):25-40.

Harris, Margaret. 2001. "Boards: Just Subsidiaries of the State?" Pp. 171-84 in Voluntary Organisations and Social Policy in Britain, edited by Margaret Harris and Colin Rochester. Basingstoke: Palgrave.

Hastings, Annette. 2007. "Territorial Justice and Neighbourhood Environmental Services: A Comparison of Provision to Deprived and Better-Off Neighbourhoods in the UK." Environment and Planning C 25(6):896.

—. 2009. "Neighbourhood Environmental Services and Neighbourhood 'Effects': Exploring the Role of Urban Services in Intensifying Neighbourhood Problems." Housing Studies 24(4):503-24. 
Hay, Colin. 2002. Political Analysis: A Critical Introduction. Basingstoke: Palgrave Macmillan.

Hénon, Sarah. 2014. Measuring Private Development Assistance: Emerging Trends and Challenges. Bristol: Development Initiatives.

Hilmers, Angela, David C Hilmers, and Jayna Dave. 2012. "Neighborhood Disparities in Access to Healthy Foods and Their Effects on Environmental Justice." American Journal of Public Health 102(9):1644-54.

Holford, Theodore R. 1980. "The Analysis of Rates and of Survivorship Using Log-Linear Models." Biometrics 36:299-305.

Ipsos Mori. 2010. National Survey of Charities and Social Enterprises: Overall Report National Results. London: Ipsos Mori.

James, Estelle. 1987. "The Nonprofit Sector in Comparative Perspective." Pp. 397-415 in The Nonprofit Sector: A Research Handbook. New Haven, Connecticut: Yale University Press.

Joassart-Marcelli, Pascale, and Jennifer R. Wolch. 2003. "The Intrametropolitan Geography of Poverty and the Nonprofit Sector in Southern California." Nonprofit and Voluntary Sector Quarterly 32(1):70-96.

Kane, David, Joe Heywood, and Pete Bass. 2014. The UK Civil Society Almanac. London: National Council of Voluntary Organisations.

Kendall, Jeremy, and Martin Knapp. 1993. Defining the Nonprofit Sector: The United Kingdom. Working Paper of the Johns Hopkins Comparative Nonprofit Sector Project. Baltimore: The Johns Hopkins University Institute for Policy Studies.

Kendall, Jeremy. 2003. The Voluntary Sector: Comparative Perspectives in the UK. London; New York: Routledge. 
Laird, Nan, and Donald Oliver. 1981. "Covariance Analysis of Censored Survival Data Using Log-Linear Analysis Technique." Journal of the American Statistical Association $76: 231-40$

Lazarsfeld, Paul F, and Herbert Menzel. 1961. "On the Relation between Individual and Collective Properties." Pp. 422-40 in Complex Organizations, edited by Amatai Etzioni. New York: Holt, Rinehart \& Winston.

Lee, Helen. 2012. "The Role of Local Food Availability in Explaining Obesity Risk among Young School-Aged Children." Social Science \& Medicine 74(8):1193-203.

Lewis, Jane. 1993. "Developing the Mixed Economy of Care: Emerging Issues for Voluntary Organisations." Journal of Social Policy 22(02):173-92.

Lichstein, Jeremy W, Theodore R Simons, Susan A Shriner, and Kathleen E Franzreb. 2002. "Spatial Autocorrelation and Autoregressive Models in Ecology." Ecological Monographs 72(3):445-63.

Lieberson, Stanley. 1987. Making It Count: The Improvement of Social Research and Theory. Berkeley and Los Angeles: University of California Press.

Lieberson, Stanley, and Joel Horwich. 2008. "Implication Analysis: A Pragmatic Proposal for Linking Theory and Data in the Social Sciences." Sociological Methodology 38(1):150.

Logan, John, and Harvey Molotch. 1987. "Urban Fortunes: The Political Economy of Place." Berkeley: University of California Press.

Marwell, Nicole P, and Aaron Gullickson. 2013. "Inequality in the Spatial Allocation of Social Services: Government Contracts to Nonprofit Organizations in New York City." Social Service Review 87(2):319-53.

Massey, Douglas S. 2012. "Location Matters. Book Review of 'Great American City Chicago and the Enduring Neighborhood Effect'." Science 336(6077):35-36. 
Massey, Douglas S, and Nancy A Denton. 1993. American Apartheid: Segregation and the Making of the Underclass. Cambridge, MA: Harvard University Press.

McCulloch, Andrew, John Mohan, and Peter Smith. 2012. "Patterns of Social Capital, Voluntary Activity, and Area Deprivation in England." Environment and PlanningPart A 44(5):1130.

McLennan, David, Helen Barnes, Michael Noble, Joanna Davies, Elisabeth Garatt, and Chris Dibben. 2011. The English Indices of Deprivation 2010: Technical Report. London, UK: Department for Communities and Local Government.

McQuarrie, Michael, and Nicole P. Marwell. 2009. "The Missing Organizational Dimension in Urban Sociology." City \& Community 8(3):247-68.

Mohan, John, and S Bulloch. 2012. "The Idea of a 'Civic Core': What Are the Overlaps between Charitable Giving, Volunteering, and Civic Participation in England and Wales?" Third Sector Research Centre Working Paper 73.

Moore, Latetia V, and Ana V Diez Roux. 2006. "Associations of Neighborhood Characteristics with the Location and Type of Food Stores." American Journal of Public Health 96(2):325-31.

Morgan, Gareth G. 2010. "The Use of Charitable Status as a Basis for Regulation of Nonprofit Accounting." Voluntary Sector Review 1(2):209-32.

—. 2012. "Public Benefit and Charitable Status: Assessing a 20-Year Process of Reforming the Primary Legal Framework for Voluntary Activity in the UK." Voluntary Sector Review 3(1):67-91.

Morland, Kimberly, Steve Wing, Ana Diez Roux, and Charles Poole. 2002. "Neighborhood Characteristics Associated with the Location of Food Stores and Food Service Places." American Journal of Preventive Medicine 22(1):23-29. 
Musick, Marc A., and John Wilson. 2008. Volunteers: A Social Profile. Bloomington: Indiana University Press.

Ní Bhrolcháin, Máire, and Tim Dyson. 2007. "On Causation in Demography: Issues and Illustrations." Population and Development Review 33(1):1-36.

Noble, Michael, Gemma Wright, George Smith, and Chris Dibben. 2006. "Measuring Multiple Deprivation at the Small-Area Level." Environment and Planning A 38:16985.

North, David John, and Stephen Syrett. 2008. "Making the Links: Economic Deprivation, Neighbourhood Renewal and Scales of Governance." Regional Studies 42(1):133-48.

Nownes, Anthony J, and Daniel Lipinski. 2005. "The Population Ecology of Interest Group Death: Gay and Lesbian Rights Interest Groups in the United States, 1945-98." Brit Journal of Political Science 35(2):303-19.

Office for National Statistics. 2013. "Super Output Area Mid-Year Population Estimates, Mid-2012." Office for National Statistics.

Owens, Ann, and Robert J Sampson. 2013. Community Well-Being and the Great Recession. Stanford, CA: Stanford Center on Poverty and Inequality.

Patuelli, Roberto, Gert-Jan M Linders, Rodolfo Metulini, and Daniel A Griffith. 2016. "The Space of Gravity: Spatially Filtered Estimation of a Gravity Model for Bilateral Trade." Pp. 145-69 in Spatial Econometric Interaction Modelling. Switzerland: Springer.

Peck, Laura R. 2008. "Do Antipoverty Nonprofits Locate Where People Need Them? Evidence from a Spatial Analysis of Phoenix." Nonprofit and Voluntary Sector Quarterly 37(1):138. 
Powell, Lisa M, Sandy Slater, Donka Mirtcheva, Yanjun Bao, and Frank J Chaloupka. 2007. "Food Store Availability and Neighborhood Characteristics in the United States." Preventive Medicine 44(3):189-95.

Powell, Martin, and George Boyne. 2001. "The Spatial Strategy of Equality and the Spatial Division of Welfare." Social Policy \& Administration 35(2):181-94.

Rae, Alasdair. 2012. "Spatially Concentrated Deprivation in England: An Empirical Assessment." Regional Studies 46(9):1183-99.

Raudenbush, Stephen W, and Robert J Sampson. 1999. "Ecometrics: Toward a Science of Assessing Ecological Settings, with Application to the Systematic Social Observation of Neighborhoods." Sociological Methodology 29(1):1-41.

Reay, Diane, and Helen Lucey. 2004. "Stigmatised Choices: Social Class, Social Exclusion and Secondary School Markets in the Inner City." Pedagogy Culture and Society 12(1):35-51.

Reitsma-Street, Marge, Mechthild Maczewski, and Sheila Neysmith. 2000. "Promoting Engagement: An Organizational Study of Volunteers in Community Resource Centres for Children." Children and Youth Services Review 22(8):651-78.

Rodriguez, Germán. 2007. 'Survival Models'. Lecture Notes on Generalized Linear Models: Princeton: Office of Population Research, Princeton University.

Salamon, Lester M. 1987. "Of Market Failure, Voluntary Failure, and Third-Party Government: Toward a Theory of Government-Nonprofit Relations in the Modern Welfare State." Nonprofit and Voluntary Sector Quarterly 16(1-2):29-49.

Salamon, Lester M, and HK Anheier. 1992. "In Search of the Non-Profit Sector. I: The Question of Definitions." Voluntas: International Journal of Voluntary and Nonprofit Organizations 3(2):125-51. 
Salamon, Lester, and Helmut Anheier. 1996. The International Classification of Nonprofit Organizations: Revision 1, 1996. Working Papers of the Johns Hopkins Comparative Nonprofit Sector Project, No. 19. Baltimore: The Johns Hopkins Institute for Policy Studies.

Sampson, Robert J. 2008. "Moving to Inequality: Neighborhood Effects and Experiments Meet Social Structure." American Journal of Sociology 114(1):189-231.

—. 2011. "Neighborhood Effects, Causal Mechanisms and the Social Structure of the City." Pp. 227-49 in Analytical Sociology and Social Mechanisms, edited by $\mathrm{P}$ Demeulenaere. New York: Cambridge University Press.

-. 2012. Great American City: Chicago and the Enduring Neighborhood Effect. Chicago: University of Chicago Press.

—. 2013. "The Place of Context: A Theory and Strategy for Criminology's Hard Problems." Criminology 51(1):1-31.

Sampson, Robert J, Jeffrey D Morenoff, and Thomas Gannon-Rowley. 2002. "Assessing" Neighborhood Effects": Social Processes and New Directions in Research." Annual Review of Sociology:443-78.

Sampson, Robert J, and William Julius Wilson. 1995. "Toward a Theory of Race, Crime, and Urban Inequality." Pp. 177-90 in Race, Crime, and Justice: A Reader, edited by John Hagan and Ruth D Peterson. Stanford, CA: Stanford University Press.

Schabenberger, Oliver, and Carol A Gotway. 2005. Statistical Methods for Spatial Data Analysis. Boca Raton: Chapman \& Hall/CRC.

Schlozman, Kay Lehman, Nancy Burns, and Sidney Verba. 1999. "“What Happened at Work Today?": A Multistage Model of Gender, Employment, and Political Participation." The Journal of Politics 61(01):29-53. 
Sharkey, Patrick. 2008. "The Intergenerational Transmission of Context." American Journal of Sociology 113(4):931-69.

—. 2013. Stuck in Place: Urban Neighborhoods and the End of Progress toward Racial Equality. Chicago: University of Chicago Press.

Sharkey, Patrick, and Jacob W Faber. 2014. "Where, When, Why, and for Whom Do Residential Contexts Matter? Moving Away from the Dichotomous Understanding of Neighborhood Effects." Annual Review of Sociology 40:559-79.

Sherman, Jill. 2012. "Government Sends in the Scouts to Riot Hotspots." The Times Newspaper August 25th 2012:1,4.

Small, Mario Luis. 2009. Unanticipated Gains: Origins of Network Inequality in Everyday Life. New York: Oxford University Press.

Small, Mario Luis. 2014. An Organizational Perspective on Social Isolation: The Decent City Initiative: The Cities Papers. Social Science Research Council.

Small, Mario Luis, Erin M Jacobs, and Rebekah Peeples Massengill. 2008. "Why Organizational Ties Matter for Neighborhood Effects: Resource Access through Childcare Centers." Social Forces 87(1):387-414.

Small, Mario Luis, and Monica McDermott. 2006. "The Presence of Organizational Resources in Poor Urban Neighborhoods: An Analysis of Average and Contextual Effects." Social Forces 84(3):1697-724.

Small, Mario Luis, and Katherine Newman. 2001. "Urban Poverty after the Truly Disadvantaged: The Rediscovery of the Family, the Neighborhood, and Culture." Annual Review of Sociology:23-45.

Small, Mario Luis, and Laura Stark. 2005. "Are Poor Neighborhoods Resource Deprived? A Case Study of Childcare Centers in New York." Social Science Quarterly 86(s1):1013-36. 
Smith, Steven Rathgeb. 2002. "Social Services." Pp. 149-86 in The State of the Nonprofit Sector, edited by Lester Salamon. Washington DC: Brookings Institution Press.

Smith, Steven Rathgeb, and Michael Lipsky. 1993. "Nonprofits for Hire: The Welfare State in the Age of Contracting." Cambridge: Harvard University Press.

Smoyer-Tomic, Karen E, John C Spence, Kim D Raine, Carl Amrhein, Nairne Cameron, Vladimir Yasenovskiy, Nicoleta Cutumisu, Eric Hemphill, and Julia Healy. 2008. "The Association between Neighborhood Socioeconomic Status and Exposure to Supermarkets and Fast Food Outlets." Health \& Place 14(4):740-54.

Stinchcombe, Arthur L. 1965. "Social Structure and Organizations." Pp. 153-93 in Handbook of Organizations, edited by J G March. Chicago: Rand McNally.

Story, Mary, Karen M Kaphingst, Ramona Robinson-O'Brien, and Karen Glanz. 2008. "Creating Healthy Food and Eating Environments: Policy and Environmental Approaches." Annu. Rev. Public Health 29:253-72.

Sturgis, Patrick, Ian Brunton-Smith, Sanna Read, and Nick Allum. 2011. "Does Ethnic Diversity Erode Trust? Putnam's 'Hunkering Down'thesis Reconsidered." British Journal of Political Science 41(01):57-82.

Taylor, Marilyn. 2003. Public Policy in the Community. Basingstoke: Palgrave, Macmillan.

Taylor, Rebecca F. 2004. "Extending Conceptual Boundaries: Work, Voluntary Work and Employment." Work, Employment \& Society 18(1):29-49.

Tuckman, Howard P., and Cyril F. Chang. 1991. "A Methodology for Measuring the Financial Vulnerability of Charitable Nonprofit Organizations." Nonprofit and Voluntary Sector Quarterly 20(4):445-60.

United Nations. 2011. State of the World's Volunteerism Report. Bonn: United Nations Volunteers. 
Uslaner, Eric M. 2002. The Moral Foundations of Trust. Cambridge: Cambridge University Press.

—. 2006. "Does Diversity Drive Down Trust?" Fondazione Eni Enrico Mattei Research Paper Series, 69.

- 2012. Segregation and Mistrust: Diversity, Isolation, and Social Cohesion. Cambridge: Cambridge University Press.

Van Ham, Maarten, David Manley, Nick Bailey, Ludi Simpson, and Duncan Maclennan. 2013. Understanding Neighbourhood Dynamics: New Insights for Neighbourhood Effects Research. London: Springer.

Verba, Sidney, Kay Lehman Schlozman, and Henry E Brady. 1995. Voice and Equality: Civic Voluntarism in American Politics. Cambridge, MA: Harvard University Press.

Walker, Edward T., and John D. McCarthy. 2010. "Legitimacy, Strategy, and Resources in the Survival of Community-Based Organizations." Social Problems 57(3):315-40.

Weisbrod, Burton A. 1975. "Toward a Theory of the Voluntary Non-Profit Sector." Pp. 17196 in Altrusim, Morality and Economic Theory. New York: Russell Sage.

Wilson, William Julius. 1987. The Truly Disadvantaged: The Inner City, the Underclass, and Public Policy. Chicago: University of Chicago Press.

—. 1996. When Work Disappears: The World of the Urban Poor. New York: Alfred Knopf.

—. 2012. "Afterword: Reflections on Responses to the Truly Disadvantaged." Pp. 251-301 in The Truly Disadvantaged. Chicago: University of Chicago.

Wollebaek, Dag. 2009. "Survival in Local Voluntary Associations." Nonprofit Management and Leadership 19(3):267-84.

Wolpert, Julian, John E Seeley, and A Motta-Moss. 2004. Nonprofit Services in New York City's Neighborhoods: An Analysis of Access, Responsiveness and Coverage. New York: New York City Nonprofits Project. 
Yamaguchi, Kazuo. 1991. Event History Analysis. London: SAGE.

Zenk, Shannon N, Amy J Schulz, Barbara A Israel, Sherman A James, Shuming Bao, and Mark L Wilson. 2005. "Neighborhood Racial Composition, Neighborhood Poverty, and the Spatial Accessibility of Supermarkets in Metropolitan Detroit." American Journal of Public Health 95(4):660-67. 


\section{NOTES}

${ }^{1}$ Sampson (2012) illustrates the salience of the organizational perspective by examining the relationship between the density of nonprofit organizations and the location of collective civic engagement in communities in Chicago. The density of organisations emerges as a strong predictor: communities with rich organizational resources are 'ahead of the curve' when it comes to collective public events (p.200).

${ }^{2}$ An important exception is the body of research examining neighborhood-level differences in the presence of organisations considered important to individuals' health behaviours. Empirical research has shown that, compared to less deprived neighborhoods, more deprived neighborhoods tend to have a lower density of supermarkets (Morland et al. 2002; Powell et al. 2007; Story et al. 2008; Zenk et al. 2005) and a higher density of convenience stores and fast food outlets (Block et al. 2004; Lee 2012; Moore and Diez Roux 2006; Smoyer-Tomic et al. 2008). This is important: since supermarkets are considered to offer greater variety, higher quality and lower cost food, limited access to supermarkets in more deprived neighborhoods may influence dietary patterns, with hypothesised implications for health outcomes given associations with levels of obesity (Hilmers, Hilmers and Dave 2012; Zenk et al. 2005).

${ }^{3}$ The few existing studies on nonprofit location in the United States provide a valuable but partial perspective. Joassert-Marcelli and Wolch (2003) and Wolpert, Seeley and MottaMoss (2004), examining Southern California and New York City respectively, illustrate the potential for nonprofit resources and services to be distributed unevenly geographically, arguing that the activity of nonprofit organizations in more deprived areas may be insufficient to guarantee services available in less deprived communities. On the other hand, Peck (2008) concludes that anti-poverty nonprofit organizations in Phoenix, Arizona are more likely to locate in high poverty areas. Note that existing studies vary in terms of the subpopulation of 
nonprofits that they examine. For example, Marwell and Gullickson (2013) examine data on those nonprofit organizations in New York City that receive government contracts to deliver social services. They show higher levels of public funding of the nonprofit delivery system in more socioeconomically disadvantaged areas. However, since they focus on public funding, they do not examine variation in the density of the broader population of (publicly and nonpublically funded) nonprofits. Existing studies also vary in terms of their scale of analysis: while Peck (2008) and Wolpert et al. (2004) focus on neighborhood-level variation, JoassertMarcelli and Wolch (2003) and Grønbjerg and Paarlberg (2001) use municipal-level or county-level data and therefore do not consider issues of intracity heterogeneity. More generally, each of the existing studies provides a cross-sectional perspective of a particular urban area /region. Therefore they have not been able to consider the durability of patterns over time or their generalizability over space. Indeed we are not aware of previous studies that have been able to follow a large population of voluntary organizations through time across the full distribution of local contexts in different parts of a country.

${ }^{4}$ In this paper we consider 'voluntary organization' as synonymous with 'nonprofit organization', but use the former which is more common in the English context.

${ }^{5}$ The organisational ecology literature has a strong tradition of examining organisational foundation and dissolution (see, for example, Carroll and Hannan 2000; Hannan and Freeman 1977, 1989; Hannan, Pólos, and Carroll 2007). In organisational ecology, the important mechanism is selection: the environment is seen to determine which organisations survive and which do not. Smaller organisations, lacking resources to carry costs and the capital to invest in development, are less able to compete. Newer organisations, being less experienced and established, are also less competitive and have higher rates of dissolution (Carroll 1983, 1984; Freeman, Carroll, and Hannan 1983; Stinchcombe 1965). Some organisational populations display a 'liability of adolescence' rather than a 'liability of newness' (for 
example, Nownes and Lipinski 2005): the very youngest organizations have a lower risk of dissolution than those a little older, consistent with the initial commitment associated with the investment of personal and financial resources as an organization is started (Wollebaek 2009). The density of organisations within the same field is important (Hannan and Freeman 1987): where there are few, the founding of more organisations serves to legitimate their existence as a means to achieve certain collective aims. This is seen to increase organisations' chance of survival and promote further foundations. However, beyond a certain threshold, further increases in organisational density lead to increased competition for limited resources. Therefore, rates of foundation decrease and rates of dissolution increase (Hannan and Freeman 1988).

${ }^{6}$ As Kendall and Knapp (1993) argue, while voluntarism is not only found in voluntary organizations, it is an essential defining characteristic of the voluntary sector.

${ }^{7}$ The concept of public benefit is not defined precisely, but hinges on case law (Morgan 2010).

${ }^{8}$ An exception are those organizations which have an exclusively political purpose.

${ }^{9}$ They apply a 'general charities' definition which excludes a small number of charities, like the British Council, that have close links to government. In keeping with the structural/operational definition, NCVO do not consider noncharitable organizations - like mutuals, cooperatives and social enterprises - as part of the voluntary sector, but include them under the wider concept of 'civil society organizations'.

10 These data are from the National Survey of Third Sector Organisations. While organisations were asked to indicate their 'most important' income source, given the potential for a variety of different sources of income this need not necessarily indicate that this source represents the majority of their income. 
${ }^{11}$ Indeed, if an 'emergent property' is to be a mechanism through which neighborhood disadvantage is transmitted, there should be a systematic link between the compositional measure of neighborhood context (concentrated poverty) and that emergent measure of neighborhood context.

${ }^{12}$ The charitable sector is diverse. Many organizations rely on paid staff, as well as volunteers, to carry out their charitable activities. However, as data from the National Survey of Charities and Social Enterprises reveals, the majority of voluntary organizations in England do not have any paid employees and are therefore entirely reliant on volunteers (Ipsos Mori 2010).

${ }^{13}$ The framework of charitable law relates to the protection of charitable funds. The Charity Commission and the courts have powers to intervene if funds are used for noncharitable purposes.

${ }^{14}$ Local authorities are areas that local government has responsibility for. The area of operation data considers 149 'upper tier' local authority areas in England. Charities can indicate operation in one or multiple local authorities (and, where applicable, one or multiple overseas countries). Charities whose work is not spatially focused / geographically bounded, or who work across more than ten local authorities, are coded 'Throughout England' or 'Throughout England and Wales'.

${ }^{15}$ Charity trustees, by law, must keep their charity's registered details up-to-date by sending an annual return to the Charity Commission every year.

${ }^{16}$ Thus we don't follow each organization from the same age since foundation: while organizations newly founded during the analysis period are followed from age 0 , pre-existing organizations are followed from age $x$ when they entered the panel. Therefore when examining charitable dissolution we assume that the hazard is, conditional on any covariates, independent of the age of entry to the panel. 
${ }^{17}$ The foundation of a charity is a process. First, the charity's legal 'governing document', which outlines how the charity is to be run, must be written. Second, once this legal framework is in place, the charity is required to register with the Charity Commission. In this paper we use the year of registration with the Charity Commission, at the end of this foundation process, as the year of charitable foundation. Therefore references to year of foundation relate to year of charitable registration.

${ }^{18}$ We tested the robustness of our results to two slightly different definitions of the year of dissolution. The first definition is the formal year of dissolution provided by the Charity Commission. The second definition is the first of consecutive years of non-reporting of financial information to the Commission. While in some cases this second definition corresponds to the formal dissolution year, often it is a year earlier than the formal definition since it takes this time for the Charity Commission to confirm that a charity has dissolved. The results were robust to which definition was chosen. We chose to use the second definition, since it may better reflect the year in which the charity stopped operating.

${ }^{19}$ Each charity has a unique charity number. We use this number to follow organizations through time by linking together financial records across years. However, if an organization changes legal form, from unincorporated (either charitable trust or unincorporated association) to incorporated (charitable company limited by guarantee), it drops off the register and reemerges with a new charity number. While technically a new legal identity, it is effectively the same organization. Failure to link together the two records for such organizations would lead to an overestimate of the number of charity dissolutions. Therefore, we linked together these records. We are confident that the linking method we used is both comprehensive and reliable. It is comprehensive because the Charity Commission maintains a specific file in order to keep a record of all of the current names, working names, and former names of an organization. We were able to use this file to link unincorporated and incorporated records 
for the same organization by matching the current, working and former names of an organization record to the current, working and former names of any other organization record. It is reliable because two records were only linked not only where names were matched - but also where the match specifically involved only two charities, with one an unincorporated charity and the other a charitable company, and where they were both located in the same local authority area. This process of linking reduced the number of dissolutions in our dataset by $11 \%$. To further demonstrate the robustness of the results, note that for many of the organizations analyzed virtually all are unincorporated in any case (for example, $100 \%$ of PTAs; $94 \%$ of playgroups; $98 \%$ of youth clubs) so are unaffected by the need to link incorporated and incorporated records.

${ }^{20}$ All of the exemplary organisations in Table 2 are included in the final subpopulation of charities used in the analysis. Note that Table 2 illustrates the nature of our data but does not include all of the covariate information for each charity. Table 1 complements Table 2 by providing a comprehensive summary of the covariates available.

${ }^{21}$ This includes, for example, the Science Museum, the Victoria and Albert Museum, the Imperial War Museum, the National Gallery and the Tate Gallery.

${ }^{22}$ Recent changes in legislation mean that the excepted status of these Christian denominations is being removed, with the aim that these churches are registered by 2021.

${ }^{23}$ We identify this subpopulation of organizations using the structured geographical information that charities report about their area of operation (see Table 1). Therefore we exclude charities that work across a variety of areas - regionally, nationally, or internationally. ${ }^{24}$ These percentages relate to charities in existence during the specific period between 2007 2011 inclusive since comprehensive classification information was not collected by the Charity Commission until the mid-2000s. They are calculated using a series of binary classification variables completed by charities in their annual return. While they should be 
treated with a certain caution - given the broad predefined categories and since charities are not asked for a primary beneficiary type but can indicate operation across any number of categories - they do serve to illustrate the variety of charities included in our analysis.

${ }^{25}$ To illustrate the different fields of activity within our subpopulation we link to our data a classification of English charities according to the International Classification of Nonprofit Organisations (ICNPO). We are grateful to the National Council of Voluntary Organisations (NCVO) for sharing these classification data, which extend to dissolved as well as to currently registered charities. The ICNPO system uses 12 major groups and categorises organisations according to their primary activity - the 'types of services or goods they provide' (Salamon and Anheier 1992, p.11). Each charity belongs to only one group.

${ }^{26}$ This group includes, for example, those providing human and social services to families, to young people, and to the elderly.

${ }^{27}$ These are 'organizations and activities administering, providing, promoting, conducting, supporting and servicing education and research' (Salamon and Anheier 1996, p.12). In our subpopulation this group includes, for example, preschool organisations, parent teacher associations and groups providing continuing/adult education.

${ }^{28}$ These are 'organizations promoting programs and providing services to help improve communities' (Salamon and Anheier 1996, p.16). In our subpopulation this group includes, for example, community centres, community associations and village halls. In practice housing providers are not included in our subpopulation since these are exempt from charitable registration.

${ }^{29}$ Note that LSOAs were specifically developed to facilitate the calculation of neighborhood statistics including the IMD. Therefore they were designed to be areas that would be comparable in size (with a target population size of 1,500 and an upper and lower threshold of 1,000 and 3,000) and whose boundaries would be consistent over time (unlike other local 
geographies, like electoral wards). The LSOA geography did not change over our analysis period: each of the measures of IMD, in 2004, 2007 and 2010, are calculated using the same LSOA boundaries. Therefore there is no need to normalize the IMD measure to adjust for changes in LSOA boundaries. The average population size in each LSOA increased between 2001 and 2011, from 1,514 to 1,614. Population data by LSOA are available from 2001 onwards: when examining the density of charitable organizations in 2001, 2006 and 2011, our offset term uses population data from the relevant year; when examining the density of organizations in 1996, we use population data from 2001. When examining charitable foundations over the period our offset term uses population data from 2011. In practice our results are robust to the choice of base population year: changes in our estimates are almost imperceptible.

${ }^{30}$ Rae (2012) reviews a range of empirical studies which point to the 'persistence' of patterns of spatially concentrated deprivation. He concludes the greatest challenge is as much temporal as spatial: there is a need for 'an inter-generational approach' to tackling entrenched patterns of deprivation (p.1197).

${ }^{31}$ Note that the IMD is a measure of relative deprivation: it is not designed to be used to examine changes in absolute levels of deprivation, since a neighborhood may change rank between 2004 and 2010 without any change in absolute deprivation. In addition, changes to the indicators and methodology which underlie the IMD undermine the validity of comparisons between 2004, 2007, and 2010: differences over time not only reflect substantive changes in relative deprivation but also changes in measurement (McLennan et al. 2011). Nevertheless, to illustrate the robustness of our results, we create a dataset which links together information on Lower Super Output Areas, in terms of their deprivation ranks according to the IMD in 2004, 2007 and 2010. First, we compare the relative position of LSOAs in the 2004 IMD distribution with their relative position in the 2010 IMD distribution. 
The overall picture is one of stability: $94 \%$ of LSOAs were in the same or adjoining decile in the 2010 IMD distribution as they were in 2004 . The residual $6 \%$ of LSOAs that change position in a substantively sizeable way are strongly concentrated in the middle of the initial 2004 IMD distribution. Second, we consider the results from a piecewise exponential survival model in which deprivation is considered as a time-varying covariate. Organisation years in 2004-2006 are linked to IMD 2004; those in 2007-2009 to IMD 2007; those in 201011 to IMD 2010. We also restrict analysis to the period from 2004 onwards to ensure correspondence with our time-varying IMD measures. Figure A1 in the Appendix presents the results. For comparison we include the results from a model which includes deprivation as a fixed covariate, using IMD 2007 as adopted in this paper, for the period 2004 onwards. Where IMD is fixed, the rate of dissolution in the most deprived neighborhoods is 1.60 times higher than in the least deprived. In the time-varying specification the results are unchanged: the rate of dissolution in the most deprived neighborhoods is 1.60 times higher than in the least deprived. We see the same pattern in a third model, which considers IMD as fixed but uses the neighborhood's average IMD rank between 2004 and 2011 (relative risk 1.62). Finally the results are also unchanged (relative risk 1.62) when we consider a fourth model, where IMD is fixed but where we exclude the residual $6 \%$ of LSOAs where there is evidence of distinctive change in the relative position in the IMD distribution between 2004 and 2010. ${ }^{32}$ See also endnote. Indeed the Charity Commission collect data on charity's area of operation for this very purpose: to enable members of the public to identify "where the charity spends its charitable funds on its charitable purposes'. More than one in five charities indicate that they operate throughout England. We also exclude the $10 \%$ of charities that indicate that their area of operation is overseas (i.e. outside the UK). Thus a strength of our analysis is that - by focusing on the subpopulation of charities whose operation is nested within one specific local authority (Table 3) - we exclude those with a regional, national or 
international geographical scope whose listed address represents administrative offices rather than the locality of charitable activity.

${ }^{33}$ A charity may list a post office box address only in special circumstances. This may apply, for example, to a women's refuge, where the safety of the charity beneficiaries may be compromised by releasing the physical address.

${ }^{34}$ These differences reflect the Commission's regulatory priorities. The maintenance of a specific financial history file, built from the financial information submitted by charities in successive annual returns, is important given that the framework of charitable law relates to the protection of charitable funds. Trends in financial data provide empirical context when the Commission assesses risk of fraud and financial abuse. In contrast, there is no such regulatory basis for retaining records of any changes in charity address.

${ }^{35} \mathrm{We}$ do not regard this as a significant problem for our analysis. For the subpopulation of charities that we consider, there is a substantive basis for expecting consistency in location over time: the charitable purposes of many charities in our analysis - including community associations, community centers, village halls, youth clubs and parent teacher associations are tied to serving a particular local community. Indeed charities that operate at a local level are often, by law, restricted to operate in a defined area as outlined in their charities' governing documents.

${ }^{36}$ Data on population size, from the Office for National Statistics (2013), were linked to the charity data using LSOA codes.

${ }^{37}$ It is worth noting that the dissolution of a charity does not always imply failure (Fernandez 2008; Hager, Galaskiewicz, and Larson 2004). There may be cases, for example, in which the original purposes of the charity have been fulfilled. Nevertheless, unless the proportion of organizations which have dissolved for reasons of goal fulfillment itself varies between different kinds of neighborhoods, the comparative aspect of this analysis will be robust. 
${ }^{38}$ Charities in our data are first 'at risk' of dissolution in 1997 , the year after the panel begins.

${ }^{39}$ To facilitate analysis, given the very large number of pseudo-observations, we group observations into distinct covariate patterns, adding up the measures of exposure and dissolution. Thus $d_{i j}$ becomes the number of dissolutions, and $t_{i j}$ the number of years of exposure, of charities with covariates $\boldsymbol{x}_{i}$ in interval $j$. The estimates, standard errors and likelihood ratio tests in this Poisson aggregate model are exactly the same as for individual data (Rodriguez 2007).

${ }^{40}$ We use the percentiles of the IMD distribution in our models, but for convenience we use deciles when presenting the summary statistics in Table 4.

${ }^{41} \mathrm{We}$ assess the significance of this interaction by examining the change in likelihood for nested regression models, one with the main additive effects, and one with an interaction term between neighborhood context and kind of organization.

${ }^{42}$ We were able to pick out these organizations, from the many thousands on the Charity Commission register, through systematic analysis of the textual information provided in charities' 'objects', which describe and identify the purpose for which the charity has been set up. Parent teacher associations, preschools and youth clubs have standard phrases in their charitable objects, which enable identification.

${ }^{43}$ Charities identify their roles through information that they provide in their annual return to the Charity Commission, in answer to the question 'how does your charity operate?' A charity can tick more than one option so may be in more than one group. All charities are included in at least one group. Disaggregating by role in this way complements the disaggregation by type, which includes a large residual 'other type' category given the diversity of the charitable population and of their charitable objects.

${ }^{44}$ These figures relate to the density of charitable organizations at the end of our panel (2011). 
${ }^{45}$ This Classification examined 325 'lower tier' local authority areas, rather than the 149 'higher tier' local authorities used in the Area of Operation data.

${ }^{46}$ The general direction of the relationship with deprivation is evident across the different area contexts. However there are also differences in terms of the shape (reflected in the functional form) and the size of the association with deprivation. This points to the value of future research, focused on a small number of different types of areas, which is able to examine how the general tendency that we identify - for lower charitable density in more deprived neighborhoods - plays out in these area contexts, taking into account regional histories of philanthropy.

${ }^{47}$ Differences in rates of survival according to organization characteristics, which are not the main focus of this paper, are as would be expected (Table 9). Larger charities, as measured by median income, have a lower rate of dissolution than the smallest charities. Patterns by age are consistent with the 'liability of adolescence': after the initial period of investment of personal and financial resources immediately following organizational foundation, rates of mortality increase with age (Wollebaek 2009); mortality then decreases with age, such that the oldest charities have low rates of dissolution. These patterns by size and age are well established findings in organizational ecology (for example, Baum and Oliver 1991; Bielefeld 1994; Hager et al. 2004; Walker and McCarthy 2010).

${ }^{48}$ Note that, in a model which does not include age and only includes neighborhood context as a covariate, the rate ratio is $1.69(95 \% \mathrm{CI} 1.63-1.75)$. Together the results from different survival models suggest that the gradient according to neighborhood context is not simply a reflection of 'collider stratification bias' (Elwert and Winship 2014): the differences persist even in models which do not condition on observed variables, like organizational size and age - strong determinants of organizational survival which may differ between neighborhoods. 
${ }^{49}$ Unlike the rest of the longitudinal analysis, the analysis by role relates to the specific period between 2007-2011 inclusive: information on role was not collected by the Charity Commission until the mid-2000s, so comprehensive data is not available for the whole period between 1997 and 2011.

${ }^{50}$ Indeed, when we examine differences according to deprivation across local authorities rather than across LSOAs, results are robust to whether we use the charities' address, or their indicated area of operation, as a means of attaching local authority covariate data.

${ }^{51}$ This evidence about dual reinforcing longitudinal processes provides empirical support for what Logan and Molotch (1987, p.136) call the 'paradox' of community organization: 'the neighborhoods with the most serious need for community organizations are those with the least capacity to [both] create and sustain them' [emphases added]. Logan and Molotch's specific substantive interest is in organizations that are urban in character - in the sense that they seek to enhance a neighborhood's use value - but their reasoning here is based on the voluntary character of these organizations and the difficulty of mobilizing the necessary resources in deprived neighborhoods.

${ }^{52}$ Note, too, that that there is some evidence for difference in the size of these gradients between the five year periods. In particular, the difference in the rate of dissolution across neighborhoods - while still substantial - is reduced during the 2007-2011 period. This may reflect the implications of a difficult macroeconomic context which - by increasing the risk of charitable dissolution overall - may serve to slightly reduce the strength of the relationship between neighborhood context and organizations' survival. We note that this would be an interesting theme to explore in more detail in future research: as Owens and Sampson (2013) point out, relatively little research has examined neighborhood-level differences in the implications of the Great Recession. 
${ }^{53}$ Therefore we conceive of strategy as one of the means through which neighborhood context affects the survival of organizations. This conception of strategy has implications for how we approach inference: since causality is seen to cut across levels, there is less of a focus on separating 'organizational' from 'contextual' effects through obtaining unbiased estimate of respective parameters (Sampson 2012). In this case, an 'organization level' variable like strategy can in fact be a product of the neighborhood context. Therefore, a fixed effects modeling approach which seeks to control for unmeasured differences in strategy between organizations is not desirable: 'controlling' for differences in strategy would be a mistake, since differences in strategy are seen as part of the pathway through which neighborhood context affects rates of survival (see, for example, Fischer 2013; see also Lieberson 1987; Sampson 2008; Sampson et al. 2002). It is also not possible: fixed effects models for event history data typically require that individuals have multiple, repeated events - in this case, organizations only dissolve once; also, in a fixed effect framework, coefficients cannot be estimated for time invariant covariates - as, in this case, for neighborhood context, the key variable of interest (see Allison 2009).

${ }^{54}$ Note that our dataset does not contain information on the sources of funding of charitable organizations. However we are able to draw on corroborative evidence from the National Survey of Third Sector Organisations (NSTSO) in England, which collected detailed information about organizations' funding base. The NSTSO illustrates variations in government funding of charitable activity according to both the neighborhood context and the kind of organization (Clifford et al. 2013). At the level of neighborhood context, a distinctively high proportion of charities in the very most deprived neighborhoods receive government grants/contracts, consistent with the importance of spatially targeted funding. At the organizational level, large charities are much more likely to be in receipt of government funds than small charities; those charities that perform certain roles, including providing 
advice, information and advocacy, and those work with certain socially marginalized groups, are more likely to receive government funding than other charities. There is also evidence for an interaction between organizational-level and neighborhood context: those charities in the most deprived neighborhoods that work with marginalized groups are particularly likely to be in receipt of government funds. The NSTSO evidence helps provide substantive context for some of this paper's disaggregated analysis: it suggests that, where there is a departure from the general pattern of a lower density of charities in more deprived neighborhoods, this reflects the presence of organizations receiving government funds. For example we better understand the distinctive pattern for charities providing advocacy/advice/information (Figure 6), and for larger as opposed to smaller charities (Figure 4), when we appreciate that these are amongst the groups of charities most likely to be receiving government funding.

${ }^{55}$ At present there is no comprehensive national-level source of data which brings together information on churches relating to these different denominations. However this analysis will be more straightforward from the early to mid-2020s, when all Christian churches will be legally required to register as charities.

${ }^{56}$ Methods for considering spatial autocorrelation developed for linear models are not straightforwardly applied to models for count data (see, for example, Lichstein et al. 2002; Patuelli et al. 2016; Schabenberger and Gotway 2005). However we do seek to account for the potential importance of other variables with a spatial structure by using the Area Classification of Great Britain to disaggregate our results: we consider patterns according to deprivation separately within specific types of local authorities that have been identified as similar on the basis on a range of socioeconomic and demographic data (Figures 7, 15-16). 57 This would be particularly challenging from an empirical perspective: meaningful measures of organizational quality are likely to be different for different fields of charitable activity. 
${ }^{58}$ However important work does consider subtle processes through which public institutions may mediate neighborhood context, beyond the presence or non-presence of public institutions (Hastings 2007; 2009). 
FIGURE 1 Institutional resources theories conceptualize organizations as a mediator between concentrated poverty and individuals' lives.

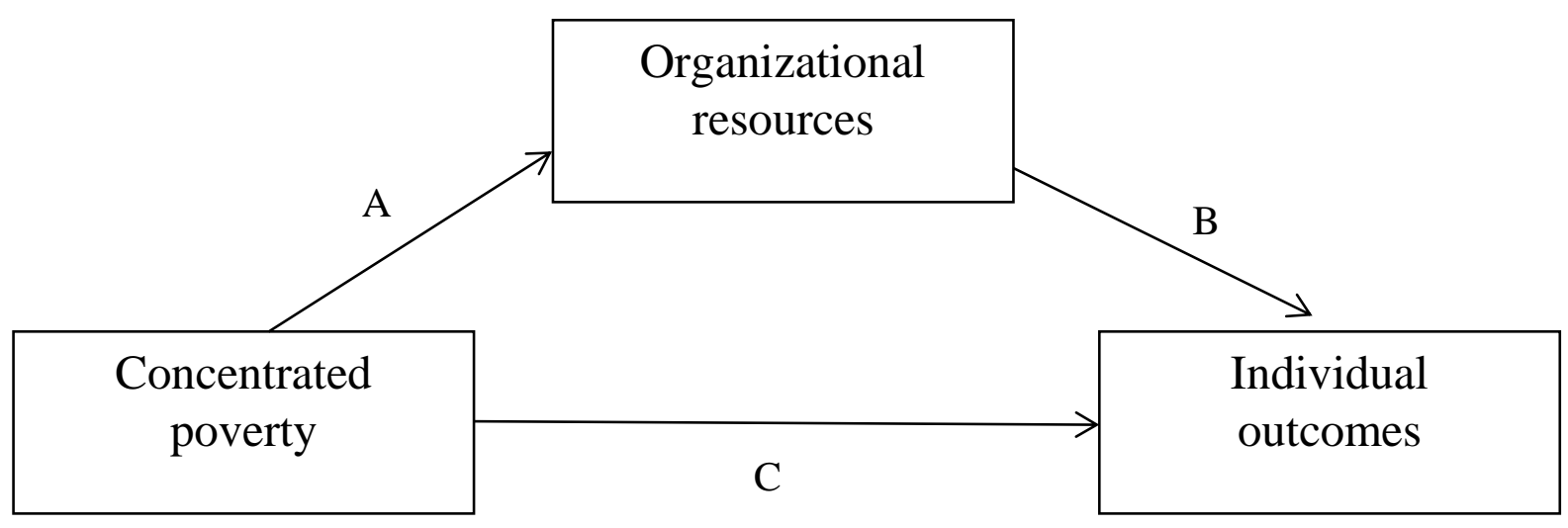


FIGURE 2 Linking charity information (shaded) to contextual data at two different geographical scales
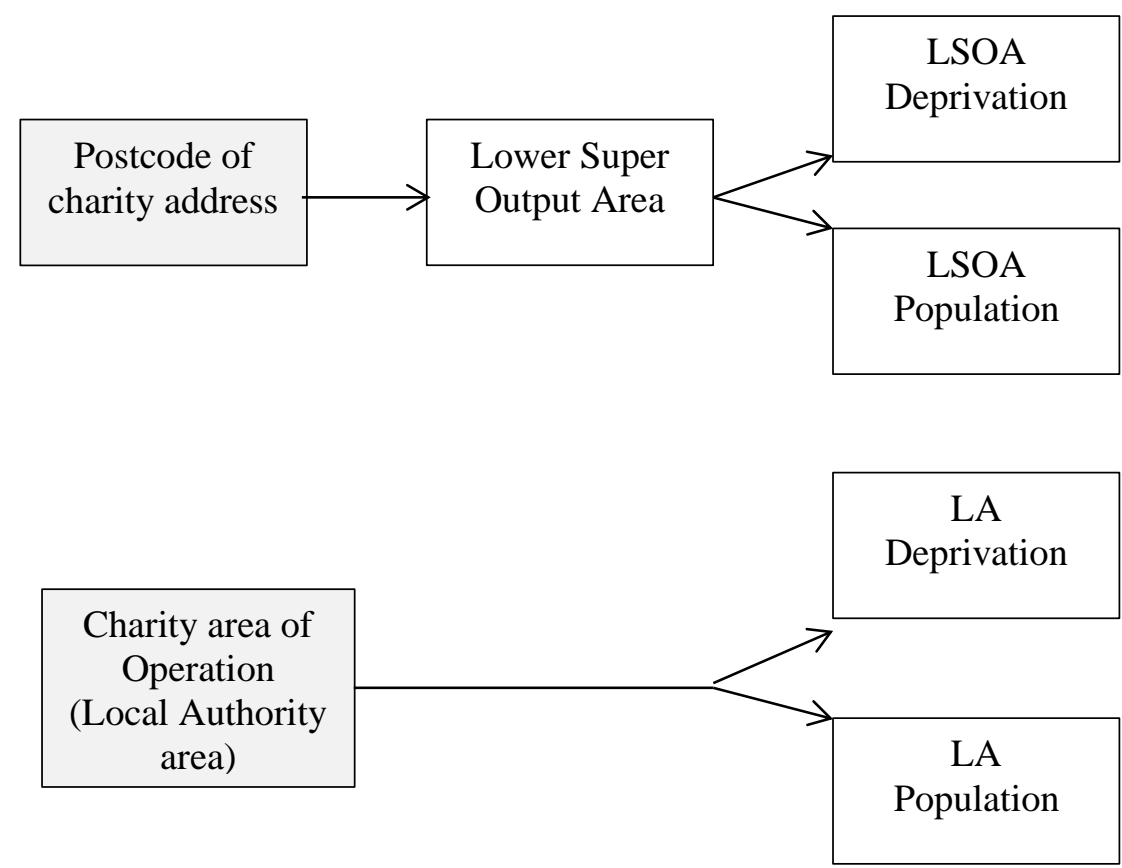
FIGURE 3 Density of charitable organizations, by percentile of deprivation

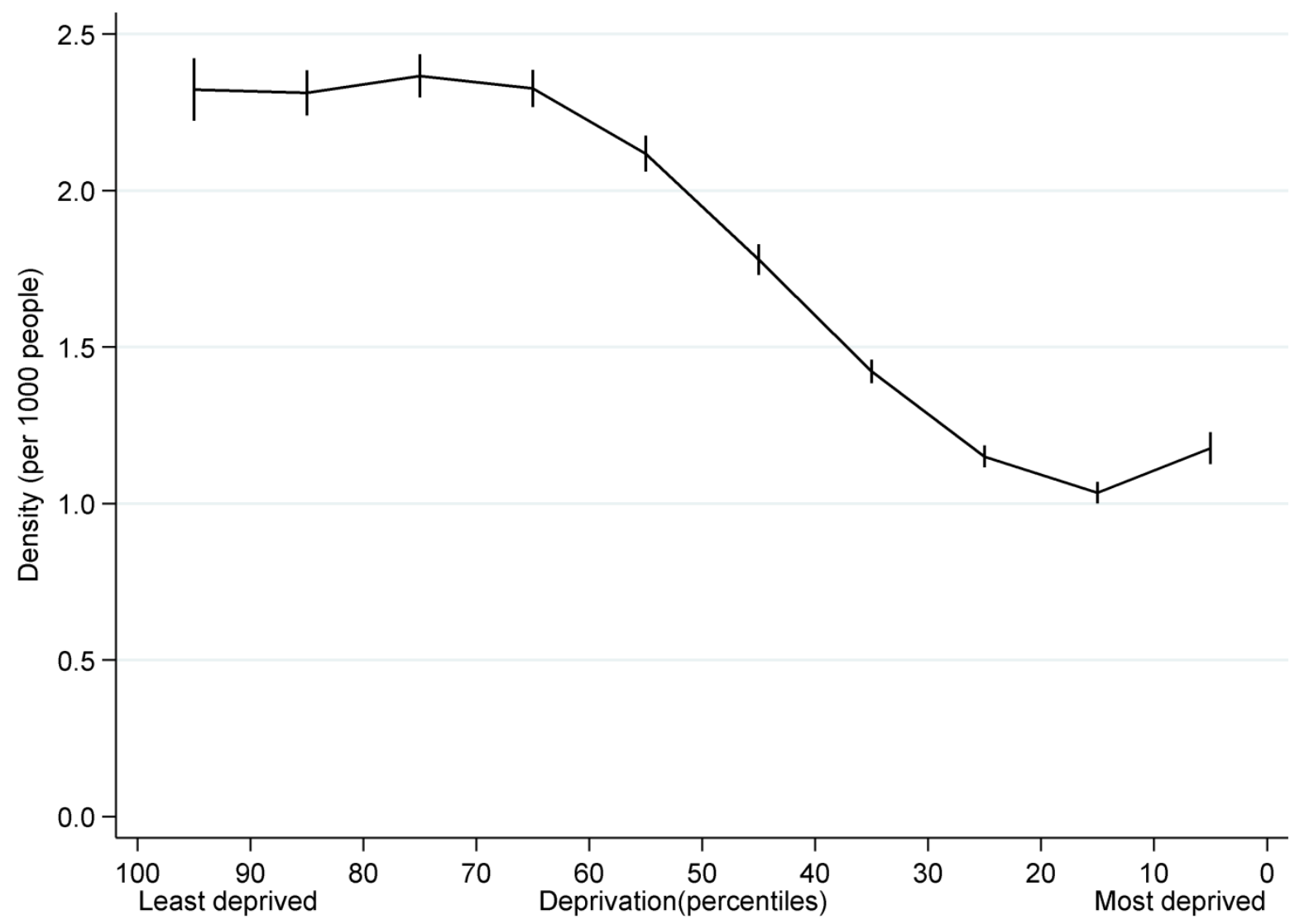

NOTE. Fitted marginal densities from Model A1 (see Table 5). Spikes are 95\% CIs 
FIGURE 4 Density of charitable organizations of different sizes, by percentile of deprivation

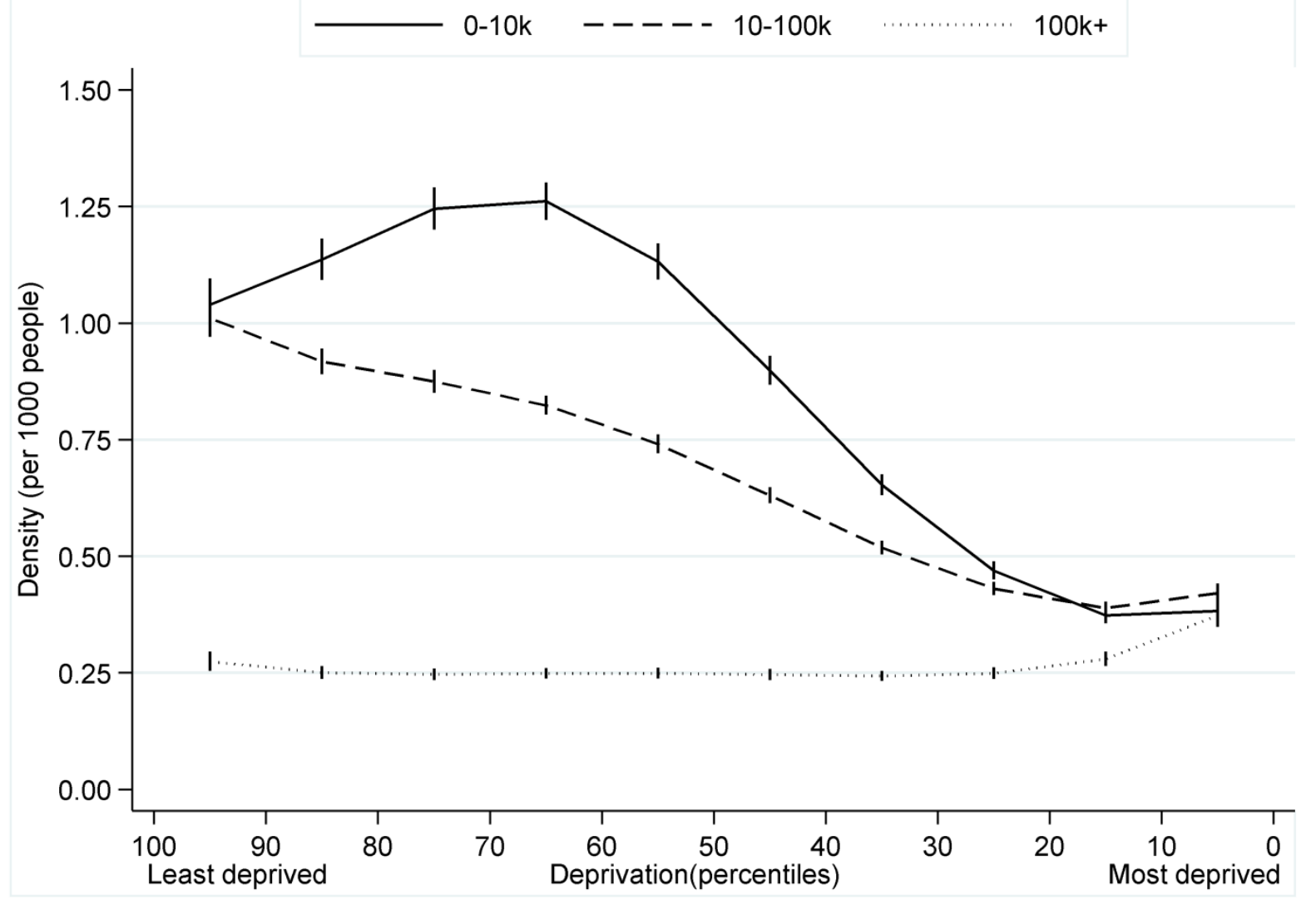

NOTE. Size measured by annual income (£). Fitted marginal densities from Models A2-A4 (see Table 5). Spikes are 95\% CIs. 
FIGURE 5 Density of specific kinds of charitable organizations, by percentile of deprivation
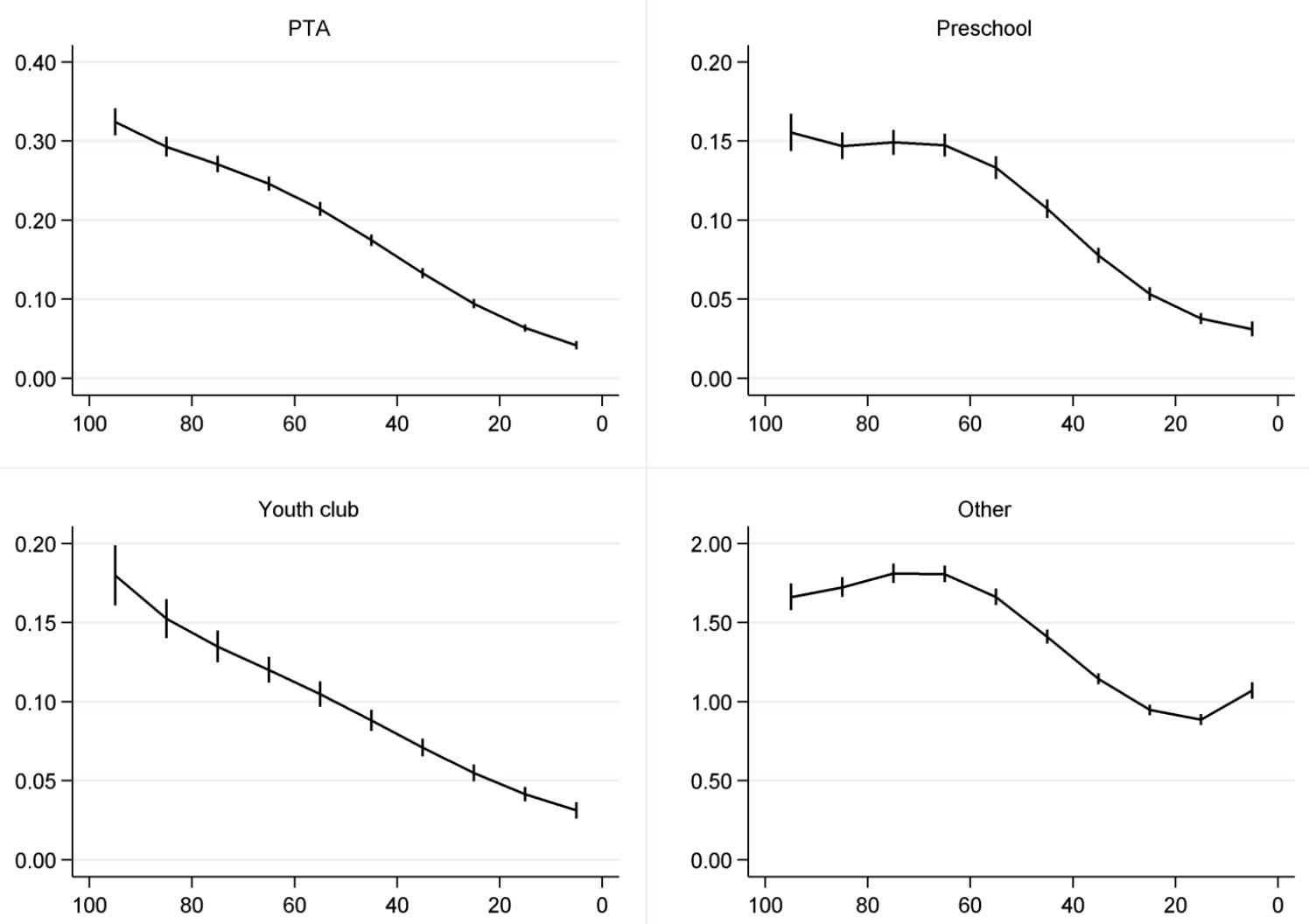

NOTE. Fitted marginal densities from Models A5-A8 (see Table 5); y-axis: Density (per 1000 people); x-axis: Deprivation (percentiles). Spikes are $95 \%$ CIs. 
FIGURE 6 Density of charitable organizations performing particular roles, by percentile of deprivation
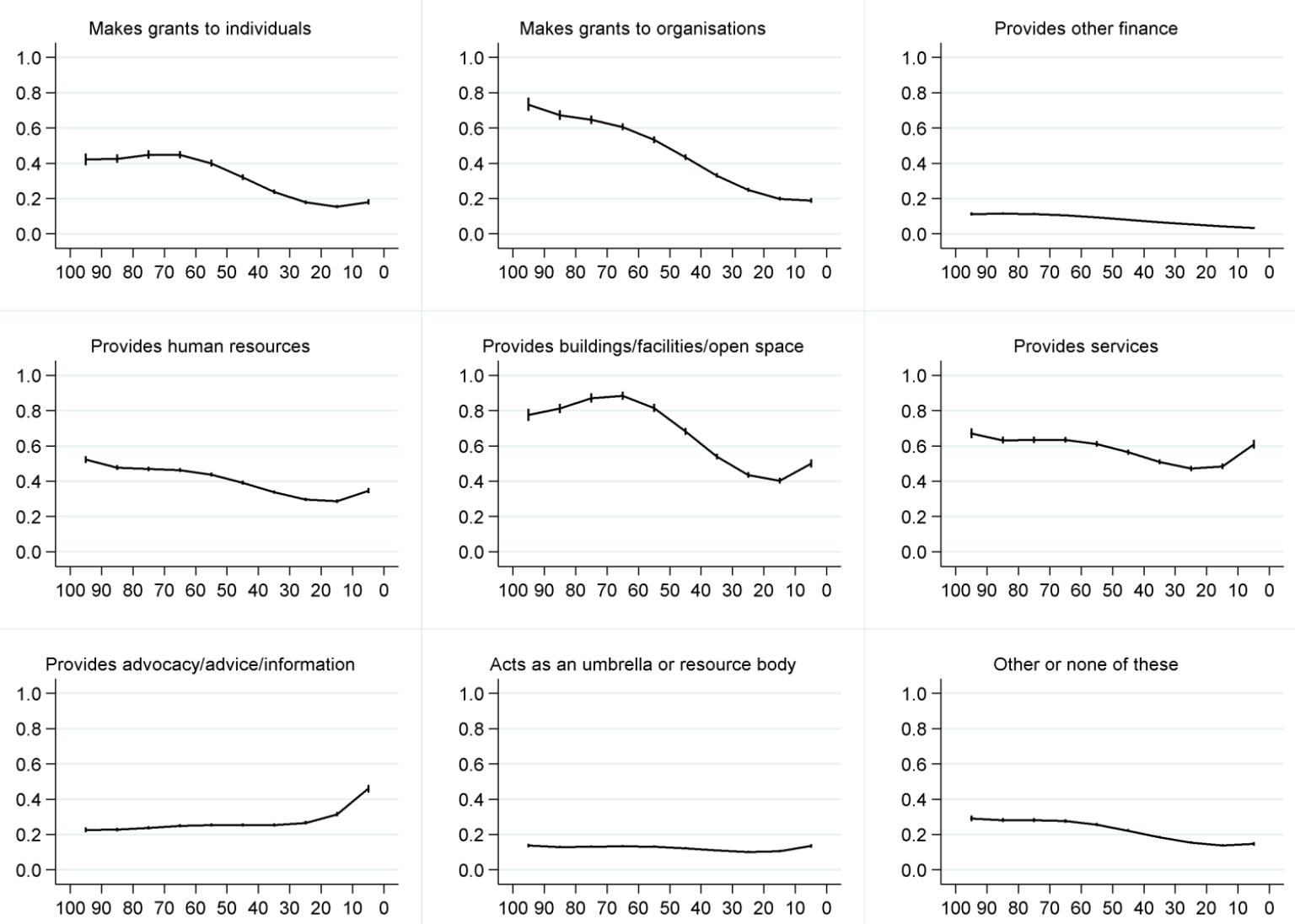

NOTE. Fitted marginal densities from Models A9-A17 (see Tables 5 and 6); y-axis: Density (per 1000 people); x-axis: Deprivation (percentiles). Charities may belong to more than one role category. Spikes are $95 \%$ CIs. 
FIGURE 7 Density of charitable organizations in different area contexts, by percentile of deprivation
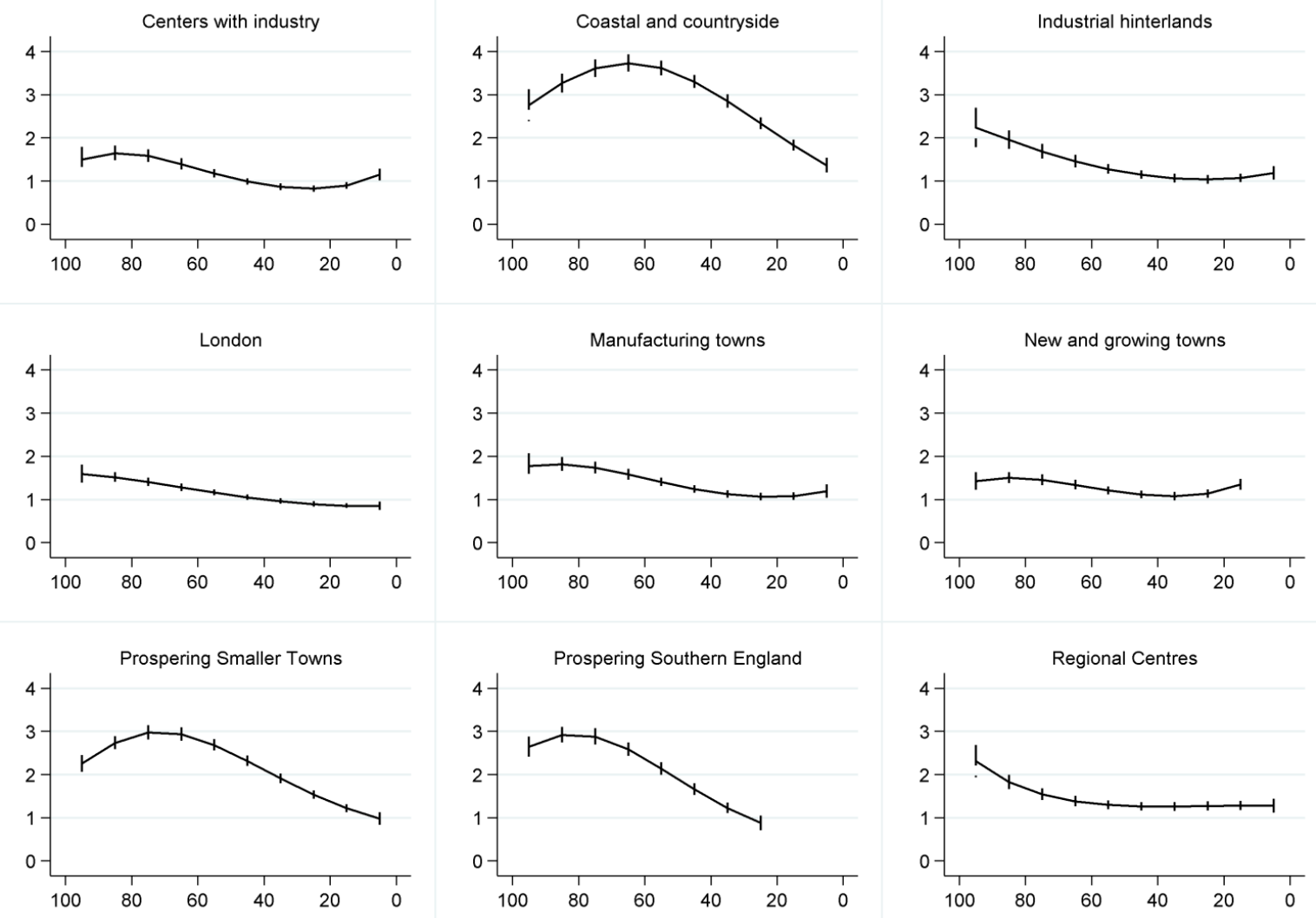

NOTE. Fitted marginal densities from Models A18-A26 (see Table 6); y-axis: Density (per 1000 people); x-axis: Deprivation (percentiles). Area Classification: 'London' groups together different area classifications: London Centre, London Cosmopolitan, London Suburbs, and Thriving London Periphery. For Prospering Southern England, and New and growing towns, fitted marginal dissolution rates are not presented for the entire range of the deprivation distribution, since there are no neighborhoods at the most deprived percentiles. Spikes are $95 \%$ CIs. 
FIGURE 8 Density of charitable organizations in different years, by percentile of deprivation
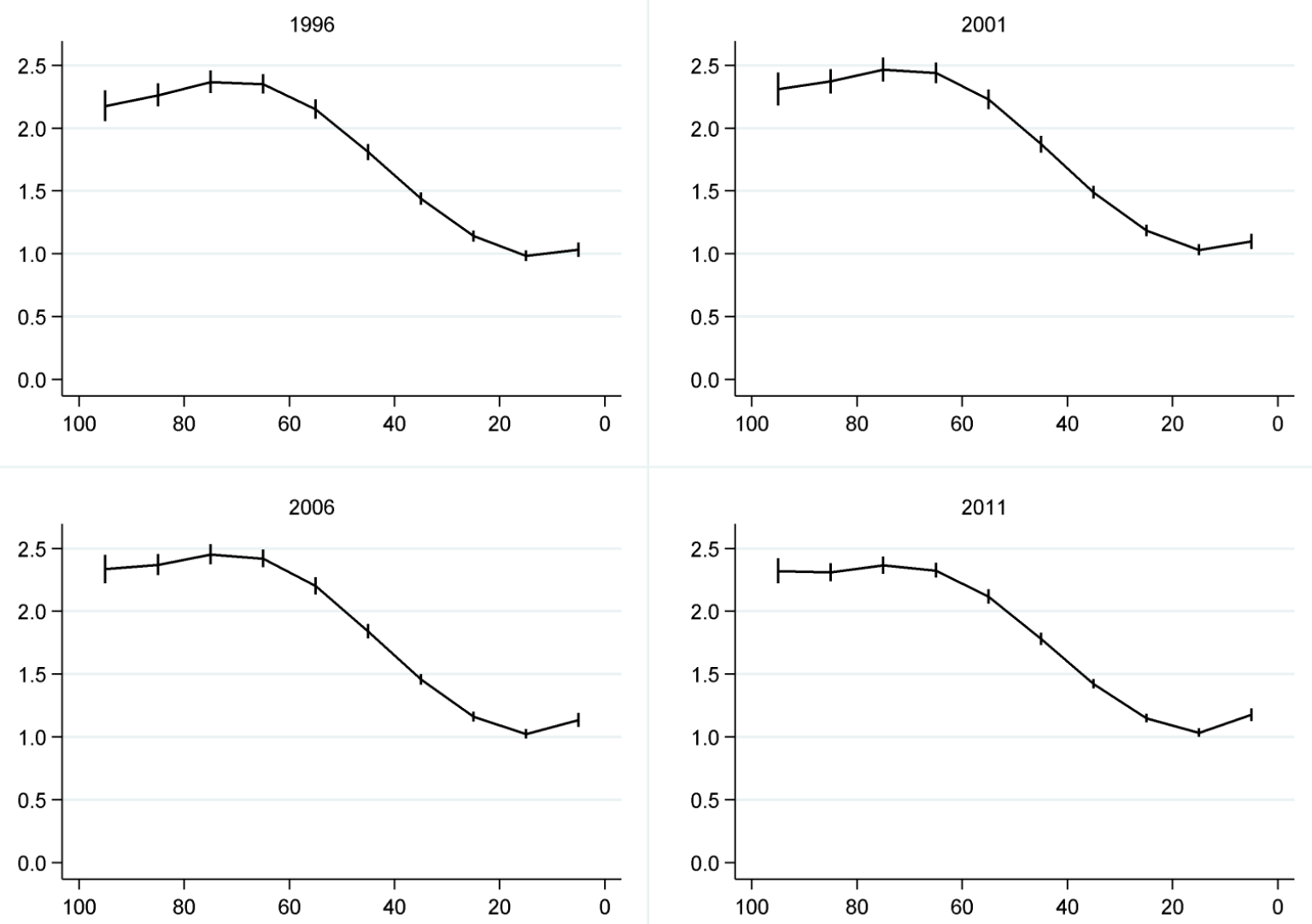

NOTE. Fitted marginal densities from Models A27-A30 (see Table 6); y-axis: Density (per 1000 people); x-axis: Deprivation (percentiles). Spikes are $95 \%$ CIs. 
FIGURE 9 Rates of charitable foundation, by percentile of deprivation

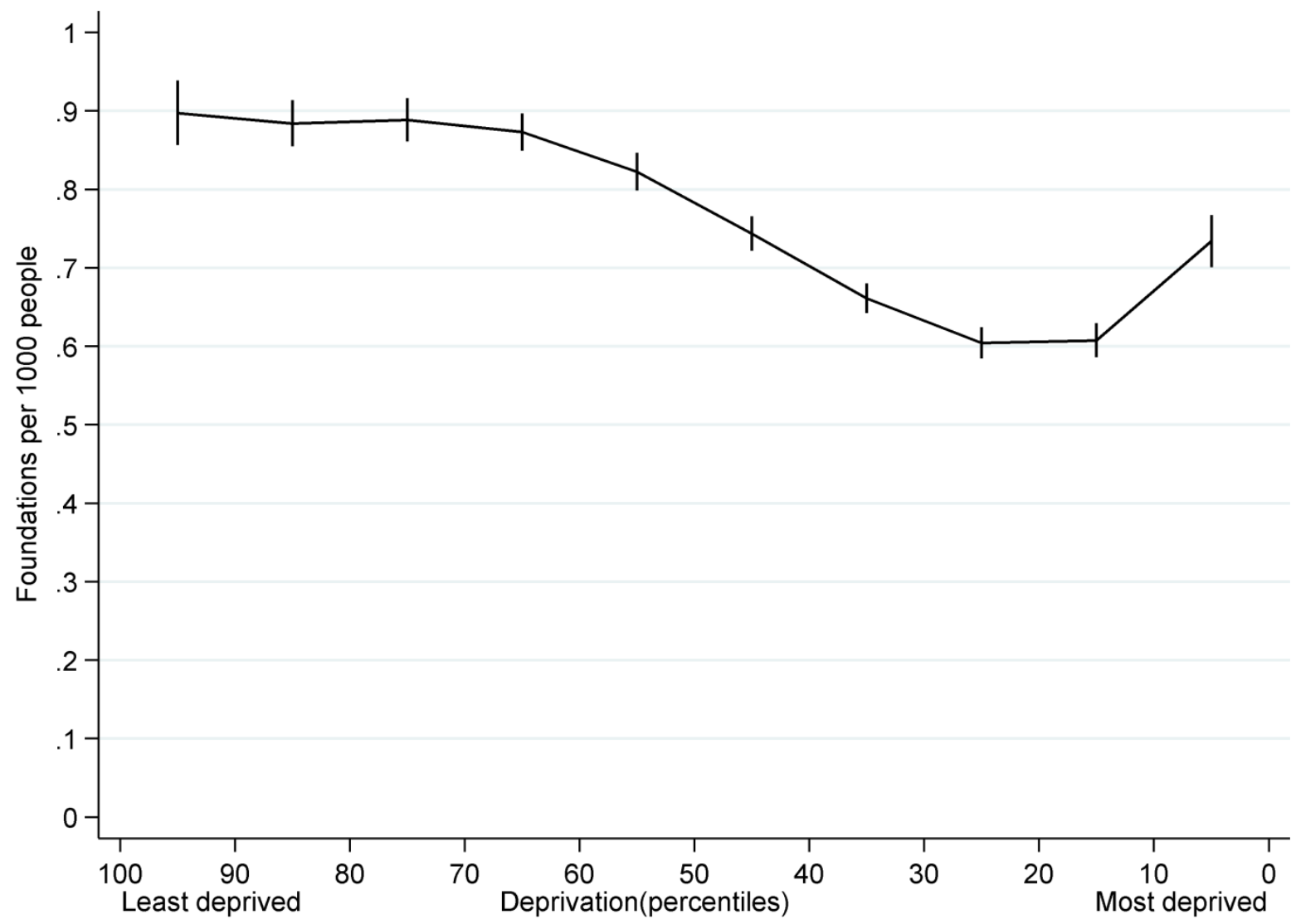

NOTE. Fitted marginal dissolution rates from Model B1 (see Table 7). Spikes are 95\% CIs.

FIGURE 10 Rates of charitable dissolution by percentile of deprivation, before and after controlling for charity size and form

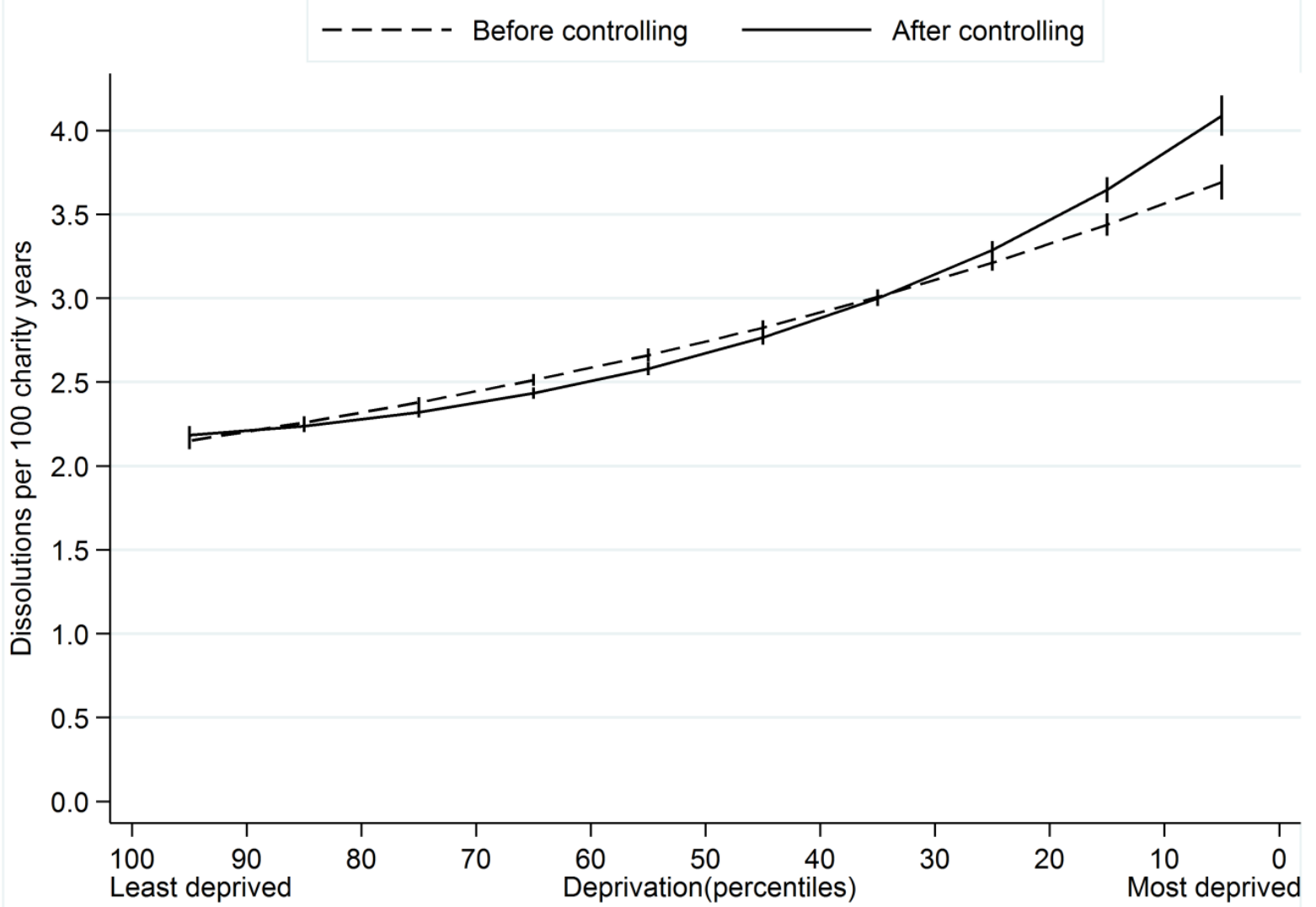

NOTE. Fitted marginal dissolution rates from Model C1 (without controls) and Model C2 (with controls for size and form) (see Table 9). Spikes are $95 \%$ CIs. 
FIGURE 11 Rates of foundation for specific kinds of charities, by percentile of deprivation
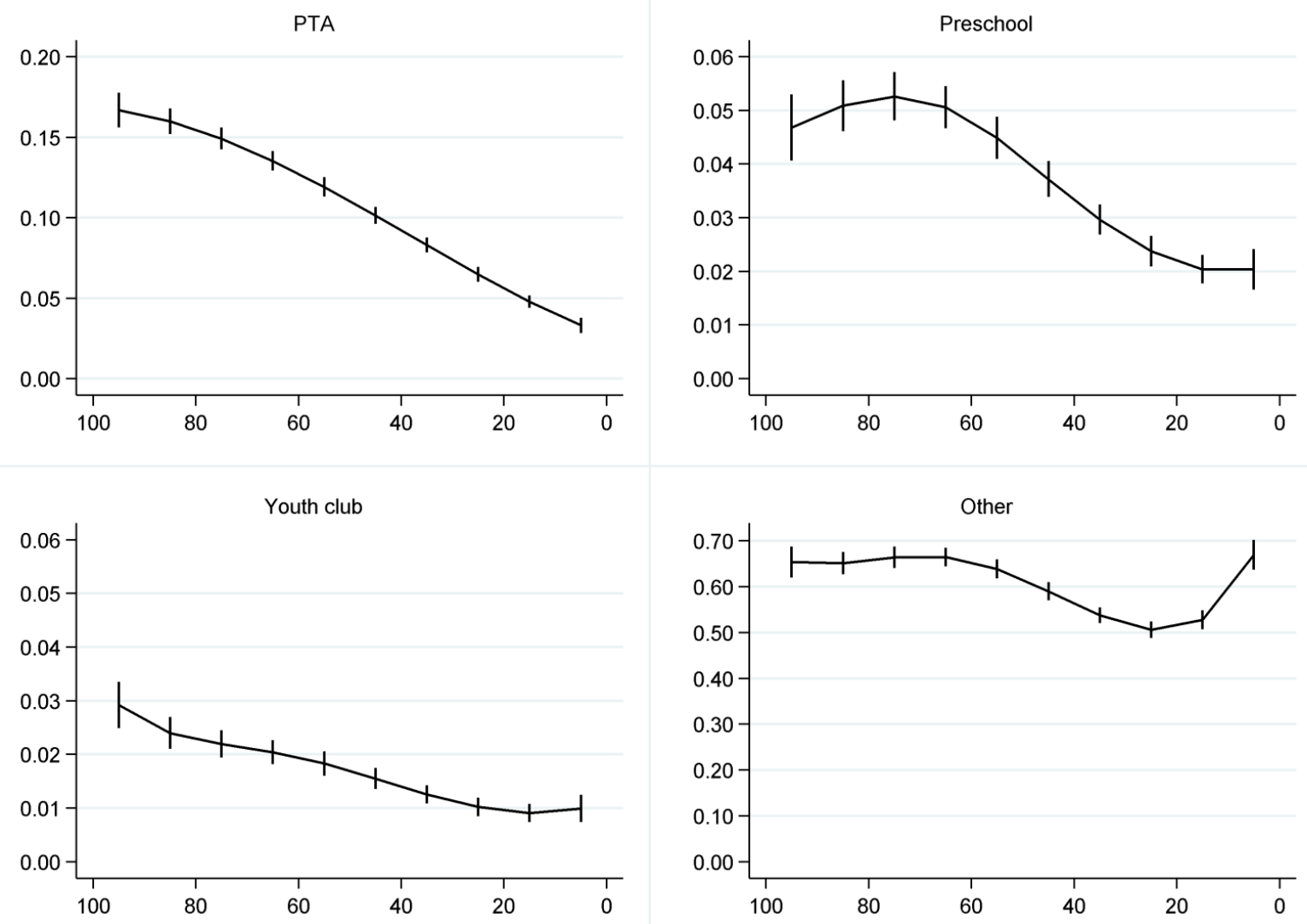

NOTE. Fitted marginal foundation rates from Models B2-B5 (see Table 6); y-axis: Foundations per 1000 people over analysis period; X-axis: Deprivation (percentiles). Spikes are 95\% CIs.

FIGURE 12 Rates of dissolution for specific kinds of charities, by percentile of deprivation
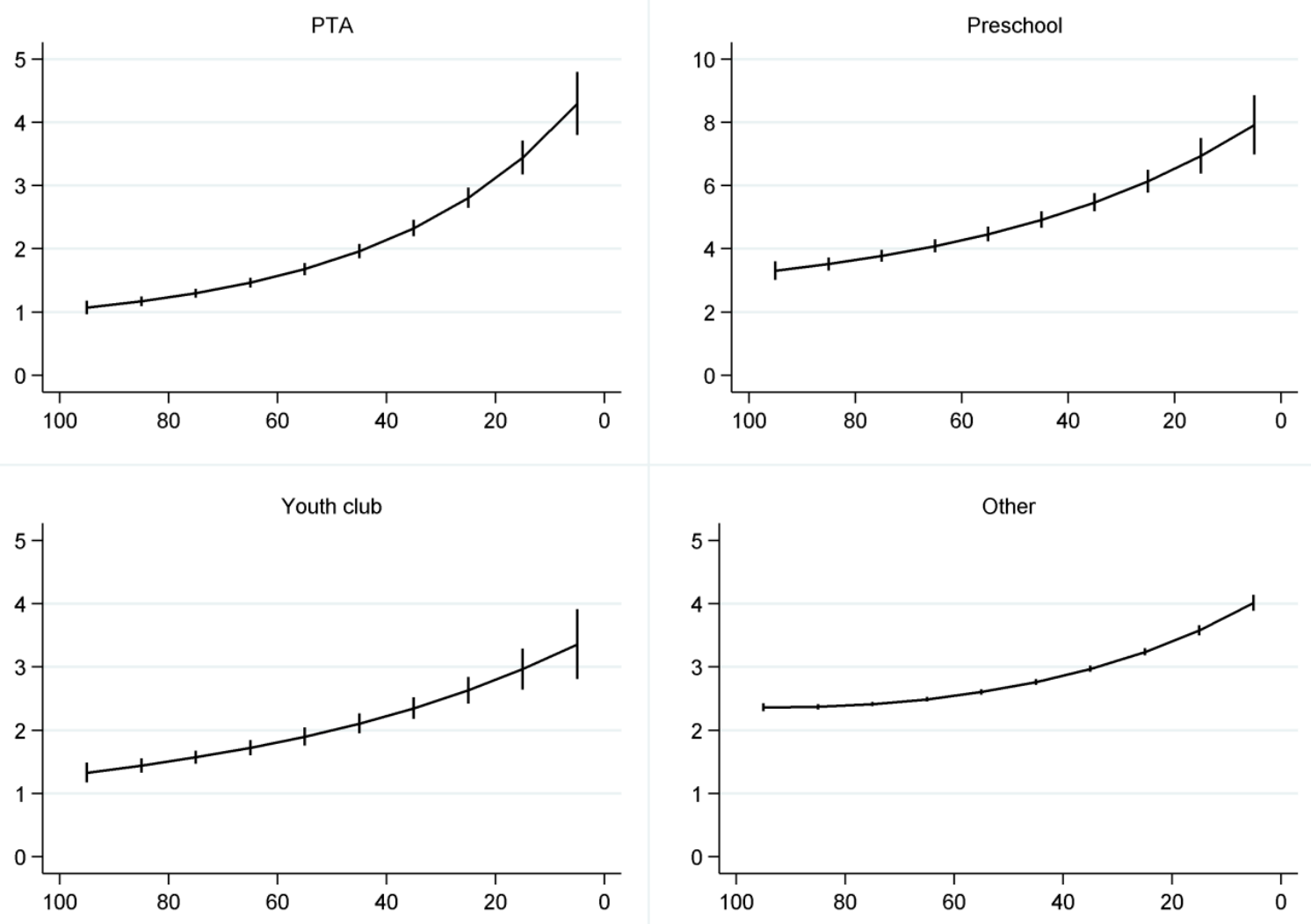

NOTE. Fitted marginal dissolution rates from Model C3 (see Table 9); y-axis: Dissolutions per 100 charity years; x-axis: Deprivation (percentiles). Spikes are 95\% CIs. 
FIGURE 13 Rates of foundation for charities performing particular roles, by percentile of deprivation
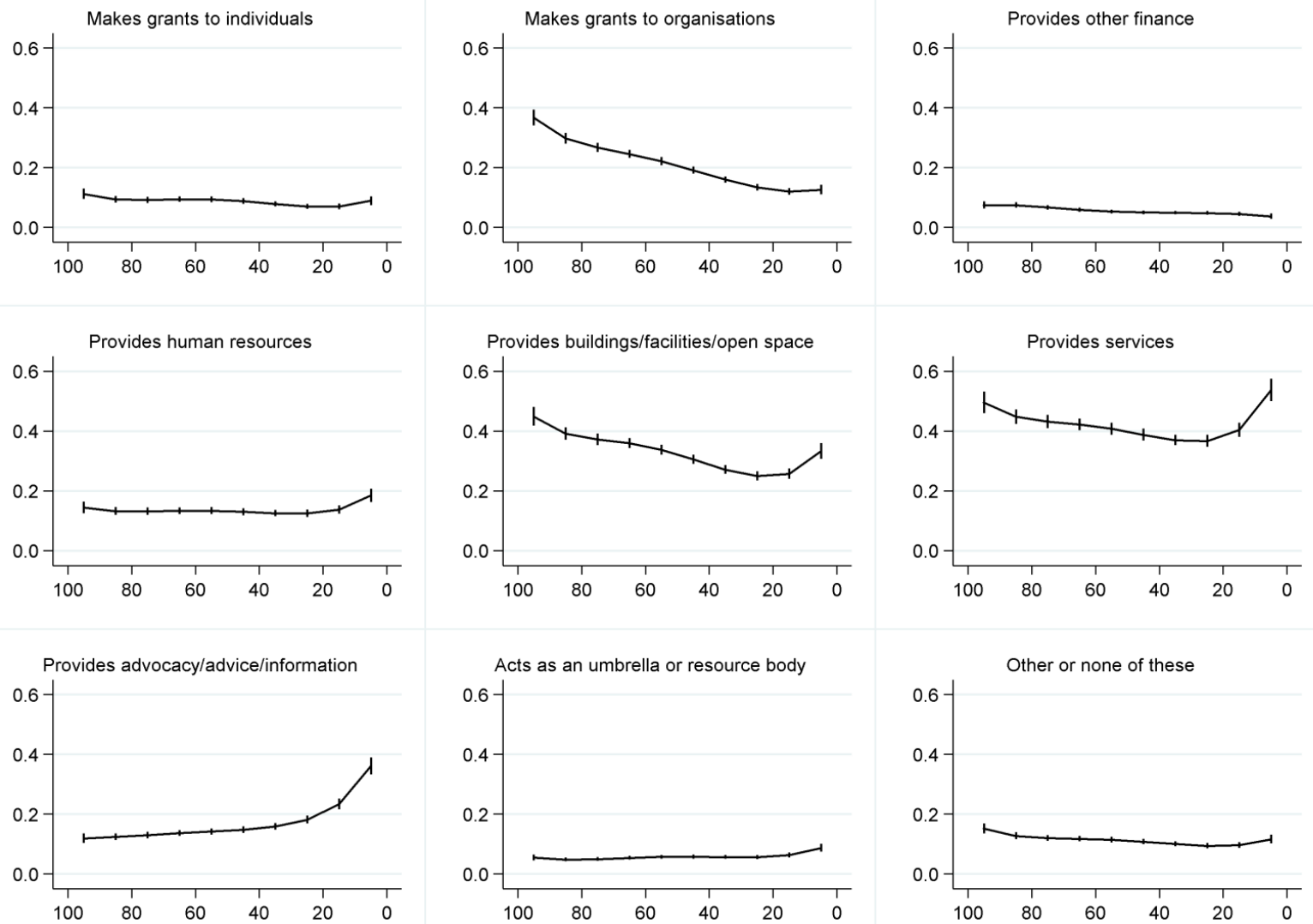

NOTE. Fitted marginal foundation rates from Models B6-B14 (see Table 7); y-axis: Foundations per 1000 people over analysis period; $\mathrm{x}$-axis: Deprivation (percentiles). Charities may belong to more than one role category. Spikes are $95 \%$ CIs.

FIGURE 14 Rates of dissolution for charities performing particular roles, by percentile of deprivation
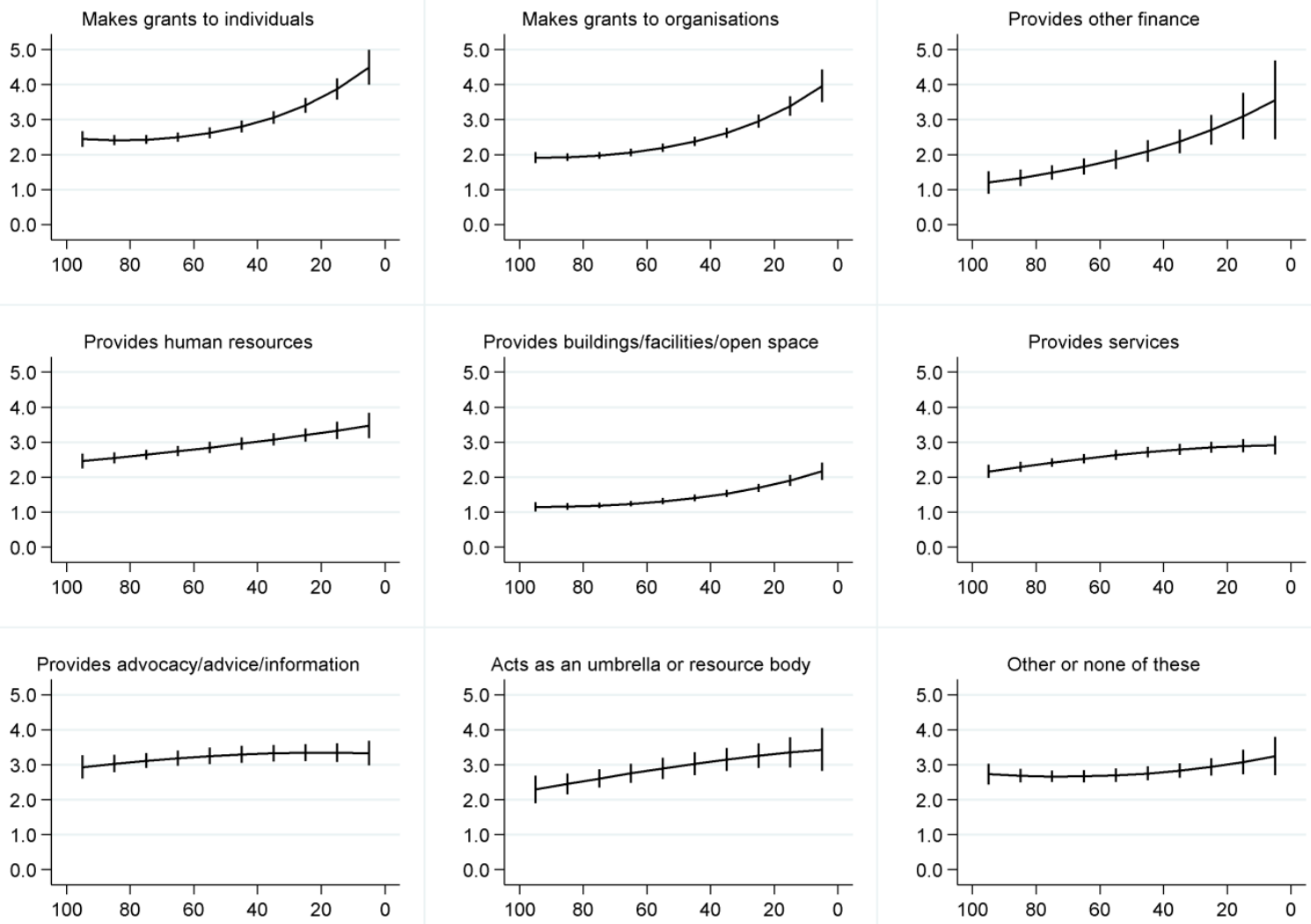

NOTE. Fitted marginal dissolution rates from Models C4-C12 (see Table 10); y-axis: Dissolutions per 100 charity years; x-axis Deprivation (percentiles). Charities may belong to more than one role category. Spikes are $95 \%$ CIs. 
FIGURE 15 Rates of foundation in different area contexts, by percentile of deprivation
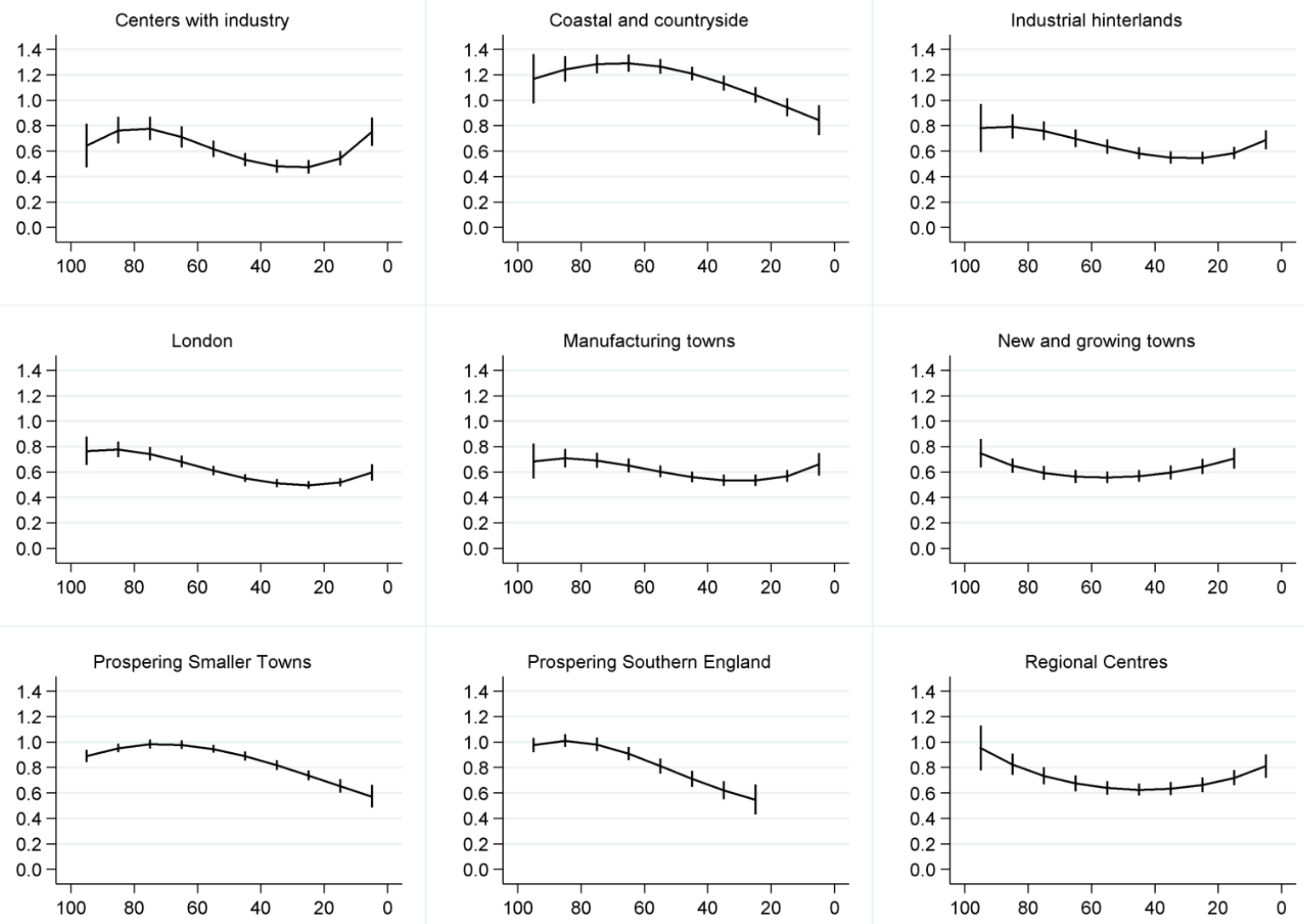

NOTE. Fitted marginal foundation rates from Models B15-B23 (see Table 8); y-axis: Foundations per 1000 people over analysis period; X-axis: Deprivation (percentiles). Spikes are $95 \%$ CIs.

FIGURE 16 Rates of dissolution in different area contexts, by percentile of deprivation
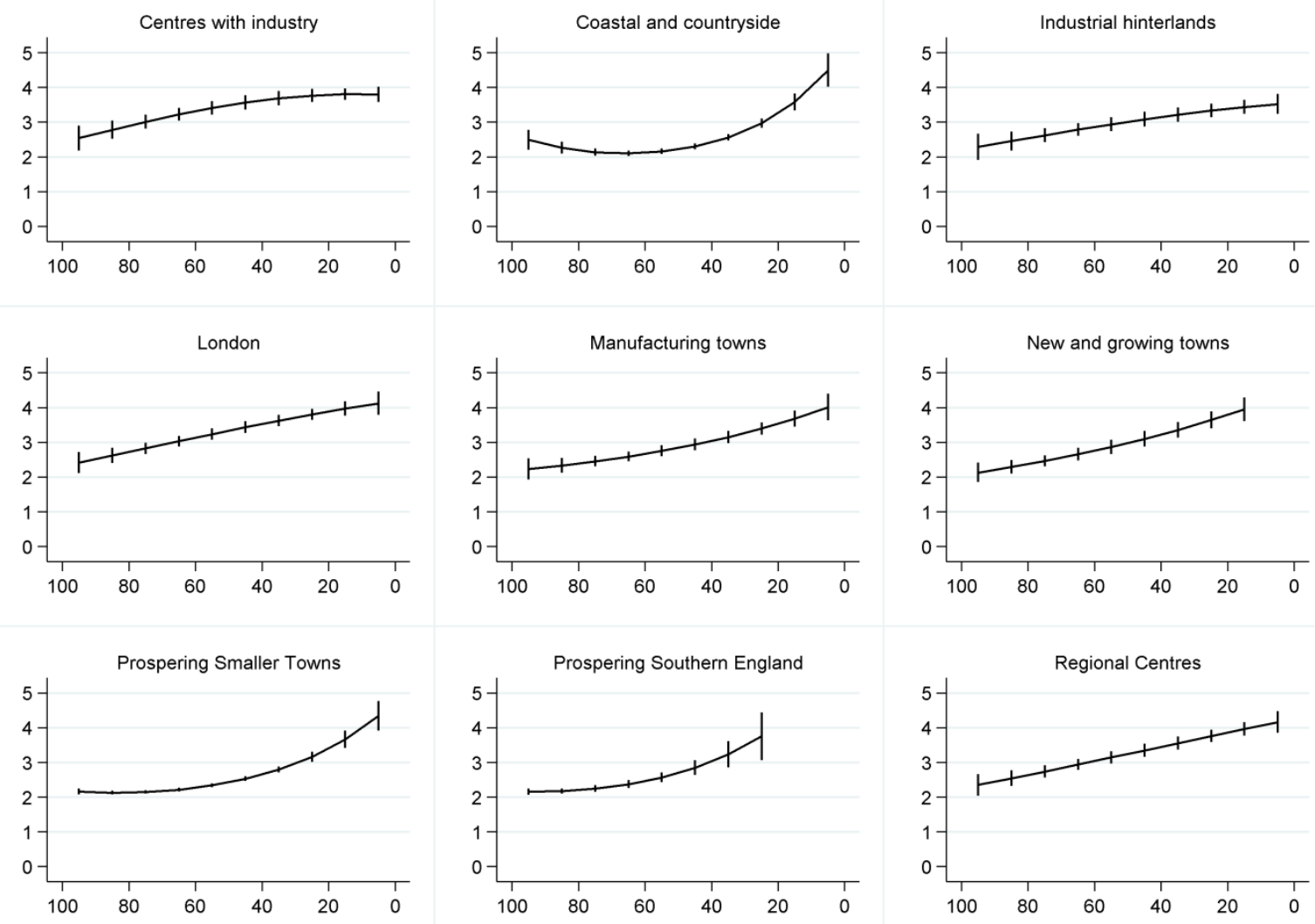

NOTE. Fitted marginal dissolution rates from Model C13 (see Table 11); y-axis: Dissolutions per 100 charity years; x-axis Deprivation (percentiles). Spikes are 95\% CIs. 
FIGURE 17 Survival functions for charities in least and most deprived neighborhood contexts.

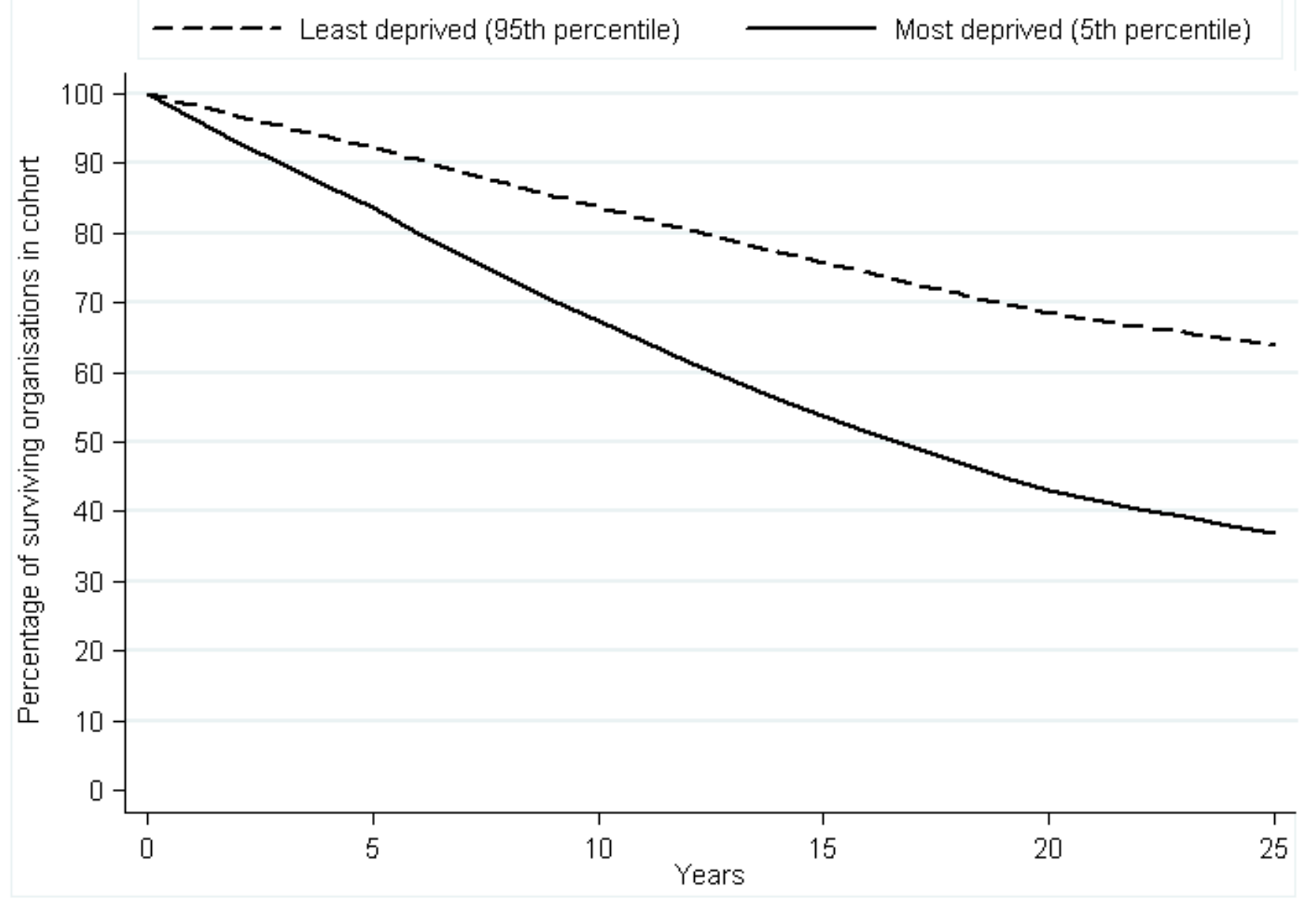

NOTE. Survival functions based on marginal dissolution rates from Model C2 (see Table 9). 
FIGURE A1 Comparing results from different specifications for neighborhood deprivation as a covariate: rates of dissolution for charities, by percentile of deprivation
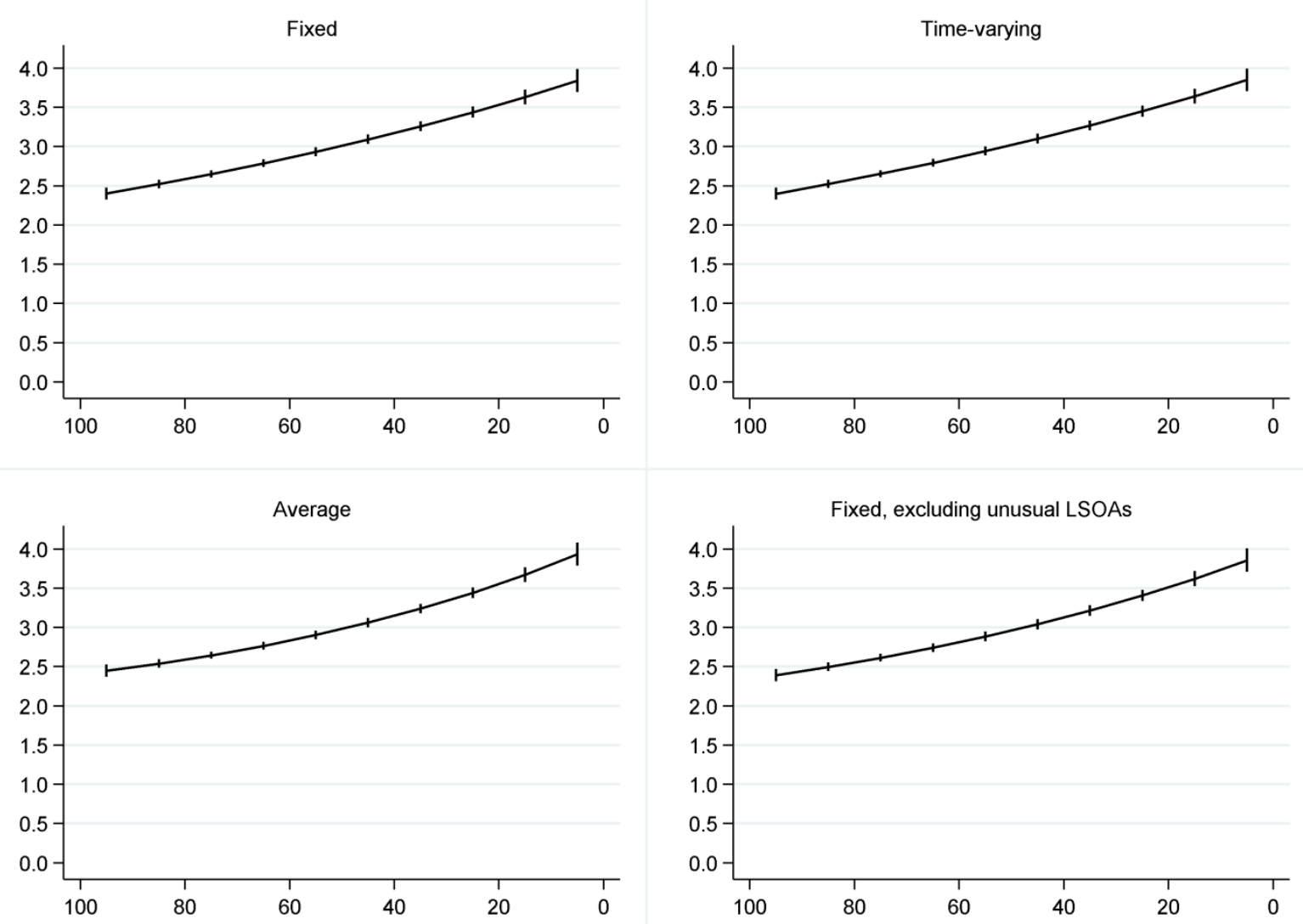

NOTE. Fixed: neighborhood deprivation as a fixed covariate (IMD 2007); Time-varying: neighborhood deprivation as a timevarying covariate (organization years in 2004-2006 are linked to IMD 2004; those in 2007-2009 to IMD 2007; those in 2010-11 to IMD 2010); Average: uses IMD 2004, 2007 and 2010 to calculate the average IMD percentile for each LSOA over our analysis period; Fixed, excluding unusual LSOAs: neighborhood deprivation as a fixed covariate (IMD 2007) excluding the 6\% of LSOAs showing substantively sizeable changes in the relative deprivation distribution. Each model has neighborhood context and process time (age of organization) as covariates and relates to an analysis period from 2004-2011 inclusive. For more details, see endnote 29. 
FIGURE A2 Comparing results from different modeling approaches: relative risks of dissolution according to neighborhood context, from Piecewise exponential model and from Cox model
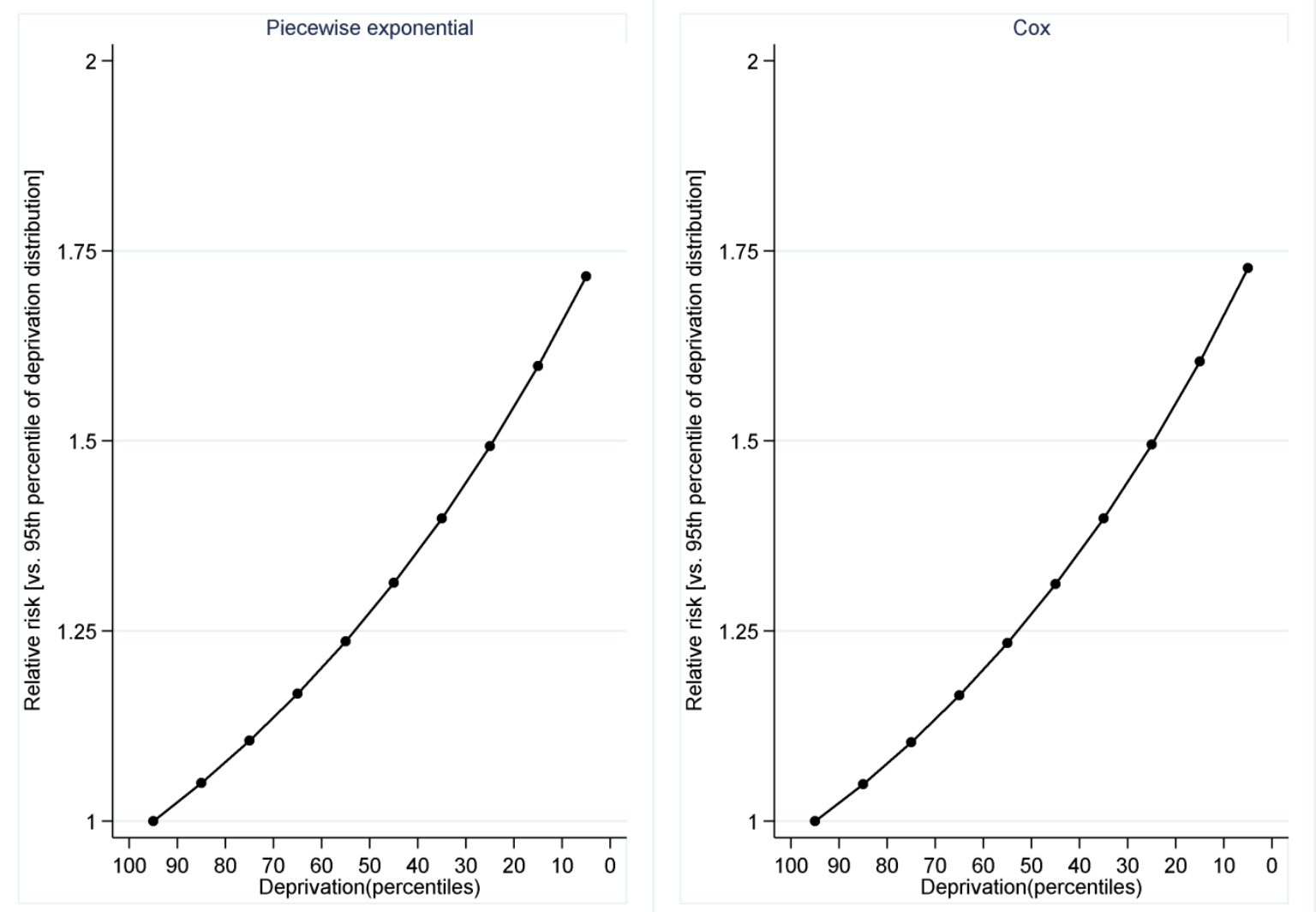

NOTE. Left graph based on piecewise exponential model (covariates: neighborhood context; age - Model C1 in Table 9); right graph based on Cox model (covariates: neighborhood context). Risks are relative to rate of dissolution at the $95^{\text {th }}$ percentile of the IMD distribution. 
FIGURE A3 Using area of operation as a measure of charity location: density of charitable organizations, by percentile of deprivation at the local authority level

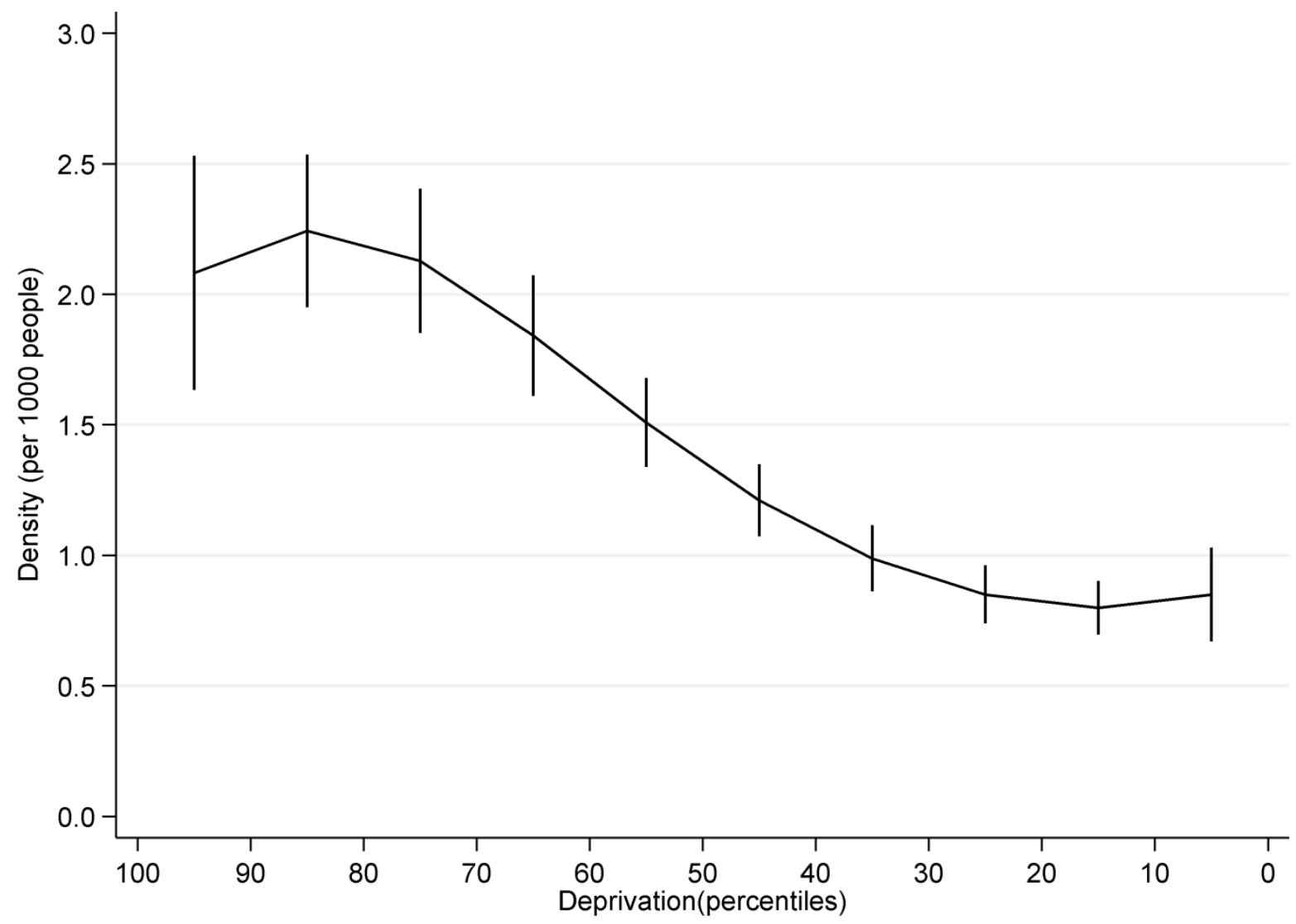

NOTE. Fitted marginal densities from Model D1 (see Table A2). Spikes are 95\% CIs 
FIGURE A4 Using area of operation as a measure of charity location: density of specific kinds of charitable organizations, by percentile of deprivation at the local authority level
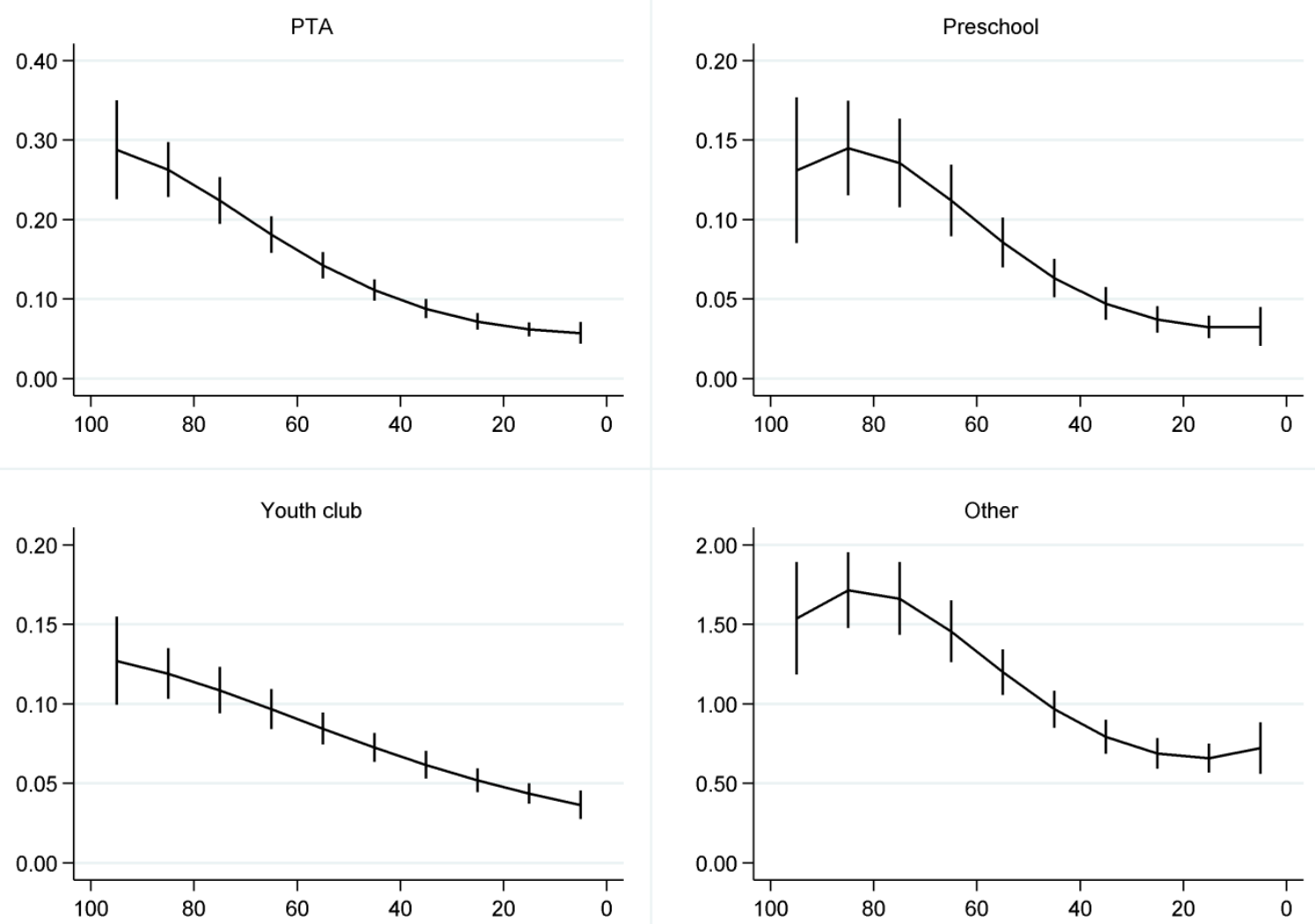

NOTE. Fitted marginal densities from Models D2-D5 (see Table A2); y-axis: Density (per 1000 people); x-axis: Deprivation (percentiles). Spikes are $95 \%$ CIs. 
FIGURE A5 Using area of operation as a measure of charity location: density of charitable organizations performing particular roles, by percentile of deprivation at the local authority level
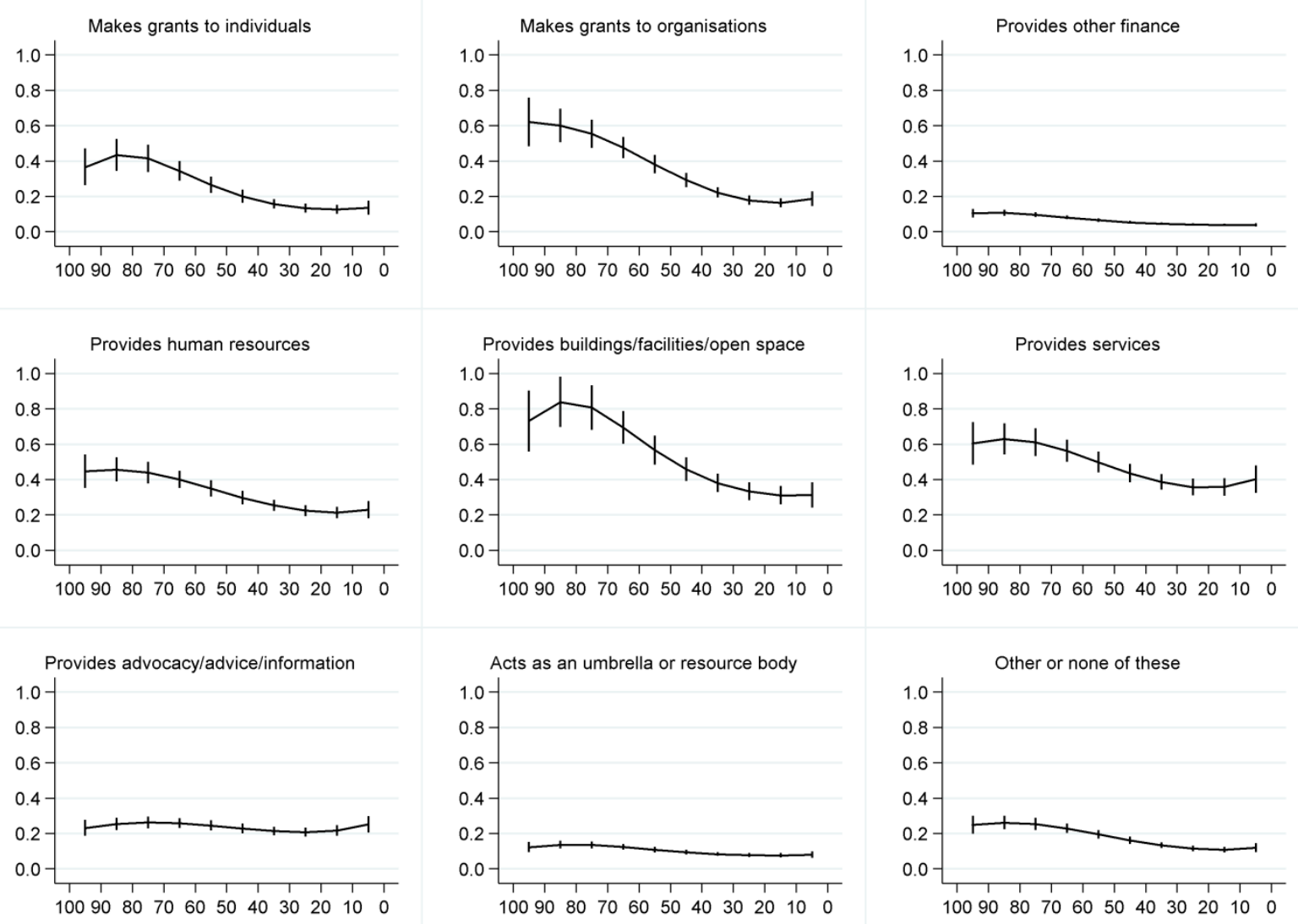

NOTE. Fitted marginal densities from Models D6-D14 (see Table A2); y-axis: Density (per 1000 people); x-axis: Deprivation (percentiles). Charities may belong to more than one role category. Spikes are 95\% CIs. 
FIGURE A6 Using area of operation as a measure of charity location: rates of charitable foundation, by percentile of deprivation at the local authority level

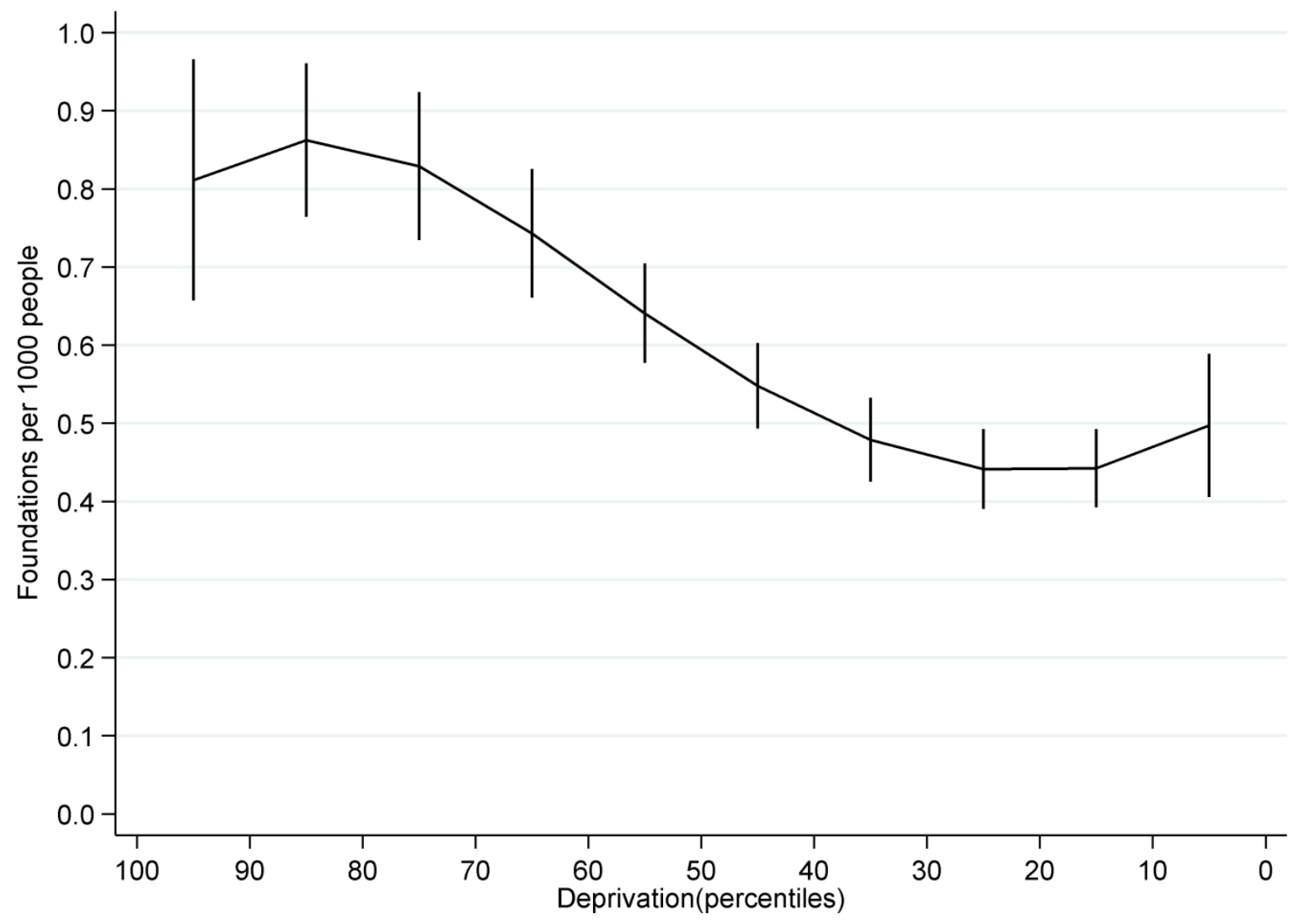

NOTE. Fitted marginal foundation rates from Model E1 (see Table A3). Spikes are 95\% CIs.

FIGURE A7 Using area of operation as a measure of charity location: rates of charitable dissolution at the local authority level, before and after controlling for charity size and form

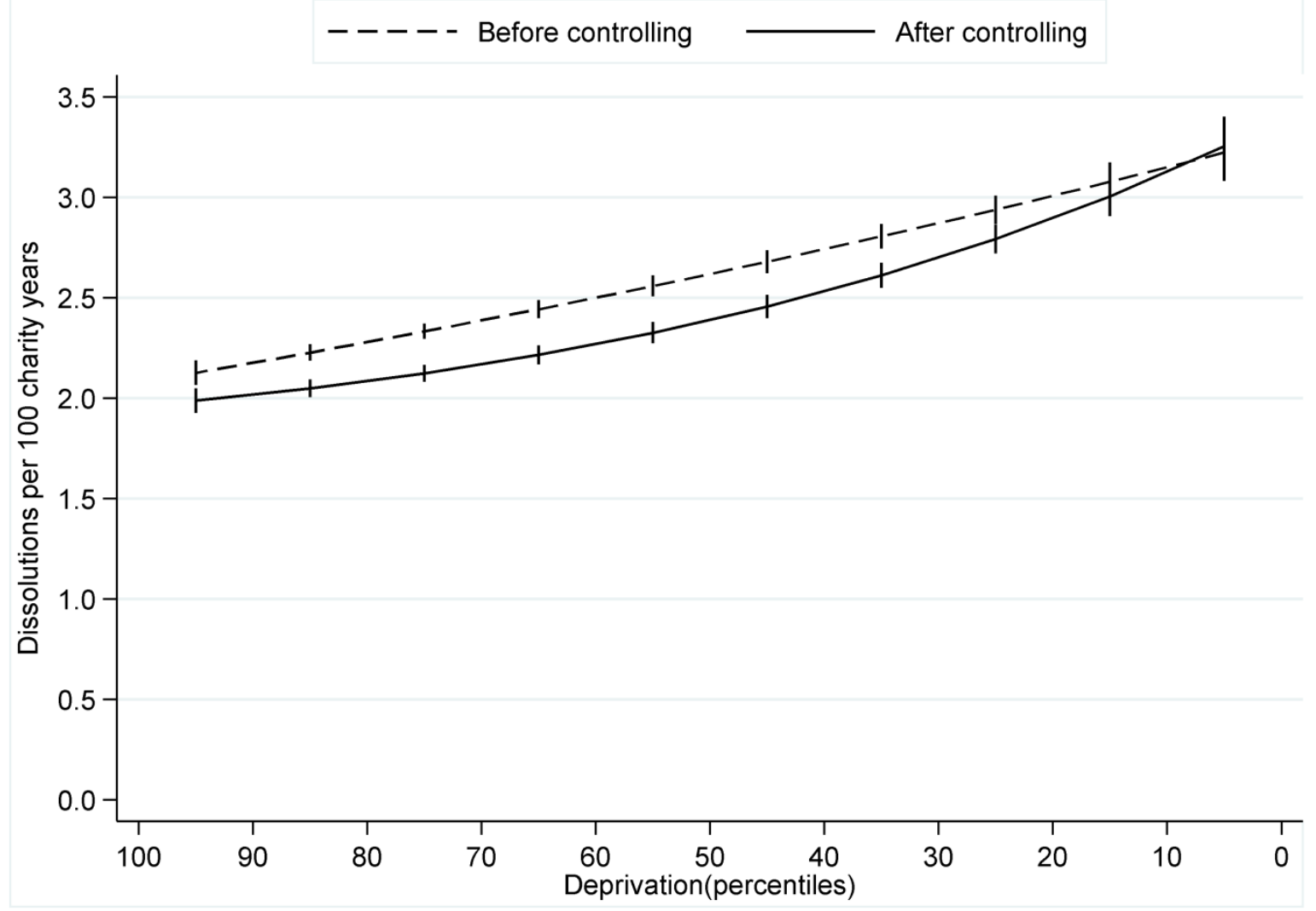

NOTE. Fitted marginal dissolution rates from Models F1 and F2 (see Table A4). Spikes are 95\% CIs. 
FIGURE A8 Using area of operation as a measure of charity location: rates of charitable foundation for specific kinds of charities, by percentile of deprivation at the local authority level
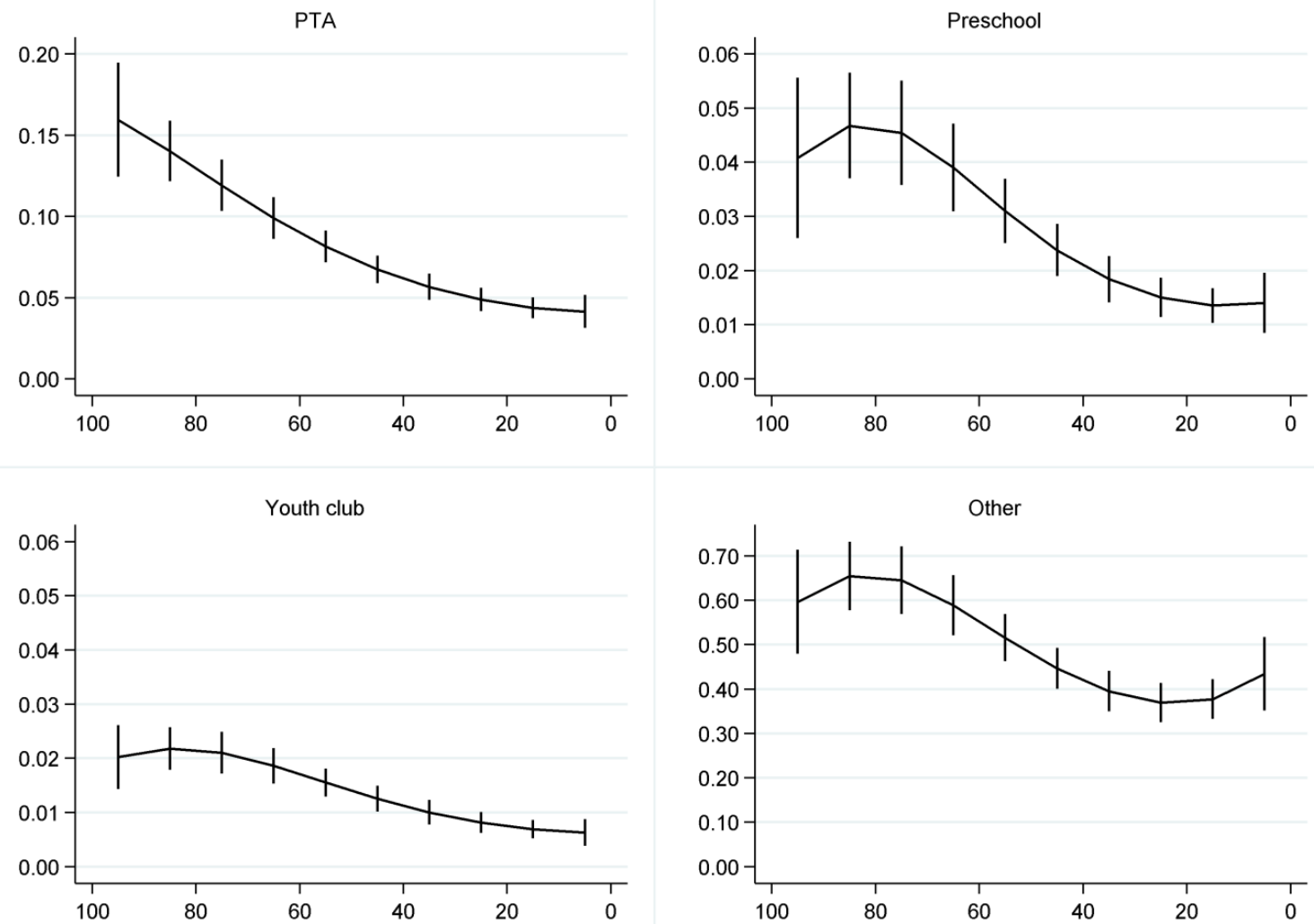

NOTE. Fitted marginal foundation rates from Models E2-E5 (see Table A3); y-axis: Foundations per 1000 people over analysis period; X-axis: Deprivation (percentiles). Spikes are 95\% CIs.

FIGURE A9 Using area of operation as a measure of charity location: rates of charitable dissolution for specific kinds of charities, by percentile of deprivation at the local authority level
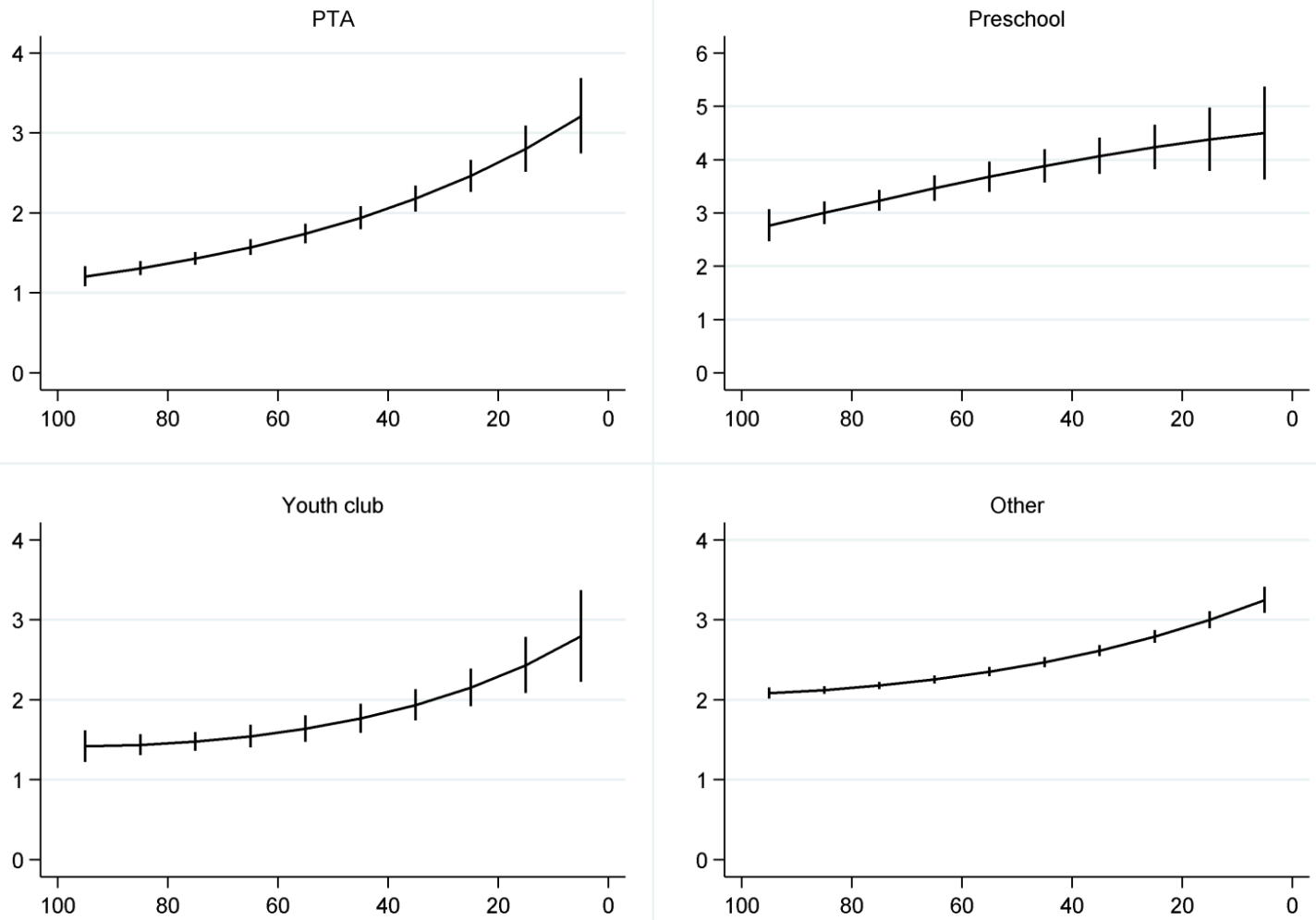

NOTE. Fitted marginal dissolution rates from Model F3 (see Table A4); y-axis: Dissolutions per 100 charity years; x-axis: Deprivation (percentiles). Spikes are 95\% CIs. 
FIGURE A10 Using area of operation as a measure of charity location: rates of charitable foundation for charities performing particular roles, by percentile of deprivation at the local authority level
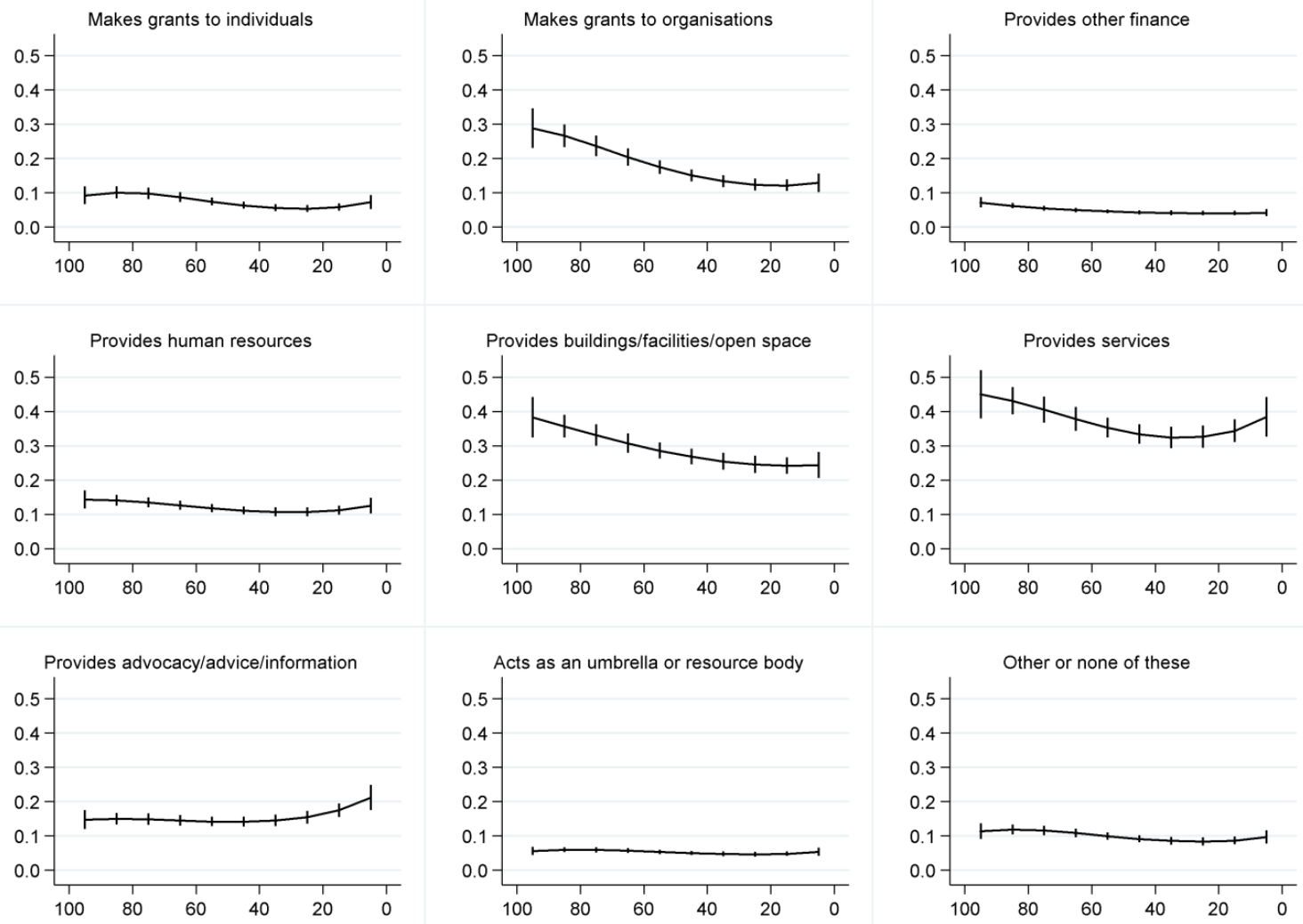

NOTE. Fitted marginal foundation rates from Models E6-E14 (see Table A3); y-axis: Foundations per 1000 people over analysis period; $x$-axis: Deprivation (percentiles). Charities may belong to more than one role category. Spikes are $95 \%$ CIs.

FIGURE A11 Using area of operation as a measure of charity location: rates of charitable dissolution for charities performing particular roles, by percentile of deprivation at the local authority level
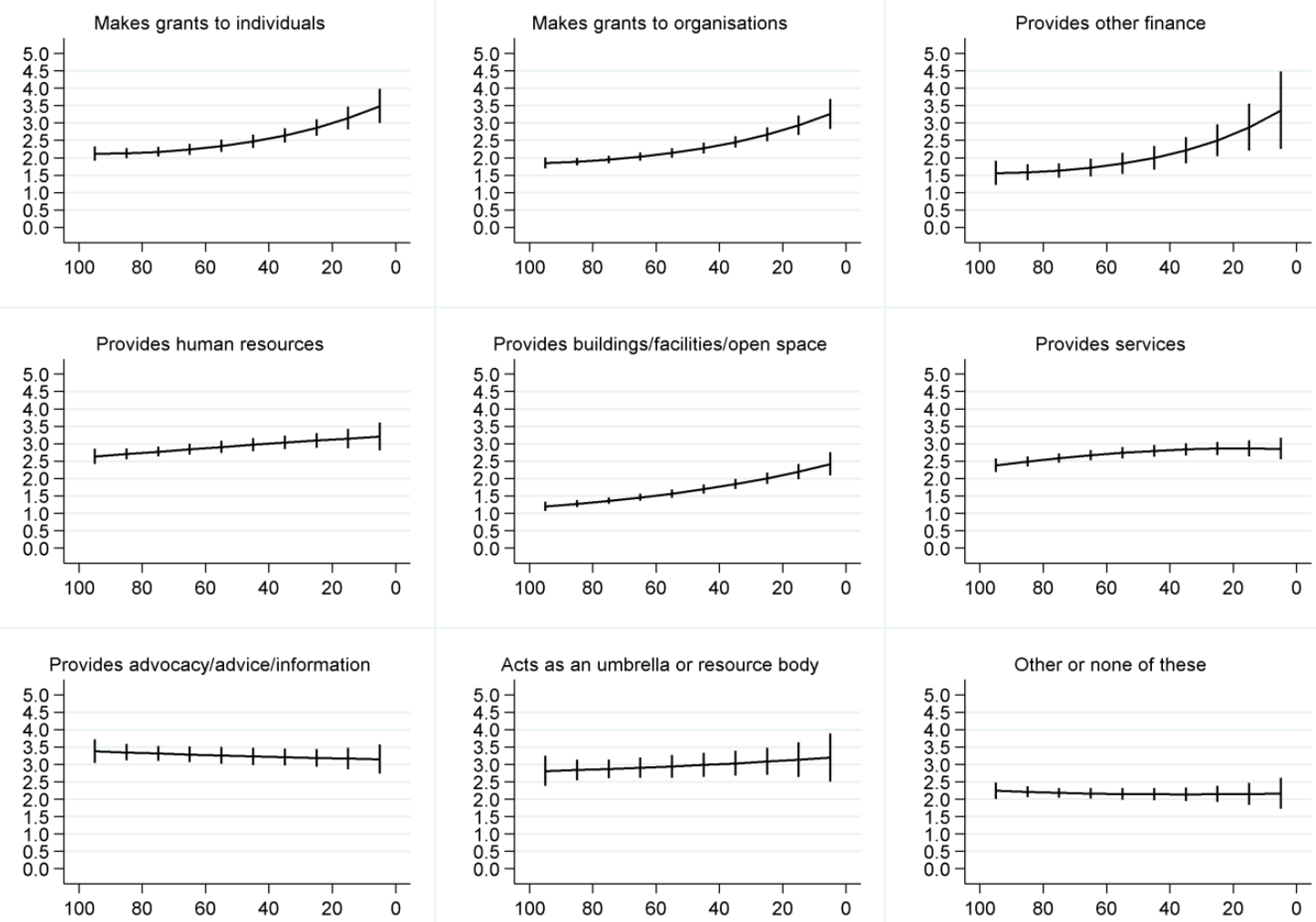

NOTE. Fitted marginal dissolution rates from Models F4-F12- (see Table A5); y-axis: Dissolutions per 100 charity years; $\mathrm{x}$-axis Deprivation (percentiles). Charities may belong to more than one role category. Spikes are $95 \%$ CIs. 


\begin{tabular}{|c|c|c|c|}
\hline Name of file & Details & Structure & Notes \\
\hline Extract_charity & $\begin{array}{l}\text { Main charity details. Includes name, address and description of governing } \\
\text { document. }\end{array}$ & One record per charity. & $\begin{array}{l}\text { Address used to link charities to contextual data } \\
\text { on population and deprivation at the Lower } \\
\text { Super Output Area level. }\end{array}$ \\
\hline Extract_registration & Date of charitable registration and, for dissolved charities, date of dissolution. & One record per charity. & \\
\hline Extract_name & $\begin{array}{l}\text { List of names associated with the charity: main name, plus any former names } \\
\text { / alternative names / acronyms and abbreviations. }\end{array}$ & $\begin{array}{l}\text { Rows indexed by charity } \\
\text { number and name. At } \\
\text { least one row per charity. }\end{array}$ & $\begin{array}{l}\text { Used to link two Register entries for same } \\
\text { charity where charity incorporates over our } \\
\text { analysis period (endnote 19) }\end{array}$ \\
\hline Extract_class & $\begin{array}{l}\text { Classification data: series of non-mutually exclusive variables indicating the } \\
\text { nature of its beneficiaries (children/ young people; elderly/ old people, etc.) } \\
\text { and the role that the charity performs (provides services; provides } \\
\text { buildings/facilities/open space; etc.) }\end{array}$ & $\begin{array}{l}\text { Rows indexed by charity } \\
\text { number and classification } \\
\text { variable. } \quad \text { Typically } \\
\text { multiple rows per charity. }\end{array}$ & \\
\hline Extract_objects & Charitable objects: the statement of the charity's purpose. & $\begin{array}{l}\text { Text string. One record } \\
\text { per charity. }\end{array}$ & $\begin{array}{l}\text { Used to identify specific kinds of charities: } \\
\text { PTAs, preschools and youth clubs (endnote } 42 \text { ) }\end{array}$ \\
\hline Extract_charity_aoo & $\begin{array}{l}\text { Structured geographical data indicating the 'area(s) of charitable operation': } \\
\text { ('the geographical area where the charity does its work or provides its } \\
\text { benefit'). This information is provided at the level of local authorities in } \\
\text { England and Wales (and overseas countries for charities working } \\
\text { internationally). Charities that work at a national level or across more than } \\
10 \text { local authorities are coded 'Throughout England' or 'Throughout England } \\
\text { and Wales'. }\end{array}$ & $\begin{array}{l}\text { Rows indexed by charity } \\
\text { number and area of } \\
\text { operation. At least one } \\
\text { row per charity. }\end{array}$ & $\begin{array}{l}\text { 1.Used to identify the subpopulation of charities } \\
\text { for analysis: those charities that work within one } \\
\text { specific local authority in England. 2. Used to } \\
\text { link charities to contextual data on population } \\
\text { and deprivation when examining differences in } \\
\text { charitable density and dynamics across local } \\
\text { authorities (Figure 2; Figures A3-A11 in } \\
\text { Appendix). }\end{array}$ \\
\hline Extract_financial & $\begin{array}{l}\text { Longitudinal data providing financial history of organisation: headline annual } \\
\text { income and expenditure. Financial information available since mid-1990s. }\end{array}$ & $\begin{array}{l}\text { Rows indexed by charity } \\
\text { number and year. } \\
\text { Multiple rows per charity. }\end{array}$ & $\begin{array}{l}\text { Span of financial information used to test the } \\
\text { robustness of our results to two slightly different } \\
\text { definitions of year of charitable dissolution } \\
\text { (endnote 18). }\end{array}$ \\
\hline
\end{tabular}


TABLE 2 Charity dataset: table of exemplary organizations

\begin{tabular}{|c|c|c|c|c|}
\hline Charity Name & $\begin{array}{l}\text { Reg. } \\
\text { Year }\end{array}$ & $\begin{array}{l}\text { Diss. } \\
\text { Year }\end{array}$ & $\begin{array}{l}\text { Longitudinal span of annual financial data } \\
\text { over analysis period }\end{array}$ & Address and postcode \\
\hline Seaham Youth Centre & 1977 & & & Seaham Youth Centre, Strangford Road, Seaham, Co Durham, SR78QE \\
\hline Whitleigh Community Association & 1979 & 2008 & & Whitleigh Community Centre, Whitleigh Green, Plymouth, PL54DE \\
\hline Kensal Green Under Fives Group & 1982 & & & Kensal Green Under Fives Group, 130 Mortimer Road, London, NW105SN \\
\hline $\begin{array}{l}\text { The Holloway Neighbourhood } \\
\text { Group }\end{array}$ & 1977 & & & $\begin{array}{l}\text { The Holloway Neighbourhood Group, the Old Fire Station, } 84 \text { Mayton } \\
\text { Street, London, N76QT }\end{array}$ \\
\hline Volunteer Centre South Lakeland & 1971 & 2010 & & $\begin{array}{l}\text { The Volunteer Centre South Lakeland, Stricklandgate House, } 92 \\
\text { Stricklandgate, Kendal, Cumbria, LA94PU }\end{array}$ \\
\hline $\begin{array}{l}\text { Holsworthy Primary School } \\
\text { Parent Teacher Association }\end{array}$ & 1995 & & & $\begin{array}{l}\text { Holsworthy C of E Primary School, Sanders Lane, Holsworthy, Devon, } \\
\text { EX226HD }\end{array}$ \\
\hline Bramley Village Hall & 1961 & & & Bramley Village Hall, Hall Road, Bramley, Guildford, Surrey, GU50AX \\
\hline Charles Young Centre & 1979 & & & Charles Young Day Centre, Talbot Road, South Shields, NE340QJ \\
\hline $\begin{array}{l}\text { Newstead Colliery Miners' } \\
\text { Welfare Trust }\end{array}$ & 1979 & & & $\begin{array}{l}\text { Newstead Community Centre, Tilford Road, Newstead Village, } \\
\text { Nottinghamshire, NG150BS }\end{array}$ \\
\hline Dosthill Boys Club & 1963 & & & $\begin{array}{l}\text { Dosthill Boys Club, Cadogan Road, Dosthill, Tamworth, Staffordshire, } \\
\text { B771PQ }\end{array}$ \\
\hline $\begin{array}{l}\text { Barnsley Youth Development } \\
\text { Association }\end{array}$ & 1989 & 2002 & & $\begin{array}{l}\text { Barnsley Youth Development Assoc, Park Road Training Centre, Park Road, } \\
\text { Barnsley, South Yorkshire, S701YD }\end{array}$ \\
\hline $\begin{array}{l}\text { Leominster District Community } \\
\text { Association }\end{array}$ & 1982 & & & LDCA, Leominster Community Centre, School Road, Leominster, HR68NJ \\
\hline Lilleshall Pre School Playgroup & 1994 & & & Lilleshall Pre-School, Limekiln Lane, Lilleshall, Newport, TF109EY \\
\hline Drake Community Centre & 1994 & & & $\begin{array}{l}\text { Drake Community Centre, Drake Road, Chafford Hundred, Grays, } \\
\text { RM166PS }\end{array}$ \\
\hline $\begin{array}{l}\text { Highfields Community Nursery } \\
\text { and Training Centre }\end{array}$ & 1997 & 2004 & & $\begin{array}{l}\text { Highfields Community Nursery and Training Centre, 5-7 Evington Street, } \\
\text { Leicester, LE20SA }\end{array}$ \\
\hline
\end{tabular}

NOTE: A summary of the full covariate data available for each charity is provided in Table 1. 
TABLE 3 Defining the final subpopulation of charities used in the analysis

(Sub)population of charities

Number of charities

Total population of

registered charities

in existence at some point

over our analysis period (1996-2011)

218,818

$$
\downarrow
$$

Charities with local remit

(operate within one specific Local Authority)

135,385

Charities with address in England

(charities in Wales excluded)

127,392 


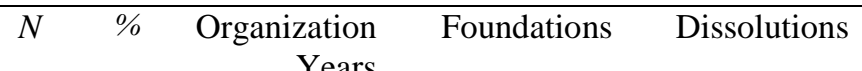

Area Classification:

Centers with Industry

Coastal and Countryside

Industrial hinterlands

London

Manufacturing towns

New and growing towns

Prospering Smaller Towns

Prospering Southern England

Regional Centers

Form:

Unincorporated

Incorporated

Neighborhood context: IMD deciles

1 st [most deprived]

2nd

3 rd

4th

5 th

6th

7 th

8 th

9th

10th [least deprived]

Role of organization:

Makes grants to individuals

Makes grants to organizations

Provides other finance

Provides human resources

Provides buildings/facilities/open space

Provides services

Provides advocacy/advice/information

Acts as an umbrella or resource body

Other or none of these

Type of organization:

\begin{tabular}{|c|c|c|c|c|c|}
\hline Other & 101,090 & 79 & $1,080,532$ & 30,394 & 30,309 \\
\hline PTA & 11,773 & 9 & 125,092 & 5,355 & 2,359 \\
\hline Preschool & 8,142 & 6 & 89,101 & 1,891 & 2,885 \\
\hline Youth club & 6,387 & 5 & 79,828 & 864 & 1,439 \\
\hline Total & 127,392 & 100 & $1,374,553$ & 38,504 & 36,992 \\
\hline
\end{tabular}

NOTE: N - total number of organizations in panel between 1997 and 2011 inclusive. Foundations and dissolutions - between 1997 and 2011 inclusive. IMD: Index of Multiple Deprivation (percentiles of the IMD distribution were used in the models, but deciles are presented here for convenience); Role of organization: note that charities may belong to more than one role category; number of organization years, foundations and dissolutions by role relates to the specific period between 2007-2011 inclusive since comprehensive information on role was not collected by the Charity Commission until the mid-2000s; Area Classification: 'London' groups together different area classifications: London Centre, London Cosmopolitan, London Suburbs, and Thriving London Periphery. 1139 charities, and associated 11,034 charity years, 292 foundations and 440 dissolutions, are missing data on Area Classification. 
TABLE 5 The density of charitable organizations and neighborhood deprivation: results from negative binomial models (Models A1-A15)

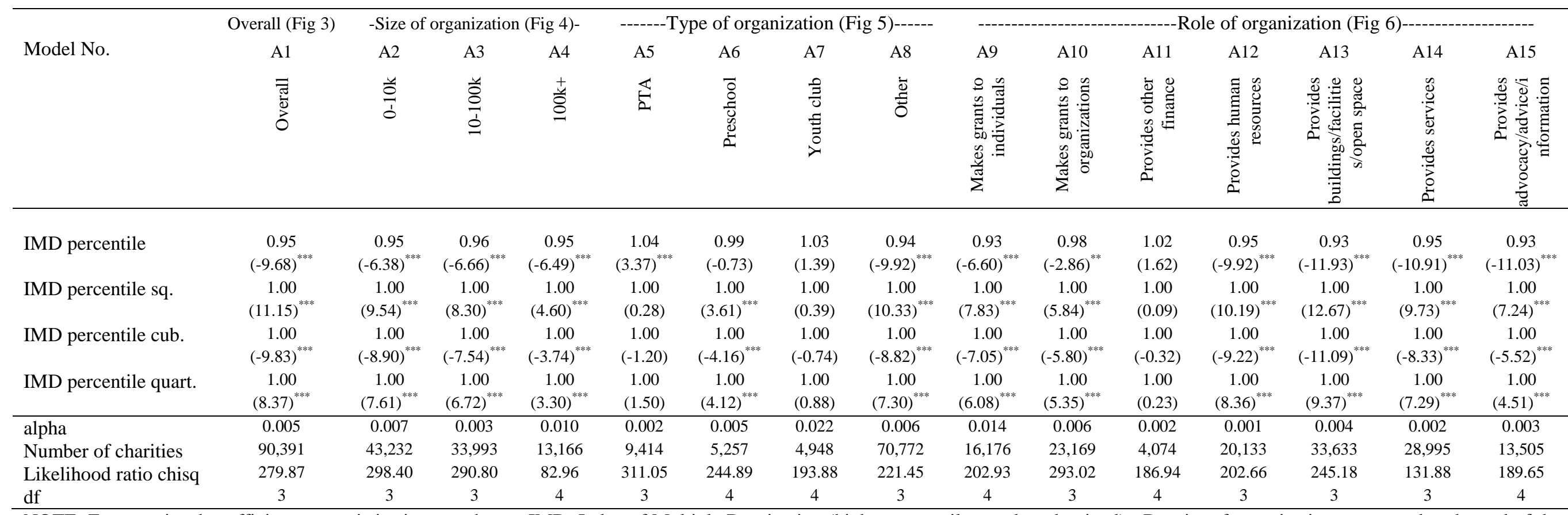

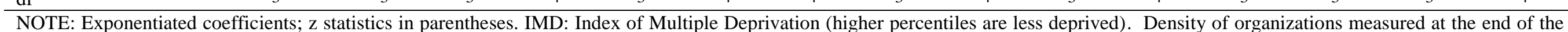

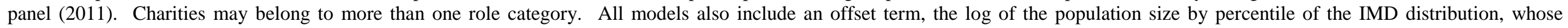
coefficient is constrained to be 1 .

${ }^{*} p<0.05,{ }^{* *} p<0.01,{ }^{* * * *} p<0.001$ 
TABLE 6 The density of charitable organizations and neighborhood deprivation: results from negative binomial models (Models A16-A30)

\begin{tabular}{|c|c|c|c|c|c|c|c|c|c|c|c|c|c|c|c|}
\hline \multirow{3}{*}{ Model No. } & \multicolumn{2}{|c|}{-Role (cont.) (Fig. 6)- } & \multicolumn{9}{|c|}{ - } & \multicolumn{4}{|c|}{ 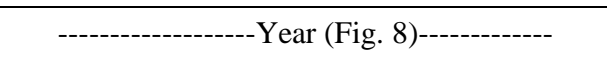 } \\
\hline & A16 & A17 & A18 & A19 & $\mathrm{A} 20$ & A 21 & $\mathrm{~A} 22$ & $\mathrm{~A} 23$ & A24 & A25 & A26 & A 27 & A28 & A29 & A 30 \\
\hline & 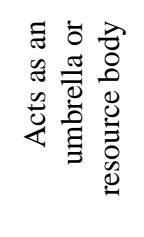 & 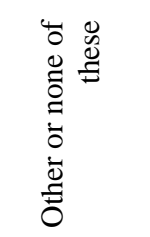 & 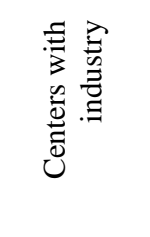 & 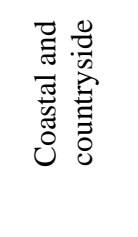 & 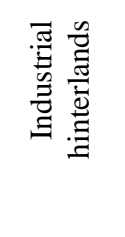 & 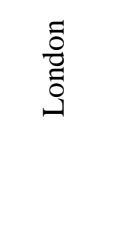 & 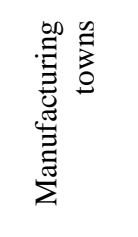 & 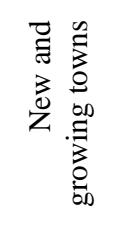 & 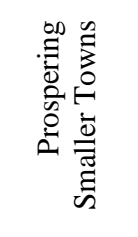 & 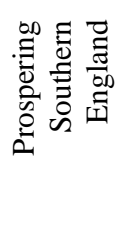 & 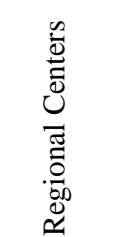 & ஓ & চ্ণ & 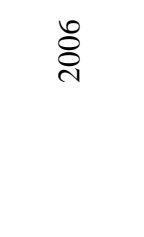 & $\overline{\bar{i}}$ \\
\hline IMD percentile & $\begin{array}{c}0.94 \\
(-6.10)^{* * * *}\end{array}$ & $\begin{array}{c}0.97 \\
(-4.14)^{* * * *}\end{array}$ & $\begin{array}{c}0.95 \\
(-5.45)^{* * * *}\end{array}$ & $\begin{array}{c}1.04 \\
(4.83)^{* * *}\end{array}$ & $\begin{array}{c}0.98 \\
(-2.16)^{*}\end{array}$ & $\begin{array}{c}0.99 \\
(-0.78)\end{array}$ & $\begin{array}{c}0.98 \\
(-2.64)^{* *}\end{array}$ & $\begin{array}{c}0.98 \\
(-2.07)^{*}\end{array}$ & $\begin{array}{c}1.02 \\
(2.38)^{*}\end{array}$ & $\begin{array}{c}1.03 \\
(0.96)\end{array}$ & $\begin{array}{c}1.00 \\
(0.13)\end{array}$ & $\begin{array}{c}0.96 \\
(-5.52)^{* * *}\end{array}$ & $\begin{array}{c}0.96 \\
(-5.89)^{* * *}\end{array}$ & $\begin{array}{c}0.95 \\
(-8.01)^{* * * *}\end{array}$ & $\begin{array}{c}0.95 \\
(-9.68)^{* * *}\end{array}$ \\
\hline IMD percentile sq. & $\begin{array}{c}1.00 \\
(5.46)^{* * * *}\end{array}$ & $\begin{array}{c}1.00 \\
(5.51)^{* * * *}\end{array}$ & $\begin{array}{c}1.00 \\
(5.53)^{* * * *}\end{array}$ & $\begin{array}{c}1.00 \\
(-1.39)\end{array}$ & $\begin{array}{c}1.00 \\
(2.07)^{*}\end{array}$ & $\begin{array}{l}1.00 \\
(1.63)\end{array}$ & $\begin{array}{c}1.00 \\
(3.10)^{* *}\end{array}$ & $\begin{array}{c}1.00 \\
(2.22)^{*}\end{array}$ & $\begin{array}{c}1.00 \\
(1.09)\end{array}$ & $\begin{array}{c}1.00 \\
(0.50)\end{array}$ & $\begin{array}{c}1.00 \\
(-0.58)\end{array}$ & $\begin{array}{c}1.00 \\
(7.43)^{* * * *}\end{array}$ & $\begin{array}{c}1.00 \\
(7.64)^{* * *}\end{array}$ & $\begin{array}{c}1.00 \\
(9.69)^{* * * *}\end{array}$ & $\begin{array}{c}1.00 \\
(11.15)^{* * * *}\end{array}$ \\
\hline IMD percentile cub. & $\begin{array}{c}1.00 \\
(-4.76)^{* * * *}\end{array}$ & $\begin{array}{c}1.00 \\
(-5.17)^{* * *}\end{array}$ & $\begin{array}{c}1.00 \\
(-4.85)^{* * * *}\end{array}$ & $\begin{array}{c}1.00 \\
(-0.39)\end{array}$ & $\begin{array}{c}1.00 \\
(-1.38)\end{array}$ & $\begin{array}{c}1.00 \\
(-1.43)\end{array}$ & $\begin{array}{c}1.00 \\
(-2.78)^{* *}\end{array}$ & $\begin{array}{c}1.00 \\
(-2.00)^{*}\end{array}$ & $\begin{array}{c}1.00 \\
(-2.84)^{* * *}\end{array}$ & $\begin{array}{c}1.00 \\
(-1.33)\end{array}$ & $\begin{array}{c}1.00 \\
(1.30)\end{array}$ & $\begin{array}{c}1.00 \\
(-6.69)^{* * *}\end{array}$ & $\begin{array}{c}1.00 \\
(-6.85)^{* * *}\end{array}$ & $\begin{array}{c}1.00 \\
(-8.60)^{* * * *}\end{array}$ & $\begin{array}{c}1.00 \\
(-9.83)^{* * *}\end{array}$ \\
\hline IMD percentile quart. & $\begin{array}{c}1.00 \\
(4.22)^{* * * *}\end{array}$ & $\begin{array}{c}1.00 \\
(4.62)^{* * * *}\end{array}$ & & & & & & & & & & $\begin{array}{c}1.00 \\
(5.64)^{* * * *}\end{array}$ & $\begin{array}{c}1.00 \\
(5.79)^{* * * *}\end{array}$ & $\begin{array}{c}1.00 \\
(7.29)^{* * * *}\end{array}$ & $\begin{array}{c}1.00 \\
(8.37)^{* * * *}\end{array}$ \\
\hline alpha & 0.005 & 0.002 & 0.048 & 0.016 & 0.055 & 0.023 & 0.037 & 0.019 & 0.022 & 0.023 & 0.045 & 0.009 & 0.009 & 0.006 & 0.005 \\
\hline Number of charities & 6,109 & 11,162 & 5,991 & 11,634 & 3,938 & 8,536 & 4,992 & 3,590 & 32,068 & 12,546 & 5,943 & 88,903 & 92,826 & 92,411 & 90,391 \\
\hline Likelihood ratio chisq & 47.09 & 199.19 & 61.18 & 128.40 & 54.64 & 83.27 & 49.36 & 21.86 & 129.27 & 114.47 & 39.87 & 244.51 & 242.89 & 267.28 & 279.87 \\
\hline df & 4 & 3 & 3 & 3 & 3 & 3 & 3 & 3 & 3 & 3 & 3 & 3 & 3 & 3 & 3 \\
\hline
\end{tabular}

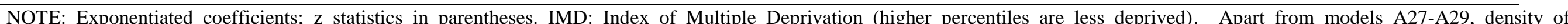

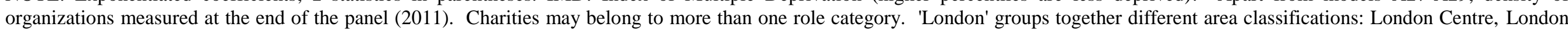

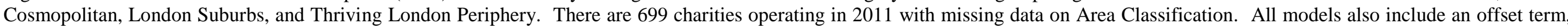
the $\log$ of the population size by percentile of the IMD distribution, whose coefficient is constrained to be 1 .

${ }^{*} p<0.05,{ }^{* * *} p<0.01,{ }^{* * * *} p<0.001$ 
TABLE 7 The rate of foundation of charitable organizations and neighborhood deprivation: results from negative binomial models (Models B1-B14)

\begin{tabular}{|c|c|c|c|c|c|c|c|c|c|c|c|c|c|c|}
\hline \multirow{3}{*}{ Model No. } & \multirow{3}{*}{$\begin{array}{c}\text { Overall (Fig 9) } \\
\text { B1 } \\
\overline{\bar{\pi}} \\
\text { ठ }\end{array}$} & \multicolumn{4}{|c|}{-------Type of organization (Fig 11)------ } & \multicolumn{9}{|c|}{ 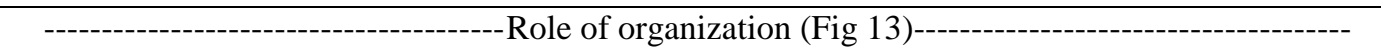 } \\
\hline & & B2 & B3 & B4 & B5 & B6 & B7 & B8 & B9 & B10 & B11 & B12 & B13 & B14 \\
\hline & & $\overleftrightarrow{\Leftrightarrow}$ & 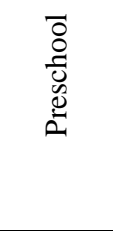 & 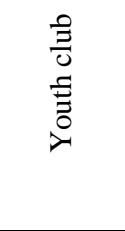 & 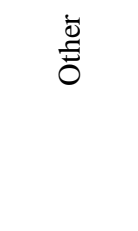 & 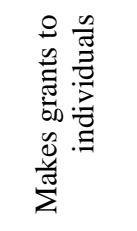 & 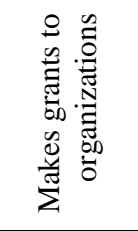 & 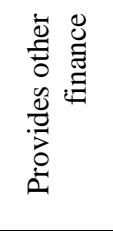 & 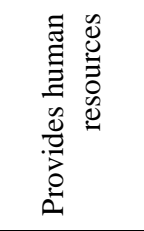 & 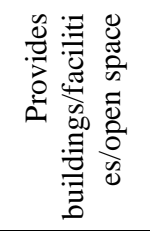 & 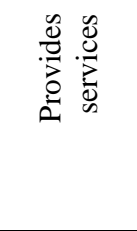 & 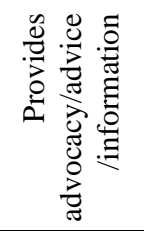 & 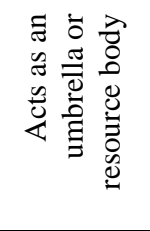 & 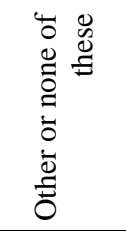 \\
\hline IMD percentile & $\begin{array}{c}0.95 \\
(-8.47)^{* * * *}\end{array}$ & $\begin{array}{c}1.05 \\
(3.16)^{* *}\end{array}$ & $\begin{array}{c}0.98 \\
(-1.16)\end{array}$ & $\begin{array}{c}0.96 \\
(-1.54)\end{array}$ & $\begin{array}{c}0.95 \\
(-8.80)^{* * *}\end{array}$ & $\begin{array}{c}0.94 \\
(-3.19)^{* *}\end{array}$ & $\begin{array}{c}0.97 \\
(-2.26)^{*}\end{array}$ & $\begin{array}{c}1.05 \\
(1.66)\end{array}$ & $\begin{array}{c}0.94 \\
(-3.86)^{* * *}\end{array}$ & $\begin{array}{c}0.94 \\
(-6.31)^{* * *}\end{array}$ & $\begin{array}{c}0.94 \\
(-6.41)^{* * * *}\end{array}$ & $\begin{array}{c}0.93 \\
(-5.98)^{* * *}\end{array}$ & $\begin{array}{c}0.93 \\
(-3.56)^{* * *}\end{array}$ & $\begin{array}{c}0.95 \\
(-2.97)^{* *}\end{array}$ \\
\hline IMD percentile sq. & $\begin{array}{c}1.00 \\
(7.71)^{* * * *}\end{array}$ & $\begin{array}{c}1.00 \\
(-0.83)\end{array}$ & $\begin{array}{c}1.00 \\
(1.87)\end{array}$ & $\begin{array}{c}1.00 \\
(2.03)^{*}\end{array}$ & $\begin{array}{c}1.00 \\
(7.38)^{* * * *}\end{array}$ & $\begin{array}{c}1.00 \\
(3.16)^{* * *}\end{array}$ & $\begin{array}{c}1.00 \\
(3.19)^{* * *}\end{array}$ & $\begin{array}{c}1.00 \\
(-1.53)\end{array}$ & $\begin{array}{c}1.00 \\
(2.94)^{* *}\end{array}$ & $\begin{array}{c}1.00 \\
(5.64)^{* * * *}\end{array}$ & $\begin{array}{c}1.00 \\
(4.77)^{* * * *}\end{array}$ & $\begin{array}{c}1.00 \\
(2.99)^{* *}\end{array}$ & $\begin{array}{c}1.00 \\
(2.85)^{* *}\end{array}$ & $\begin{array}{c}1.00 \\
(2.76)^{* *}\end{array}$ \\
\hline IMD percentile cub. & $\begin{array}{c}1.00 \\
(-6.34)^{* * *}\end{array}$ & $\begin{array}{l}1.00 \\
(0.33)\end{array}$ & $\begin{array}{c}1.00 \\
(-1.64)\end{array}$ & $\begin{array}{c}1.00 \\
(-1.98)^{*}\end{array}$ & $\begin{array}{c}1.00 \\
(-5.98)^{* * *}\end{array}$ & $\begin{array}{c}1.00 \\
(-2.99)^{* *}\end{array}$ & $\begin{array}{c}1.00 \\
(-3.16)^{* *}\end{array}$ & $\begin{array}{c}1.00 \\
(1.56)\end{array}$ & $\begin{array}{c}1.00 \\
(-2.44)^{*}\end{array}$ & $\begin{array}{c}1.00 \\
(-4.86)^{* * *}\end{array}$ & $\begin{array}{c}1.00 \\
(-3.81)^{* * * *}\end{array}$ & $\begin{array}{c}1.00 \\
(-1.92)\end{array}$ & $\begin{array}{c}1.00 \\
(-2.57)^{*}\end{array}$ & $\begin{array}{c}1.00 \\
(-2.53)^{*}\end{array}$ \\
\hline IMD percentile quart. & $\begin{array}{c}1.00 \\
(5.24)^{* * * *}\end{array}$ & $\begin{array}{c}1.00 \\
(-0.22)\end{array}$ & $\begin{array}{c}1.00 \\
(1.28)\end{array}$ & $\begin{array}{c}1.00 \\
(1.92)\end{array}$ & $\begin{array}{c}1.00 \\
(4.93)^{* * * *}\end{array}$ & $\begin{array}{c}1.00 \\
(2.86)^{* *}\end{array}$ & $\begin{array}{c}1.00 \\
(3.11)^{* *}\end{array}$ & $\begin{array}{c}1.00 \\
(-1.55)\end{array}$ & $\begin{array}{c}1.00 \\
(2.16)^{*}\end{array}$ & $\begin{array}{c}1.00 \\
(4.37)^{* * *}\end{array}$ & $\begin{array}{c}1.00 \\
(3.29)^{* * * *}\end{array}$ & $\begin{array}{c}1.00 \\
(1.38)\end{array}$ & $\begin{array}{c}1.00 \\
(2.40)^{*}\end{array}$ & $\begin{array}{c}1.00 \\
(2.43)^{*}\end{array}$ \\
\hline alpha & 0.004 & 0.001 & 0.009 & 0.000 & 0.005 & 0.020 & 0.000 & 0.000 & 0.014 & 0.001 & 0.004 & 0.003 & 0.000 & 0.000 \\
\hline Number of charities & 38,504 & 5,355 & 1,891 & 864 & 30,394 & 1,467 & 3,580 & 927 & 2,276 & 5,544 & 7,088 & 2,839 & 959 & 1,904 \\
\hline Likelihood ratio chisq & 145.07 & 245.58 & 105.75 & 81.21 & 91.11 & 21.41 & 177.60 & 37.34 & 26.18 & 99.51 & 67.14 & 153.09 & 30.07 & 36.29 \\
\hline df & 3 & 4 & 4 & 4 & 3 & 4 & 4 & 4 & 4 & 4 & 4 & 4 & 4 & 4 \\
\hline
\end{tabular}

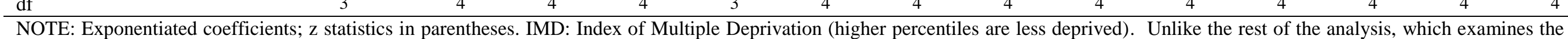

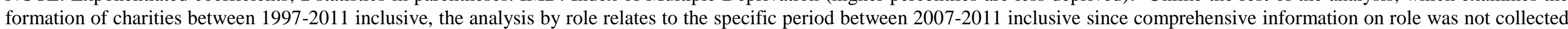

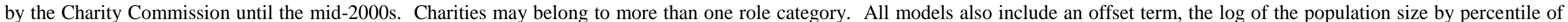
the IMD distribution, whose coefficient is constrained to be 1 .

${ }^{*} p<0.05,{ }^{* *} p<0.01,{ }^{* * *} p<0.001$ 
TABLE 8 The rate of foundation of charitable organizations and neighborhood deprivation: results from negative binomial models (Models B15-B23)

\begin{tabular}{|c|c|c|c|c|c|c|c|c|c|}
\hline \multirow{3}{*}{ Model No. } & \multicolumn{9}{|c|}{ 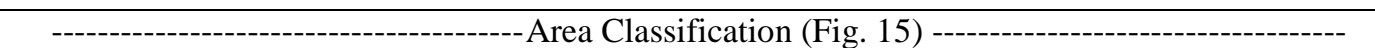 } \\
\hline & B15 & B16 & B17 & B18 & B19 & B20 & B21 & B22 & B23 \\
\hline & 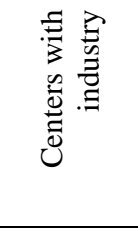 & 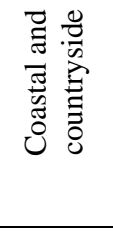 & 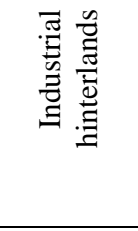 & 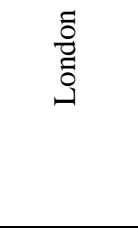 & 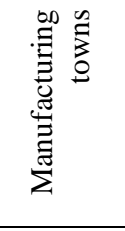 & 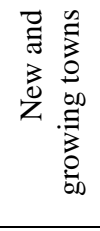 & 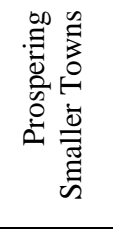 & 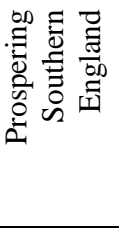 & 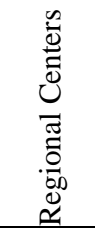 \\
\hline IMD percentile & $\begin{array}{c}0.95 \\
(-5.16)^{* * *}\end{array}$ & $\begin{array}{c}1.01 \\
(1.61)\end{array}$ & $\begin{array}{c}0.97 \\
(-3.35)^{* * * *}\end{array}$ & $\begin{array}{c}0.97 \\
(-3.42)^{* * * *}\end{array}$ & $\begin{array}{c}0.97 \\
(-2.77)^{* *}\end{array}$ & $\begin{array}{c}0.99 \\
(-0.95)\end{array}$ & $\begin{array}{c}1.01 \\
(1.98)^{*}\end{array}$ & $\begin{array}{c}1.00 \\
(0.01)\end{array}$ & $\begin{array}{c}0.98 \\
(-1.91)\end{array}$ \\
\hline IMD percentile sq. & $\begin{array}{c}1.00 \\
(4.86)^{* * *}\end{array}$ & $\begin{array}{c}1.00 \\
(-0.28)\end{array}$ & $\begin{array}{c}1.00 \\
(2.95)^{* *}\end{array}$ & $\begin{array}{c}1.00 \\
(3.64)^{* * * *}\end{array}$ & $\begin{array}{c}1.00 \\
(2.63)^{* * *}\end{array}$ & $\begin{array}{c}1.00 \\
(0.15)\end{array}$ & $\begin{array}{c}1.00 \\
(-0.22)\end{array}$ & $\begin{array}{c}1.00 \\
(0.73)\end{array}$ & $\begin{array}{c}1.00 \\
(0.94)\end{array}$ \\
\hline IMD percentile cub. & $\begin{array}{c}1.00 \\
(-4.28)^{* * * *}\end{array}$ & $\begin{array}{c}1.00 \\
(-0.34)\end{array}$ & $\begin{array}{c}1.00 \\
(-2.33)^{*}\end{array}$ & $\begin{array}{c}1.00 \\
(-3.17)^{* *}\end{array}$ & $\begin{array}{c}1.00 \\
(-2.24)^{*}\end{array}$ & $\begin{array}{c}1.00 \\
(0.45)\end{array}$ & $\begin{array}{c}1.00 \\
(-0.78)\end{array}$ & $\begin{array}{c}1.00 \\
(-1.13)\end{array}$ & $\begin{array}{c}1.00 \\
(-0.13)\end{array}$ \\
\hline alpha & 0.071 & 0.004 & 0.018 & 0.015 & 0.019 & 0.016 & 0.004 & 0.004 & 0.031 \\
\hline Number of charities & 3,435 & 4,413 & 2,011 & 4,736 & 2,272 & 1,777 & 11,696 & 4,562 & 3,100 \\
\hline Likelihood ratio chisq & 30.09 & 38.01 & 22.01 & 51.45 & 15.26 & 13.62 & 70.35 & 50.80 & 20.03 \\
\hline df & 3 & 3 & 3 & 3 & 3 & 3 & 3 & 3 & 3 \\
\hline
\end{tabular}

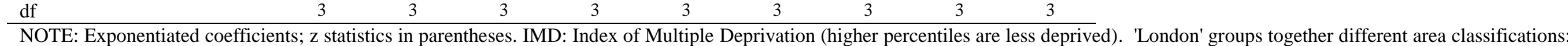

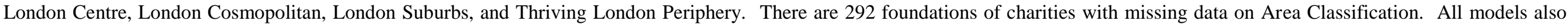
include an offset term, the log of the population size by percentile of the IMD distribution, whose coefficient is constrained to be 1 .

${ }^{*} p<0.05,{ }^{* *} p<0.01,{ }^{* * *} p<0.001$ 
TABLE 9 The rate of dissolution of charitable organizations and neighborhood deprivation: results from piecewise exponential survival models (Models C1-C3)

Neighborhood context:

IMD percentile

IMD percentile sq.

Process time: age [Ref:0-4]

$5-9$

$10-19$

$20+$

Size: [Ref:0-10k]

$10 \mathrm{k}-100 \mathrm{k}$

$100 \mathrm{k}+$

Form: [Ref: Unincorporated]

Incorporated

Type of organization: [Ref: Other]

PTA

$\begin{array}{ccc}0.99 & 0.99 & 0.99 \\ (-9.88)^{* * * *} & (-16.68)^{* * *} & (-15.56)^{* * * *} \\ 1.00 & 1.00 & 1.00 \\ (1.96) & (7.90)^{* * *} & (8.86)^{* * *}\end{array}$

\section{$\begin{array}{lll}1.53 & 1.50 & 1.47\end{array}$}

$(20.12)^{* * *} \quad(19.20)^{\text {*** }} \quad(18.45)^{* * *}$

$\begin{array}{rrr}1.65 & 1.62 & 1.60\end{array}$

$(25.29)^{* * *} \quad(24.30)^{* * *} \quad(23.62)^{* * * *}$

$\begin{array}{rrr}1.39 & 1.26 & 1.24\end{array}$

$(17.60)^{* * *} \quad(12.00)^{* * *} \quad(11.22)^{* * *}$

$0.46 \quad 0.42$

$(-59.10)^{* * *} \quad(-61.58)^{* * *}$

$0.48 \quad 0.46$

$(-31.15)^{* * *} \quad(-32.97)^{* * *}$

$1.05 \quad 1.05$

$(2.18)^{*} \quad(2.01)^{*}$

Preschool

Youth club

0.84

$(-1.70)$

IMD percentile X Type of organization:

PTA

Preschool

Youth club

IMD percentile sq. X Type of organization:

PTA

Preschool

Youth club

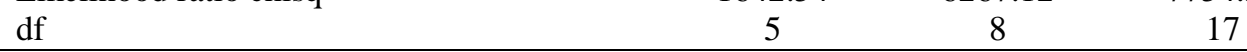

NOTE: Exponentiated coefficients; $z$ statistics in parentheses. IMD: Index of Multiple Deprivation (higher percentiles are less deprived); Age: years since foundation; Size: median annual income (£). All models also include an offset term, the log of the number of years of exposure to dissolution, whose coefficient is constrained to be 1 .

${ }^{*} p<0.05,{ }^{* *} p<0.01,{ }^{* * *} p<0.001$ 
TABLE 10 The rate of dissolution of charitable organizations and neighborhood deprivation: results from piecewise exponential survival models (Models C4C12)

\begin{tabular}{|c|c|c|c|c|c|c|c|c|c|}
\hline Model No. & $\begin{array}{c}\mathrm{C} 4 \\
\text { Makes grants } \\
\text { to } \\
\text { individuals }\end{array}$ & $\begin{array}{c}\text { C5 } \\
\text { Makes grants } \\
\text { to } \\
\text { organizations }\end{array}$ & $\begin{array}{c}\text { C6 } \\
\text { Provides } \\
\text { other finance }\end{array}$ & $\begin{array}{c}\text { C7 } \\
\text { Provides } \\
\text { human } \\
\text { resources }\end{array}$ & $\begin{array}{c}\text { C8 } \\
\text { Provides } \\
\text { buildings/ } \\
\text { facilities/ } \\
\text { open space } \\
\end{array}$ & $\begin{array}{c}\text { C9 } \\
\text { Provides } \\
\text { services }\end{array}$ & $\begin{array}{c}\text { C10 } \\
\text { Provides } \\
\text { advocacy/ } \\
\text { advice/ } \\
\text { information } \\
\end{array}$ & $\begin{array}{c}\text { C11 } \\
\text { Acts as an } \\
\text { umbrella or } \\
\text { resource } \\
\text { body }\end{array}$ & $\begin{array}{c}\text { C12 } \\
\text { Other or } \\
\text { none of these }\end{array}$ \\
\hline \multicolumn{10}{|l|}{ Neighborhood context: } \\
\hline IMD percentile & $\begin{array}{c}0.98 \\
(-5.93)^{* * * *}\end{array}$ & $\begin{array}{c}0.98 \\
(-5.97)^{* * * *}\end{array}$ & $\begin{array}{c}0.99 \\
(-1.76)\end{array}$ & $\begin{array}{c}1.00 \\
(-1.61)\end{array}$ & $\begin{array}{c}0.99 \\
(-4.91)^{* * * *}\end{array}$ & $\begin{array}{c}1.00 \\
(-0.09)\end{array}$ & $\begin{array}{c}1.00 \\
(0.29)\end{array}$ & $\begin{array}{c}1.00 \\
(-0.38)\end{array}$ & $\begin{array}{c}0.99 \\
(-1.59)\end{array}$ \\
\hline IMD percentile sq. & $\begin{array}{c}1.00 \\
(3.77)^{* * *}\end{array}$ & $\begin{array}{c}1.00 \\
(3.51)^{* * * *}\end{array}$ & $\begin{array}{c}1.00 \\
(0.31)\end{array}$ & $\begin{array}{c}1.00 \\
(0.16)\end{array}$ & $\begin{array}{c}1.00 \\
(2.61)^{* *}\end{array}$ & $\begin{array}{c}1.00 \\
(-1.37)\end{array}$ & $\begin{array}{c}1.00 \\
(-0.79)\end{array}$ & $\begin{array}{c}1.00 \\
(-0.60)\end{array}$ & $\begin{array}{c}1.00 \\
(1.23)\end{array}$ \\
\hline \multicolumn{10}{|c|}{ Process time: age [Ref:0-4] } \\
\hline $5-9$ & $\begin{array}{c}1.40 \\
(2.13)^{*}\end{array}$ & $\begin{array}{c}1.71 \\
(5.11)^{* * *}\end{array}$ & $\begin{array}{c}2.73 \\
(4.22)^{* * *}\end{array}$ & $\begin{array}{c}1.72 \\
(7.03)^{* * *}\end{array}$ & $\begin{array}{c}1.80 \\
(7.09)^{* * *}\end{array}$ & ${ }^{1.80}(9.36)^{* * *}$ & $\begin{array}{c}1.68 \\
(6.71)^{* * *}\end{array}$ & $\begin{array}{c}2.04 \\
(5.56)^{* * *}\end{array}$ & $\begin{array}{c}1.79 \\
(4.41)^{* * *}\end{array}$ \\
\hline $10-19$ & $\begin{array}{c}2.13 \\
(5.63)^{* * *}\end{array}$ & $\begin{array}{c}1.98 \\
(7.22)^{* * * *}\end{array}$ & $\begin{array}{c}2.28 \\
(3.67)^{* * *}\end{array}$ & $\begin{array}{c}1.55 \\
(6.10)^{* * *}\end{array}$ & $\begin{array}{c}1.21 \\
(2.32)^{*}\end{array}$ & $\begin{array}{c}1.57 \\
(7.89)^{* * *}\end{array}$ & $\begin{array}{c}1.57 \\
(6.11)^{* * * *}\end{array}$ & $\begin{array}{c}1.72 \\
(4.32)^{* * *}\end{array}$ & $\begin{array}{c}2.45 \\
(7.65)^{* * *}\end{array}$ \\
\hline $20+$ & $\begin{array}{c}1.61 \\
(3.66)^{* * *}\end{array}$ & $\begin{array}{c}1.65 \\
(5.42)^{* * * *}\end{array}$ & $\begin{array}{c}2.65 \\
(4.41)^{* * *}\end{array}$ & $\begin{array}{c}1.03 \\
(0.45)\end{array}$ & $\begin{array}{c}0.81 \\
(-2.74)^{* *}\end{array}$ & $\begin{array}{c}1.03 \\
(0.55)\end{array}$ & $\begin{array}{c}1.02 \\
(0.20)\end{array}$ & $\begin{array}{c}1.15 \\
(1.09)\end{array}$ & $\begin{array}{c}1.53 \\
(3.53)^{* * *}\end{array}$ \\
\hline \multicolumn{10}{|l|}{ Size: [Ref:0-10k] } \\
\hline $10 \mathrm{k}-100 \mathrm{k}$ & $\begin{array}{c}0.35 \\
(-15.39)^{* * *}\end{array}$ & $\begin{array}{c}0.37 \\
(-18.60)^{* * *}\end{array}$ & $\begin{array}{c}0.40 \\
(-6.07)^{* * *}\end{array}$ & $\begin{array}{c}0.54 \\
(-14.79)^{* * *}\end{array}$ & $\begin{array}{c}0.67 \\
(-7.82)^{* * *}\end{array}$ & $\begin{array}{c}0.65 \\
(-10.74)^{* * *}\end{array}$ & $\begin{array}{c}0.63 \\
(-8.74)^{* * *}\end{array}$ & $\begin{array}{c}0.62 \\
(-5.83)^{* * *}\end{array}$ & $\begin{array}{c}0.20 \\
(-18.16)^{* * *}\end{array}$ \\
\hline $100 \mathrm{k}+$ & $\begin{array}{c}0.30 \\
(-9.45)^{* * *}\end{array}$ & $\begin{array}{c}0.33 \\
(-11.24)^{* * *}\end{array}$ & $\begin{array}{c}0.70 \\
(-1.31)\end{array}$ & $\begin{array}{c}0.72 \\
(-5.25)^{* * *}\end{array}$ & $\begin{array}{c}0.81 \\
(-3.15)^{* *}\end{array}$ & $\begin{array}{c}0.72 \\
(-6.11)^{* * *}\end{array}$ & $\begin{array}{c}0.80 \\
(-3.37)^{* * *}\end{array}$ & $\begin{array}{c}0.76 \\
(-2.57)^{*}\end{array}$ & $\begin{array}{c}0.24 \\
(-8.25)^{* * *}\end{array}$ \\
\hline \multicolumn{10}{|c|}{ Form: [Ref:Unincorporated] } \\
\hline Incorporated & $\begin{array}{c}1.38 \\
(2.62)^{* *}\end{array}$ & $\begin{array}{c}1.58 \\
(4.75)^{* * *}\end{array}$ & $\begin{array}{c}0.67 \\
(-1.11)\end{array}$ & $\begin{array}{c}0.87 \\
(-2.29)^{*}\end{array}$ & $\begin{array}{c}1.36 \\
(4.92)^{* * *}\end{array}$ & $\begin{array}{c}0.93 \\
(-1.39)\end{array}$ & $\begin{array}{c}0.72 \\
(-5.53)^{* * *}\end{array}$ & $\begin{array}{c}0.89 \\
(-1.19)\end{array}$ & $\begin{array}{c}0.66 \\
(-2.37)^{*} \\
\end{array}$ \\
\hline Number of charities & 1,335 & 3,549 & 794 & 2,392 & 5,248 & 6,452 & 2,664 & 1,010 & 1,855 \\
\hline Likelihood ratio chisq & 512.36 & 706.36 & 114.62 & 407.68 & 432.66 & 330.25 & 246.16 & 109.47 & 794.18 \\
\hline df & 8 & 8 & 8 & 8 & 8 & 8 & 8 & 8 & 8 \\
\hline
\end{tabular}

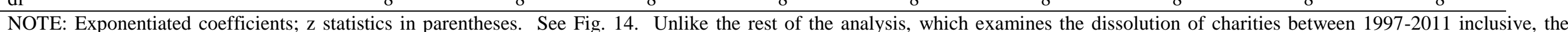

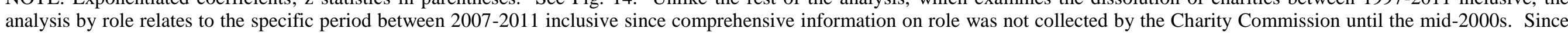

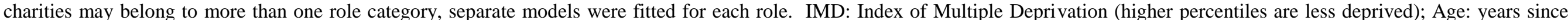

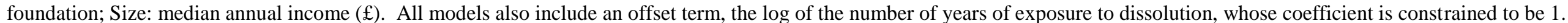

${ }^{*} p<0.05,{ }^{* *} p<0.01,{ }^{* * *} p<0.001$ 
TABLE 11 The rate of dissolution of charitable organizations and neighborhood deprivation: results from piecewise exponential survival model (Model C13)

Model No. C13

(Fig. 16)

Neighborhood context:

IMD percentile

IMD percentile sq.

Process time: age [Ref:0-4]

5-9

$10-19$

$20+$

Size: [Ref:0-10k]

$10 \mathrm{k}-100 \mathrm{k}$

$100 \mathrm{k}+$

Form: [Ref: Unincorporated] Incorporated

Area Classification: [Ref: Centers with Industry]

Coastal and Countryside

Industrial hinterlands

London

Manufacturing towns

New and growing towns

Prospering Smaller Towns

Prospering Southern England

Regional Centers

IMD percentile X Area Classification:

Coastal and Countryside

Industrial hinterlands

London

Manufacturing towns

New and growing towns

Prospering Smaller Towns

Prospering Southern England

Regional Centers

IMD percentile sq. X Area Classification:

Coastal and Countryside

Industrial hinterlands

London

Manufacturing towns

New and growing towns

Prospering Smaller Towns

Prospering Southern England

Regional Centers

Number of charities

Likelihood ratio chisq

df

$1.00 \quad(0.54)$

$1.00 \quad(-2.09)^{*}$

$1.49 \quad(18.89)^{* * *}$

$1.63 \quad(24.46)^{* * * *}$

$1.26 \quad(12.12)^{* * * *}$

$0.44 \quad(-60.48)^{* * * *}$

$0.46 \quad(-32.43)^{* * *}$

$1.04 \quad(1.62)$

$1.35 \quad(3.95)^{* * *}$

$0.94 \quad(-0.96)$

$1.11 \quad(1.61)$

$1.11 \quad(1.47)$

$1.19 \quad(1.87)$

$1.26 \quad(3.30)^{* * * *}$

$1.60 \quad(2.13)^{*}$

$1.13 \quad(1.96)^{*}$

$0.97 \quad(-7.66)^{* * *}$

$1.00 \quad(-0.84)$

$1.00 \quad(-1.27)$

$0.99 \quad(-2.70)^{* *}$

$0.99 \quad(-2.16)^{*}$

$0.98 \quad(-6.59)^{\text {**** }}$

$0.98 \quad(-3.50)^{\text {*** }}$

$0.99 \quad(-1.65)$

$1.00 \quad(6.68)^{* * *}$

$1.00 \quad(0.66)$

$1.00 \quad(0.78)$

$1.00 \quad$ (1.98)

$1.00 \quad(1.39)$

$1.00 \quad(5.38)^{* * *}$

$1.00 \quad(3.43)^{* * *}$

1.00

126,253

6794.51

32

NOTE: Exponentiated coefficients; z statistics in parentheses. IMD: Index of Multiple Deprivation (higher percentiles are less deprived); Age: years since foundation; Size: median annual income (£); 'London' groups together different area classifications: London Centre, London Cosmopolitan, London Suburbs, and Thriving London Periphery. 1139 charities, and associated 11,034 charity years and 440 dissolutions, are missing data on Area Classification. The model also includes an offset term, the log of the number of years of exposure to dissolution, whose coefficient is constrained to be 1 .

${ }^{*} p<0.05,{ }^{* *} p<0.01,{ }^{* * *} p<0.001$ 
Centers with

industry

Coastal and

Countryside

Industrial

hinterlands

London

Manufacturing towns

New and growing towns

Smaller Towns

Prospering

Southern

England

Regional

Centers
Prospering

Barking and Dagenham, Birmingham, Blackburn with Darwen, Bolton, Bradford, Burnley, Calderdale, Coventry, Derby, Hyndburn, Kirklees, Leicester, Manchester, Nottingham, Oldham, Pendle, Preston, Rochdale, Sandwell, Walsall, Wolverhampton.

Allerdale, Arun, Blackpool, Carlisle, Chichester, Christchurch, Cornwall, Craven, Dover, East Devon, East Lindsey, Eden, Fylde, Great Yarmouth, Isle of Wight, North Devon, North Norfolk, Purbeck, Rother, Ryedale, Scarborough, Shepway, South Hams, South Lakeland, Teignbridge, Tendring, Thanet, Torbay, Torridge, Waveney, West Devon,West Dorset,West Somerset, Weymouth and Portland, Wyre.

Barrow-in-Furness, Copeland, County Durham, Darlington, Gateshead, Halton, Hartlepool, Kingston upon Hull, Knowsley, Middlesbrough, North Tyneside, Redcar and Cleveland, Sefton, South Tyneside, St Helens, Stoke-on-Trent, Sunderland, Tameside, Wirral.

Barnet, Brent, Bromley, Cambridge, Camden, Croydon, Ealing, Enfield, Greenwich, Hackney, Hammersmith and Fulham, Haringey, Harrow, Hillingdon, Hounslow, Islington, Kensington and Chelsea, Kingston upon Thames, Lambeth, Lewisham, Luton, Merton, Newham, Oxford, Reading, Redbridge, Richmond upon Thames, Slough, Southwark, Sutton, Tower Hamlets, Waltham Forest, Wandsworth, Watford, Westminster.

Amber Valley, Ashfield, Barnsley, Bassetlaw, Bolsover, Cannock Chase, Chesterfield, Corby, Doncaster, Dudley, East Staffordshire, Erewash, Havant, Mansfield, Newcastleunder-Lyme, North East Derbyshire, North East Lincolnshire, North Lincolnshire, Nuneaton and Bedworth, Redditch, Rossendale, Rotherham, Stockton-on-Tees, Swale, Tamworth, Telford and Wrekin, Wakefield, Wigan.

Basildon, Bedford, Bexley, Broxbourne, Crawley, Dartford, Forest Heath, Gloucester, Gosport, Gravesham, Harlow, Havering, Ipswich, Medway, Milton Keynes, Northampton, Peterborough, Rushmoor, Stevenage, Swindon, Thurrock, Wellingborough, Worcester.

Adur, Ashford, Babergh, Bath and North East Somerset, Blaby, Boston, Braintree, Breckland, Broadland, Bromsgrove, Broxtowe, Bury, Canterbury, Castle Point, Central Bedfordshire, Charnwood, Cheltenham, Cherwell, Cheshire East, Cheshire West and Chester, Chorley, Colchester, Cotswold, Daventry, Derbyshire Dales, East Cambridgeshire, East Dorset, East Northamptonshire, East Riding of Yorkshire, Eastleigh, Fareham, Fenland, Forest of Dean, Gedling, Hambleton, Harborough, Harrogate, Herefordshire, High Peak, Hinckley and Bosworth, Huntingdonshire, Kettering, King's Lynn and West Norfolk, Lewes, Lichfield, Maidstone, Maldon, Malvern Hills, Melton, Mendip, Mid Devon, Mid Suffolk, New Forest, Newark and Sherwood, North Dorset, North Kesteven, North Somerset, North Warwickshire, North West Leicestershire, Northumberland, Oadby and Wigston, Poole, Ribble Valley, Richmondshire, Rugby, Rushcliffe, Rutland, Sedgemoor, Selby, Shropshire, Solihull, South Derbyshire, South Gloucestershire, South Holland, South Kesteven, South Norfolk, South Northamptonshire, South Ribble, South Somerset, South Staffordshire, St Edmundsbury, Stafford, Staffordshire Moorlands, Stockport, Stratford-on-Avon, Stroud, Suffolk Coastal, Taunton Deane, Tewkesbury, Trafford, Warrington, Warwick, Wealden, West Lancashire, West Lindsey, West Oxfordshire, Wiltshire, Wychavon, Wyre Forest, York.

Aylesbury Vale, Basingstoke and Deane, Bracknell Forest, Brentwood, Chelmsford, Chiltern, Dacorum, East Hampshire, East Hertfordshire, Elmbridge, Epping Forest, Epsom and Ewell, Guildford, Hart, Hertsmere, Horsham, Mid Sussex, Mole Valley, North Hertfordshire, Reigate and Banstead, Rochford, Runnymede, Sevenoaks, South Bucks, South Cambridgeshire, South Oxfordshire, Spelthorne, Surrey Heath, Tandridge, Test Valley, Three Rivers, Tonbridge and Malling, Tunbridge Wells, Uttlesford, Vale of White Horse, Waverley, West Berkshire, Winchester, Windsor and Maidenhead, Woking (borough), Wokingham, Wycombe.

Bournemouth, Brighton and Hove, Bristol, Eastbourne, Exeter, Hastings, Lancaster, Leeds, Lincoln, Liverpool, Newcastle upon Tyne, Norwich, Plymouth, Portsmouth, Salford, Sheffield, Southampton, Southend-on-Sea, Worthing.

NOTE. 'London' groups together different area classifications: London Centre, London Cosmopolitan, London Suburbs, and Thriving London Periphery. 
TABLE A2 Using area of operation as a measure of charity location: the density of charitable organizations and local authority deprivation - results from negative binomial models (Models D1-D14)

\begin{tabular}{|c|c|c|c|c|c|c|c|c|c|c|c|c|c|c|}
\hline \multirow{3}{*}{ Model No. } & \multirow{3}{*}{$\begin{array}{c}\text { Overall (A3) } \\
\text { D1 } \\
\overline{\bar{\pi}} \\
\text { ठँ }\end{array}$} & \multicolumn{4}{|c|}{-------Type of organization (Fig A4)----- } & \multicolumn{9}{|c|}{ 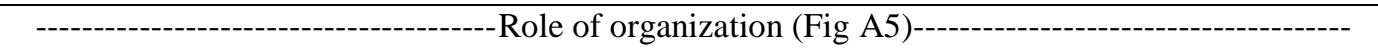 } \\
\hline & & D2 & D3 & D4 & D5 & D6 & D7 & D8 & D9 & D10 & D11 & D12 & D13 & D14 \\
\hline & & 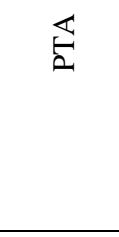 & 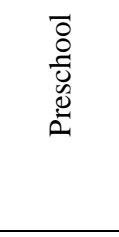 & 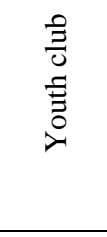 & $\frac{\bar{\Phi}}{\overline{0}}$ & 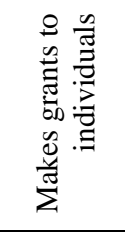 & 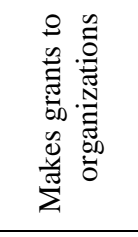 & 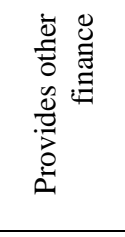 & 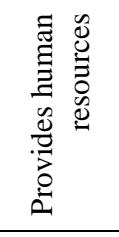 & 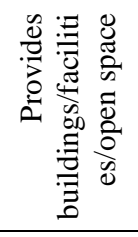 & 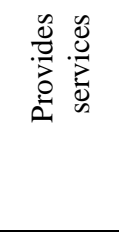 & 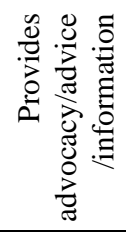 & 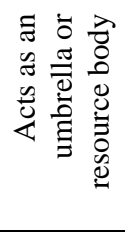 & 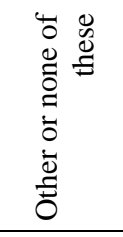 \\
\hline IMD percentile & $\begin{array}{c}0.98 \\
(-1.64)\end{array}$ & $\begin{array}{c}1.00 \\
(-0.14)\end{array}$ & $\begin{array}{c}0.98 \\
(-0.83)\end{array}$ & $\begin{array}{c}1.02 \\
(1.16)\end{array}$ & $\begin{array}{c}0.97 \\
(-1.87)\end{array}$ & $\begin{array}{c}0.97 \\
(-1.88)\end{array}$ & $\begin{array}{c}0.98 \\
(-1.83)\end{array}$ & $\begin{array}{c}0.98 \\
(-1.06)\end{array}$ & $\begin{array}{c}0.98 \\
(-1.27)\end{array}$ & $\begin{array}{c}0.98 \\
(-1.34)\end{array}$ & $\begin{array}{c}0.98 \\
(-1.90)\end{array}$ & $\begin{array}{c}0.98 \\
(-2.09)^{*}\end{array}$ & $\begin{array}{c}0.98 \\
(-1.40)\end{array}$ & $\begin{array}{c}0.98 \\
(-1.67)\end{array}$ \\
\hline IMD percentile sq. & $\begin{array}{c}1.00 \\
(2.87)^{* *}\end{array}$ & $\begin{array}{c}1.00 \\
(1.58)\end{array}$ & $\begin{array}{c}1.00 \\
(1.97)^{*}\end{array}$ & $\begin{array}{c}1.00 \\
(0.08)\end{array}$ & $\begin{array}{c}1.00 \\
(2.97)^{* *}\end{array}$ & $\begin{array}{c}1.00 \\
(3.07)^{* * *}\end{array}$ & $\begin{array}{c}1.00 \\
(3.25)^{* *}\end{array}$ & $\begin{array}{c}1.00 \\
(2.02)^{*}\end{array}$ & $\begin{array}{c}1.00 \\
(2.19)^{*}\end{array}$ & $\begin{array}{c}1.00 \\
(2.56)^{*}\end{array}$ & $\begin{array}{c}1.00 \\
(2.51)^{*}\end{array}$ & $\begin{array}{c}1.00 \\
(2.29)^{*}\end{array}$ & $\begin{array}{c}1.00 \\
(2.09)^{*}\end{array}$ & $\begin{array}{c}1.00 \\
(2.84)^{* * *}\end{array}$ \\
\hline IMD percentile cub. & $\begin{array}{c}1.00 \\
(-2.94)^{* * *}\end{array}$ & $\begin{array}{c}1.00 \\
(-1.59)\end{array}$ & $\begin{array}{c}1.00 \\
(-2.13)^{*}\end{array}$ & $\begin{array}{c}1.00 \\
(-0.29)\end{array}$ & $\begin{array}{c}1.00 \\
(-3.05)^{\text {** }}\end{array}$ & $\begin{array}{c}1.00 \\
(-3.17)^{\text {** }}\end{array}$ & $\begin{array}{c}1.00 \\
(-3.26)^{* *}\end{array}$ & $\begin{array}{c}1.00 \\
(-1.98)^{*}\end{array}$ & $\begin{array}{c}1.00 \\
(-2.23)^{*}\end{array}$ & $\begin{array}{c}1.00 \\
(-2.71)^{* *}\end{array}$ & $\begin{array}{c}1.00 \\
(-2.43)^{*}\end{array}$ & $\begin{array}{c}1.00 \\
(-2.26)^{*}\end{array}$ & $\begin{array}{c}1.00 \\
(-2.15)^{*}\end{array}$ & $\begin{array}{c}1.00 \\
(-2.94)^{* *}\end{array}$ \\
\hline alpha & 0.139 & 0.130 & 0.327 & 0.126 & 0.156 & 0.224 & 0.134 & 0.121 & 0.121 & 0.154 & 0.105 & 0.095 & 0.129 & 0.106 \\
\hline Likelihood ratio chisq & 73.26 & 107.87 & 61.08 & 64.40 & 59.86 & 65.30 & 98.67 & 64.18 & 49.22 & 63.19 & 34.37 & 6.26 & 27.61 & 63.57 \\
\hline df & 3 & 3 & 3 & 3 & 3 & 3 & 3 & 3 & 3 & 3 & 3 & 3 & 3 & 3 \\
\hline
\end{tabular}

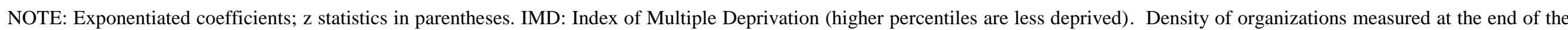

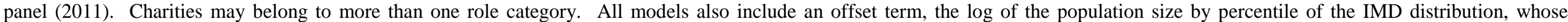
coefficient is constrained to be 1 .

${ }^{*} p<0.05,{ }^{* * *} p<0.01,{ }^{* * *} p<0.001$ 
TABLE A3 Using area of operation as a measure of charity location: the rate of foundation of charitable organizations and local authority deprivation - results from negative binomial models (Models E1-E14)

\begin{tabular}{|c|c|c|c|c|c|c|c|c|c|c|c|c|c|c|}
\hline \multirow{3}{*}{ Model No. } & \multirow{3}{*}{$\begin{array}{c}\text { Overall (A6) } \\
\text { E1 } \\
\overline{\bar{\pi}} \\
\text { ठ } \\
\text { ठ }\end{array}$} & \multicolumn{4}{|c|}{-------Type of organization (Fig A8)------ } & \multicolumn{9}{|c|}{ 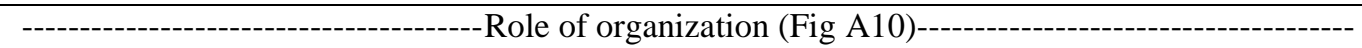 } \\
\hline & & $\mathrm{E} 2$ & E3 & $\mathrm{E} 4$ & E5 & E6 & E7 & E8 & E9 & E10 & E11 & E12 & E13 & E14 \\
\hline & & 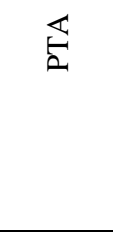 & 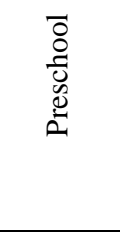 & 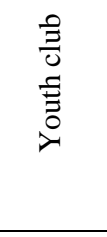 & 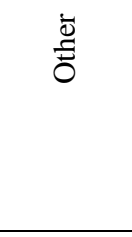 & 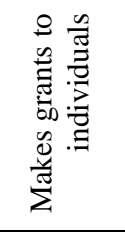 & 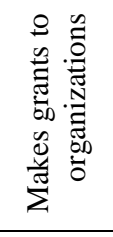 & 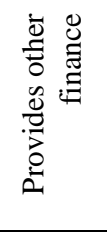 & 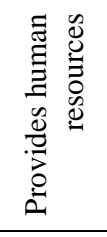 & 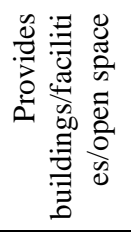 & 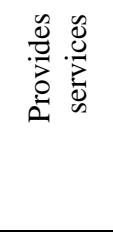 & 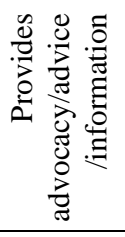 & 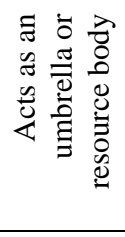 & 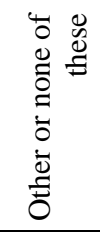 \\
\hline IMD percentile & $\begin{array}{c}0.97 \\
(-2.21)^{*}\end{array}$ & $\begin{array}{c}1.00 \\
(-0.06)\end{array}$ & $\begin{array}{c}0.98 \\
(-0.88)\end{array}$ & $\begin{array}{c}1.00 \\
(0.02)\end{array}$ & $\begin{array}{c}0.97 \\
(-2.39)^{*}\end{array}$ & $\begin{array}{c}0.96 \\
(-2.33)^{*}\end{array}$ & $\begin{array}{c}0.98 \\
(-1.17)\end{array}$ & $\begin{array}{c}1.00 \\
(-0.28)\end{array}$ & $\begin{array}{c}0.98 \\
(-1.57)\end{array}$ & $\begin{array}{c}1.00 \\
(-0.36)\end{array}$ & $\begin{array}{c}0.98 \\
(-1.83)\end{array}$ & $\begin{array}{c}0.97 \\
(-2.39)^{*}\end{array}$ & $\begin{array}{c}0.98 \\
(-1.35)\end{array}$ & $\begin{array}{c}0.98 \\
(-1.66)\end{array}$ \\
\hline IMD percentile sq. & $\begin{array}{c}1.00 \\
(2.93)^{* *}\end{array}$ & $\begin{array}{c}1.00 \\
(1.03)\end{array}$ & $\begin{array}{l}1.00 \\
(1.83)\end{array}$ & $\begin{array}{c}1.00 \\
(1.04)\end{array}$ & $\begin{array}{c}1.00 \\
(2.98)^{* *}\end{array}$ & $\begin{array}{c}1.00 \\
(2.53)^{*}\end{array}$ & $\begin{array}{c}1.00 \\
(1.68)\end{array}$ & $\begin{array}{c}1.00 \\
(0.30)\end{array}$ & $\begin{array}{c}1.00 \\
(1.51)\end{array}$ & $\begin{array}{c}1.00 \\
(0.66)\end{array}$ & $\begin{array}{c}1.00 \\
(1.63)\end{array}$ & $\begin{array}{c}1.00 \\
(1.67)\end{array}$ & $\begin{array}{c}1.00 \\
(1.48)\end{array}$ & $\begin{array}{c}1.00 \\
(1.85)\end{array}$ \\
\hline IMD percentile cub. & $\begin{array}{c}1.00 \\
(-2.84)^{* * *}\end{array}$ & $\begin{array}{c}1.00 \\
(-0.92)\end{array}$ & $\begin{array}{c}1.00 \\
(-1.98)^{*}\end{array}$ & $\begin{array}{c}1.00 \\
(-1.31)\end{array}$ & $\begin{array}{c}1.00 \\
(-2.91)^{* *}\end{array}$ & $\begin{array}{c}1.00 \\
(-2.34)^{*}\end{array}$ & $\begin{array}{c}1.00 \\
(-1.42)\end{array}$ & $\begin{array}{c}1.00 \\
(0.00)\end{array}$ & $\begin{array}{c}1.00 \\
(-1.24)\end{array}$ & $\begin{array}{c}1.00 \\
(-0.45)\end{array}$ & $\begin{array}{c}1.00 \\
(-1.22)\end{array}$ & $\begin{array}{c}1.00 \\
(-1.27)\end{array}$ & $\begin{array}{c}1.00 \\
(-1.42)\end{array}$ & $\begin{array}{c}1.00 \\
(-1.71)\end{array}$ \\
\hline alpha & 0.104 & 0.126 & 0.306 & 0.162 & 0.110 & 0.171 & 0.098 & 0.048 & 0.054 & 0.051 & 0.055 & 0.063 & 0.037 & 0.064 \\
\hline Likelihood ratio chisq & 46.46 & 81.48 & 41.16 & 40.05 & 32.44 & 16.52 & 49.67 & 18.70 & 9.39 & 27.95 & 14.92 & 13.69 & 4.75 & 11.42 \\
\hline df & 3 & 3 & 3 & 3 & 3 & 3 & 3 & 3 & 3 & 3 & 3 & 3 & 3 & 3 \\
\hline
\end{tabular}

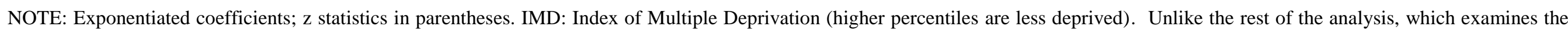

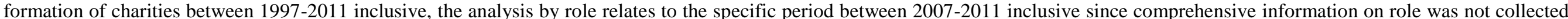

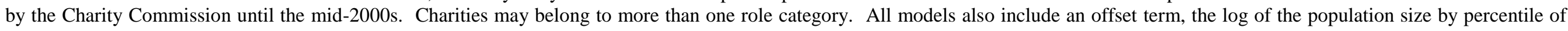
the IMD distribution, whose coefficient is constrained to be 1 .

${ }^{*} p<0.05,{ }^{* *} p<0.01,{ }^{* * *} p<0.001$ 
TABLE A4 Using area of operation as a measure of charity location: the rate of dissolution of charitable organizations and neighborhood deprivation - results from piecewise exponential survival models (Models F1-F3)

\begin{tabular}{|c|c|c|c|}
\hline Model No. & $\begin{array}{c}\text { F1 } \\
\text { (Fig. A7) }\end{array}$ & $\begin{array}{c}\text { F2 } \\
\text { (Fig. A7) }\end{array}$ & $\begin{array}{c}\text { F3 } \\
\text { (Fig. A9) }\end{array}$ \\
\hline \multicolumn{4}{|l|}{ Neighborhood context: } \\
\hline IMD percentile & $\begin{array}{c}1.00 \\
(-4.40)^{* * *}\end{array}$ & $\begin{array}{c}0.99 \\
(-8.14)^{* * *}\end{array}$ & $\begin{array}{c}0.99 \\
(-7.52)^{* * *}\end{array}$ \\
\hline IMD percentile sq. & $\begin{array}{c}1.00 \\
(-0.00)\end{array}$ & $(3.23)^{* *}$ & $(3.61)^{* * *}$ \\
\hline \multicolumn{4}{|c|}{ Process time: age [Ref:0-4] } \\
\hline $5-9$ & $\begin{array}{c}1.49 \\
(13.26)^{* * * *}\end{array}$ & $\begin{array}{c}1.47 \\
(12.76)^{* * *}\end{array}$ & $\begin{array}{c}1.45 \\
(12.27)^{* * * *}\end{array}$ \\
\hline $10-19$ & $\begin{array}{c}1.77 \\
(20.61)^{* * * *}\end{array}$ & $\begin{array}{c}1.74 \\
(19.98)^{* * *}\end{array}$ & $\begin{array}{c}1.69 \\
(18.74)^{* * * *}\end{array}$ \\
\hline $20+$ & $\begin{array}{c}1.29 \\
(9.41)^{* * * *}\end{array}$ & $\begin{array}{c}1.17 \\
(5.86)^{* * * *}\end{array}$ & $\begin{array}{c}1.14 \\
(4.61)^{* * *}\end{array}$ \\
\hline \multicolumn{4}{|l|}{ Size: [Ref:0-10k] } \\
\hline $10 \mathrm{k}-100 \mathrm{k}$ & & $\begin{array}{c}0.43 \\
(-49.09)^{* * *}\end{array}$ & $\begin{array}{c}0.41 \\
(-49.92)^{* * *}\end{array}$ \\
\hline $100 \mathrm{k}+$ & & $\begin{array}{c}0.51 \\
(-23.07)^{* * *}\end{array}$ & $\begin{array}{c}0.48 \\
(-24.60)^{* * * *}\end{array}$ \\
\hline \multicolumn{4}{|c|}{ Form: [Ref: Unincorporated] } \\
\hline Incorporated & & $\begin{array}{c}1.13 \\
(4.17)^{* * *}\end{array}$ & ${ }^{1.11}{ }^{* * * *}$ \\
\hline \multicolumn{4}{|c|}{ Type of organization: [Ref: Other] } \\
\hline PTA & & & $\begin{array}{c}1.02 \\
(0.17)\end{array}$ \\
\hline Preschool & & & $\begin{array}{c}1.34 \\
(2.43)^{*}\end{array}$ \\
\hline Youth club & & & $\begin{array}{c}0.89 \\
(-0.92)\end{array}$ \\
\hline \multicolumn{4}{|c|}{ IMD percentile $X$ Type of organization: } \\
\hline PTA & & & $\begin{array}{c}0.99 \\
(-1.46)\end{array}$ \\
\hline Preschool & & & $\begin{array}{c}1.01 \\
(1.50)\end{array}$ \\
\hline Youth club & & & $\begin{array}{c}0.99 \\
(-1.26)\end{array}$ \\
\hline \multicolumn{4}{|c|}{ IMD percentile sq. X Type of organization: } \\
\hline PTA & & & $\begin{array}{c}1.00 \\
(-0.11)\end{array}$ \\
\hline Preschool & & & $\begin{array}{c}1.00 \\
(-1.80)\end{array}$ \\
\hline Youth club & & & $\begin{array}{c}1.00 \\
(0.84)\end{array}$ \\
\hline $\begin{array}{l}\text { Likelihood ratio chisq } \\
\text { df }\end{array}$ & $\begin{array}{c}932.78 \\
5.00\end{array}$ & $\begin{array}{c}3910.57 \\
8.00\end{array}$ & $\begin{array}{c}4501.60 \\
17.00\end{array}$ \\
\hline
\end{tabular}

NOTE: Exponentiated coefficients; $\mathrm{z}$ statistics in parentheses. IMD: Index of Multiple Deprivation (higher percentiles are less deprived); Age: years since foundation; Size: median annual income (£). All models also include an offset term, the log of the number of years of exposure to dissolution, whose coefficient is constrained to be 1 .

${ }^{*} p<0.05,{ }^{* *} p<0.01,{ }^{* * *} p<0.001$ 
TABLE A5 Using area of operation as a measure of charity location: the rate of dissolution of charitable organizations and neighborhood deprivation - results from piecewise exponential survival models (Models F4-F12)

\begin{tabular}{|c|c|c|c|c|c|c|c|c|c|}
\hline Model No. & $\begin{array}{c}\mathrm{F} 4 \\
\text { Makes grants } \\
\text { to } \\
\text { individuals }\end{array}$ & $\begin{array}{c}\text { F5 } \\
\text { Makes grants } \\
\text { to } \\
\text { organizations }\end{array}$ & $\begin{array}{c}\text { F6 } \\
\text { Provides } \\
\text { other finance }\end{array}$ & $\begin{array}{c}\text { F7 } \\
\text { Provides } \\
\text { human } \\
\text { resources }\end{array}$ & $\begin{array}{c}\text { F8 } \\
\text { Provides } \\
\text { buildings/ } \\
\text { facilities/ } \\
\text { open space } \\
\end{array}$ & $\begin{array}{c}\text { F9 } \\
\text { Provides } \\
\text { services }\end{array}$ & $\begin{array}{c}\text { F10 } \\
\text { Provides } \\
\text { advocacy/ } \\
\text { advice/ } \\
\text { information } \\
\end{array}$ & $\begin{array}{c}\text { F11 } \\
\text { Acts as an } \\
\text { umbrella or } \\
\text { resource } \\
\text { body }\end{array}$ & $\begin{array}{c}\text { F12 } \\
\text { Other or } \\
\text { none of these }\end{array}$ \\
\hline \multicolumn{10}{|l|}{ Neighborhood context: } \\
\hline IMD percentile & $\begin{array}{c}0.99 \\
(-4.01)^{* * *}\end{array}$ & $\begin{array}{c}0.99 \\
(-3.59)^{* * *}\end{array}$ & $\begin{array}{c}0.98 \\
(-2.21)^{*}\end{array}$ & $\begin{array}{c}1.00 \\
(-1.19)\end{array}$ & $\begin{array}{c}0.99 \\
(-3.21)^{* * *}\end{array}$ & $\begin{array}{c}1.00 \\
(-0.02)\end{array}$ & $\begin{array}{c}1.00 \\
(-0.46)\end{array}$ & $\begin{array}{c}0.99 \\
(-1.02)\end{array}$ & $\begin{array}{c}1.00 \\
(-0.39)\end{array}$ \\
\hline IMD percentile sq. & $\begin{array}{c}1.00 \\
(2.80)^{* *}\end{array}$ & $\begin{array}{c}1.00 \\
(1.81)\end{array}$ & $\begin{array}{c}1.00 \\
(1.19)\end{array}$ & $\begin{array}{c}1.00 \\
(0.35)\end{array}$ & $\begin{array}{c}1.00 \\
(0.76)\end{array}$ & $\begin{array}{c}1.00 \\
(-0.79)\end{array}$ & $\begin{array}{c}1.00 \\
(0.68)\end{array}$ & $\begin{array}{c}1.00 \\
(0.77)\end{array}$ & $\begin{array}{c}1.00 \\
(0.57)\end{array}$ \\
\hline \multicolumn{10}{|c|}{ Process time: age [Ref:0-4] } \\
\hline $5-9$ & $\begin{array}{c}1.29 \\
(1.62)\end{array}$ & $\begin{array}{c}1.53 \\
(4.22)^{* * * *}\end{array}$ & $\begin{array}{c}2.73 \\
(3.94)^{* * *}\end{array}$ & $\begin{array}{c}1.51 \\
(5.51)^{* * *}\end{array}$ & $\begin{array}{c}1.43 \\
(4.35)^{* * *}\end{array}$ & $\begin{array}{l}1.52 \\
(6.47)^{* * *}\end{array}$ & $\begin{array}{c}1.51 \\
(5.27)^{* * *}\end{array}$ & $\begin{array}{c}1.94 \\
(5.16)^{* * * *}\end{array}$ & $\begin{array}{c}1.99 \\
(4.57)^{* * *}\end{array}$ \\
\hline $10-19$ & $\begin{array}{c}1.89 \\
(4.59)^{* * *}\end{array}$ & $\begin{array}{c}1.71 \\
(5.87)^{* * *}\end{array}$ & $\begin{array}{l}2.10 \\
(3.07)^{* * *}\end{array}$ & $\begin{array}{c}1.45 \\
(5.38)^{* * *}\end{array}$ & $\begin{array}{c}1.02 \\
(0.29)\end{array}$ & $\begin{array}{c}1.40 \\
(5.63)^{* * * *}\end{array}$ & $\begin{array}{c}1.45 \\
(5.06)^{* * *}\end{array}$ & $\begin{array}{c}1.67 \\
(4.15)^{* * *}\end{array}$ & $\begin{array}{c}2.86 \\
(7.79)^{* * * *}\end{array}$ \\
\hline $20+$ & $\begin{array}{c}1.43 \\
(2.66)^{* *}\end{array}$ & $\begin{array}{c}1.43 \\
(3.98)^{* * * *}\end{array}$ & $\begin{array}{c}2.49 \\
(3.87)^{* * *}\end{array}$ & $\begin{array}{c}0.97 \\
(-0.36)\end{array}$ & $\begin{array}{c}0.71 \\
(-4.48)^{* * *}\end{array}$ & $\begin{array}{c}0.91 \\
(-1.47)\end{array}$ & $\begin{array}{c}0.93 \\
(-0.91)\end{array}$ & $\begin{array}{c}1.09 \\
(0.68)\end{array}$ & $\begin{array}{c}1.66 \\
(3.65)^{* * * *}\end{array}$ \\
\hline \multicolumn{10}{|l|}{ Size: [Ref:0-10k] } \\
\hline $10 \mathrm{k}-100 \mathrm{k}$ & $\begin{array}{c}0.38 \\
(-13.98)^{* * *}\end{array}$ & $\begin{array}{c}0.38 \\
(-17.55)^{* * * *}\end{array}$ & $\begin{array}{c}0.41 \\
(-5.54)^{* * * *}\end{array}$ & $\begin{array}{c}0.59 \\
(-12.40)^{* * *}\end{array}$ & $\begin{array}{c}0.71 \\
(-6.55)^{* * * *}\end{array}$ & $\begin{array}{c}0.69 \\
(-8.82)^{* * * *}\end{array}$ & $\begin{array}{c}0.66 \\
(-7.66)^{* * * *}\end{array}$ & $\begin{array}{c}0.66 \\
(-5.06)^{* * *}\end{array}$ & $\begin{array}{c}0.19 \\
(-16.63)^{* * *}\end{array}$ \\
\hline $100 \mathrm{k}+$ & $\begin{array}{c}0.30 \\
(-8.75)^{* * *}\end{array}$ & $\begin{array}{c}0.37 \\
(-9.64)^{* * *}\end{array}$ & $\begin{array}{c}0.66 \\
(-1.36)\end{array}$ & $\begin{array}{c}0.77 \\
(-4.11)^{* * *}\end{array}$ & $\begin{array}{c}0.87 \\
(-2.03)^{*}\end{array}$ & $\begin{array}{c}0.78 \\
(-4.50)^{* * *}\end{array}$ & $\begin{array}{c}0.79 \\
(-3.50)^{* * *}\end{array}$ & $\begin{array}{c}0.73 \\
(-2.84)^{* *}\end{array}$ & $\begin{array}{c}0.19 \\
(-7.53)^{* * *}\end{array}$ \\
\hline \multicolumn{10}{|c|}{ Form: [Ref:Unincorporated] } \\
\hline Incorporated & $\begin{array}{c}1.45 \\
(2.83)^{* *}\end{array}$ & $\begin{array}{c}1.76 \\
(5.80)^{* * * *}\end{array}$ & $\begin{array}{l}1.07 \\
(0.17)\end{array}$ & $\begin{array}{c}0.97 \\
(-0.55)\end{array}$ & $\begin{array}{c}1.40 \\
(5.22)^{* * *}\end{array}$ & $\begin{array}{c}0.97 \\
(-0.64)\end{array}$ & $\begin{array}{c}0.75 \\
(-4.57)^{* * * *}\end{array}$ & $\begin{array}{c}1.03 \\
(0.27)\end{array}$ & $\begin{array}{c}0.82 \\
(-1.03)\end{array}$ \\
\hline Likelihood ratio chisq & 376.94 & 528.84 & 78.46 & 277.34 & 380.37 & 213.36 & 199.10 & 83.79 & 708.91 \\
\hline df & 80 & 8 & 8 & 8 & 8 & 8 & 8 & 8 & 8 \\
\hline
\end{tabular}

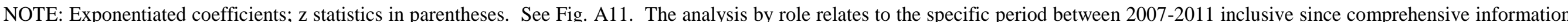

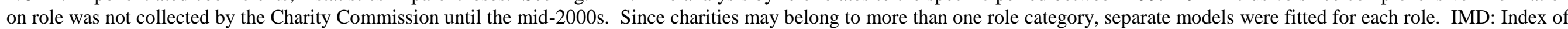

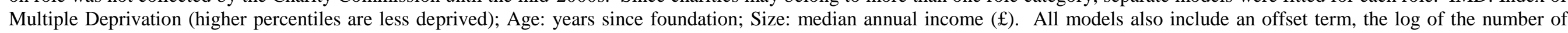
years of exposure to dissolution, whose coefficient is constrained to be 1 .

${ }^{*} p<0.05,{ }^{* *} p<0.01,{ }^{* * *} p<0.001$ 